41 | 2010

Le cheval : monture, nourriture et figure

\title{
Les avatars du cheval iakoute
}

The avatars of the Yakut horse

\section{Carole Ferret}

\section{(2) OpenEdition}

Journals

Édition électronique

URL : https://journals.openedition.org/emscat/1675

DOI : $10.4000 /$ emscat.1675

ISSN : 2101-0013

Éditeur

Centre d'Etudes Mongoles \& Sibériennes / École Pratique des Hautes Études

\section{Référence électronique}

Carole Ferret, "Les avatars du cheval iakoute », Études mongoles et sibériennes, centrasiatiques et tibétaines [En ligne], 41 | 2010, mis en ligne le 15 avril 2010, consulté le 13 juillet 2021. URL : http:// journals.openedition.org/emscat/1675; DOI : https://doi.org/10.4000/emscat.1675

Ce document a été généré automatiquement le 13 juillet 2021.

(c) Tous droits réservés 


\title{
Les avatars du cheval iakoute
}

\author{
The avatars of the Yakut horse
}

\section{Carole Ferret}

1 Le cheval iakoute est un animal extraordinaire, paré des vertus de maintes autres espèces (mammouth, porc, mouton, chameau, renne et vache). Les Iakoutes ne laissent pas de répéter au visiteur que ces chevaux exceptionnels leur donnent tout sans rien exiger en retour, qu'ils les transportent et surtout les nourrissent sans être alimentés par eux, qu'ils les habillent sans être jamais eux-mêmes ni couverts ni protégés dans le pays le plus froid de la Terre, où ils sont élevés en liberté, dans un état semi-sauvage, grattant la neige de leurs sabots pour paître. L'élevage équin iakoute permettrait d'avoir un bénéfice maximal (sous forme de viande, lait, fourrure, travail, ...) avec un coût minimal (pas d'affouragement et guère de soins).

Lors d'enquêtes de terrain menées entre 1994 et 2008 dans les régions centrales et septentrionales de Iakoutie, j'ai tenté de démêler le vrai du faux dans les discours tenus sur le cheval iakoute, son origine, sa production et sa consommation. Ces légendes, nées d'un mode d'élevage réellement exceptionnel dans des conditions naturelles extrêmes, sont d'autant plus tenaces que les Iakoutes ont fait du cheval l'emblème de leur nation.

3 J'ai déjà décrit dans un ouvrage (Ferret 2009) les multiples usages de l'équidé dans la taïga sibérienne. Dans cet article, j'apporterai des éléments nouveaux sur sa position vis-à-vis des autres espèces et sur l'évolution de son élevage dans les années 2000.

\section{Un cheval...}

4 Contrairement à une idée préconçue faisant accroire que les Nord-Sibériens n'élèvent que des rennes, croyance largement partagée non seulement parmi les néophytes, mais aussi chez les spécialistes de l'Asie centrale (Grousset 1938, p. 21 ; Dor 1993, p. 36) ${ }^{1}$, les Iakoutes possèdent bien des chevaux. S'il est vrai que l'une des premières descriptions connues de la Iakoutie, datée de 1666, affirme que «le pays est dépourvu de chevaux » et que ce sont des chiens qui sont employés au transport ${ }^{2}$, cette assertion fut contredite 
par plusieurs témoignages de la même époque, dont celle du Polonais A. KamienskiDluzyk, qui dépeint les Iakoutes comme des éleveurs de chevaux (et «surtout de chevaux blancs $»)^{3}$. Les Cosaques qui conquirent le territoire au $\mathrm{xVII}^{\mathrm{e}}$ siècle ${ }^{4}$, annoncèrent au tsar qu'ils y avaient trouvé un "peuple cavalier $»^{5}$. C'est souvent par cette expression que les Russes désignaient les Iakoutes, tant ils étaient frappés par l'omniprésence du cheval dans leur société. Actuellement, la République Sakha (Iakoutie) demeure une zone majeure d'élevage équin extensif, avec plus du tiers des chevaux élevés en troupeaux de la Fédération de Russie (Kalašnikov 2008, pp. 28-29) et $12 \%$ de son cheptel équin total - pour seulement $0,6 \%$ de la population ${ }^{6}$. Même si, aujourd'hui, les Iakoutes montent rarement à cheval, ils continuent à mettre en avant leur relation privilégiée avec l'équidé comme une composante essentielle de leur identité.

5 La Iakoutie, immense territoire de plus de trois millions de $\mathrm{km}^{2}$ constituant la majeure partie de la Sibérie orientale, se caractérise par un climat continental d'une rigueur inouïe. Les Iakoutes (autoappellation Sakha ${ }^{7}$ ) sont des pasteurs turcophones, qui ont migré vers le Nord depuis la Cisbaïkalie entre le $\mathrm{x}^{\mathrm{e}}$ et le $\mathrm{xv}^{\mathrm{e}}$ siècle, $\mathrm{y}$ important bovins et chevaux et adaptant le pastoralisme des steppes de la Sibérie méridionale aux conditions de la taïga septentrionale. Avec le temps, les chevaux, qui occupaient une place prépondérante dans le bétail, ont vu leur nombre décroître au profit des bovins. Cette évolution ne fut possible qu'avec un développement de la fenaison, puisque, à la différence des chevaux, les vaches sont, elles, gardées dans des étables et doivent être affouragées durant les huit mois d'hiver. Aujourd'hui, la République Sakha compte environ 140000 chevaux, 250000 bovins et 170000 rennes.

Chevaux iakoutes alimentés en kombikorm sur les pâtures

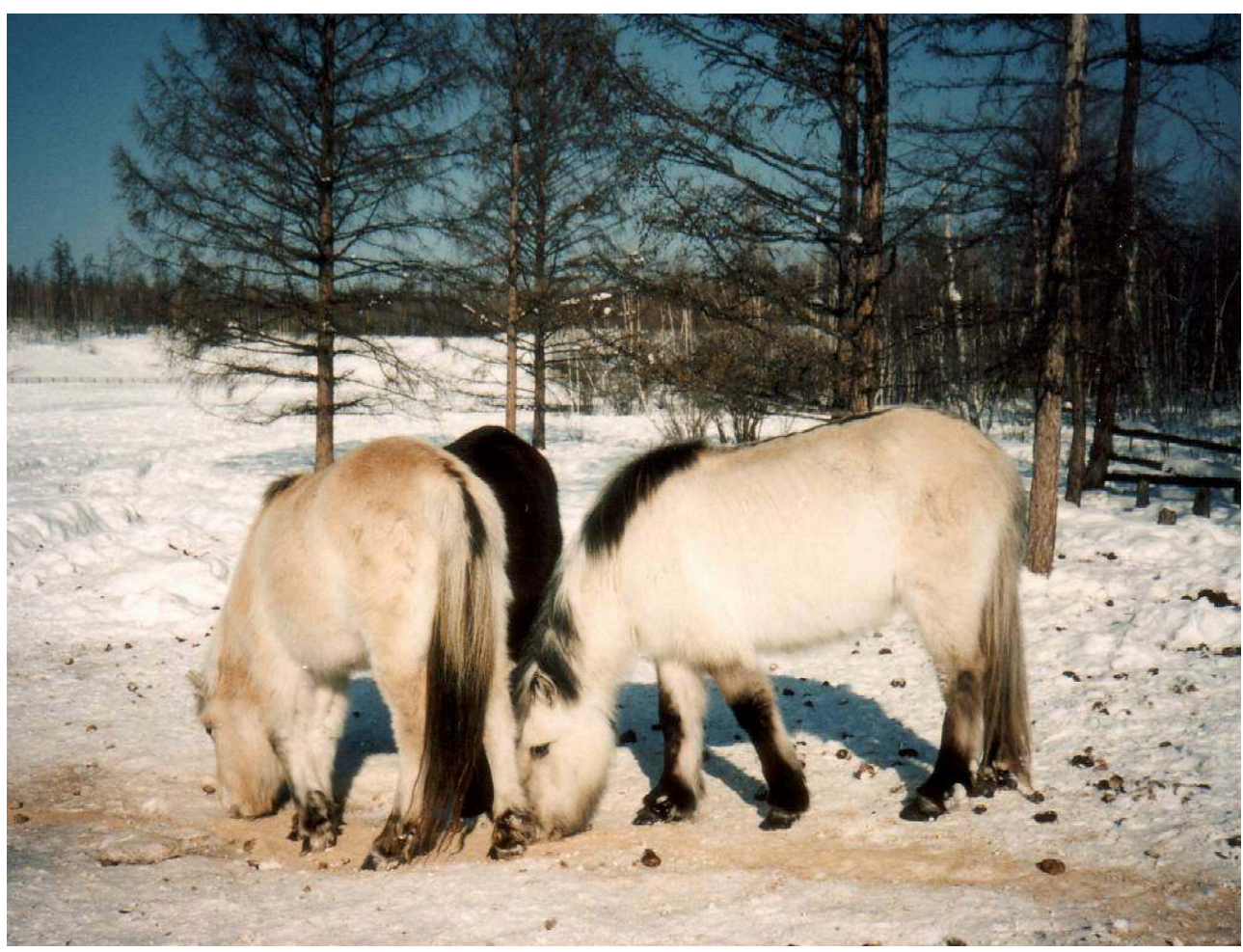

Ust'-Aldan, mars 1994

Photographie de Carole Ferret 
6 S'il existe, parmi les historiens, un consensus sur l'origine méridionale du peuple iakoute, le débat ne portant plus que sur l'itinéraire, les dates de la migration ou sur le «lieu de formation de l'ethnie »-question typique de l'ethnographie soviétique et de l'ethnologie post-soviétique, adepte d'une conception essentialiste de l'etnos et friande d'ethnogenèse -, les opinions divergent quant à l'origine de son cheval.

7 Une certaine ressemblance avec les races centrasiatiques conduit généralement à considérer que les ancêtres des Iakoutes élevaient des chevaux et que ce sont eux qui les ont introduits en Iakoutie ${ }^{8}$. Après tout, quoi de plus naturel que de lier les destins d'un peuple et d'un animal qui portent le même nom?

«Le cheval iakoute, comme les Iakoutes eux-mêmes, vient du Sud. [...] Il a conservé beaucoup de traits communs avec ses ancêtres centrasiatiques (mongols), notamment un grand tour de poitrine. Sa migration depuis la zone des steppes et des forêts steppiques dans les conditions extrêmement rigoureuses de la Iakoutie a eu pour conséquence le raccourcissement de ses extrémités et de sa face » (Lipping 1937, p. 29, c'est moi qui souligne).

Plusieurs auteurs, néanmoins, soulignent l'originalité de cet animal: plus haut, plus long, à la face plus courte ${ }^{9}$ que les autres chevaux sibériens et centrasiatiques (Gabyšev 1957, pp. 7, 53-54 ; Gabyšev 1972, pp. 260-261). Il est vrai qu'avec une taille moyenne de $136-139 \mathrm{~cm}$ au garrot, toute modeste soit-elle, il surpasse assez nettement le cheval mongol (122-129 cm) (Lošad'... 1992, pp. 43-57). Il se distingue également par sa robe claire : souvent blanche ou grise, avec des nuances isabelle, cendré ou souris (Gol'man 1877, p. 123; Gabyšev 1972, p. 230), son poil fin et dense, ainsi que par son exceptionnelle résistance au froid (Alekseev 1984). Aussi V. L. Seroševskij remarque-til :

«L'hypothèse selon laquelle le cheval iakoute est originaire de Transbaïkalie et serait le plus proche parent du cheval bouriate et du cheval mongol m'incita à examiner ces derniers avec une attention particulière. Je reconnais que je n'ai pas trouvé de ressemblance entre eux. Plus encore, il me semble que si, à l'époque où mes souvenirs étaient encore frais, il s'était trouvé un cheval iakoute parmi des mongols, je l'aurais reconnu sans aucune peine. Les chevaux mongols m'ont semblé avoir une petite tête, une taille plus basse, un corps plus court et plus rond; leur tempérament est indubitablement plus ardent que celui des iakoutes. Ceux-ci sont plus grands et plus élancés, ils ont une grosse tête au profil busqué ; leur croupe est longue et solide; ils sont moins rapides et moins chauds à la course, mais semblent plus forts et plus résistants. La comparaison des selles iakoute et mongole témoigne à son tour d'une différence significative dans l'ossature de ces deux chevaux. La selle iakoute est plus longue et plus large que la mongole et un cheval bouriate ou mongol harnaché de cette manière finirait inévitablement par se démettre l'épaule » (1896, pp. 157-158).

\section{... plus iakoute que le mammouth}

Ces spécificités ont suscité l'idée qu'un cheval aborigène vivait sur le territoire avant l'arrivée des Iakoutes. Des restes d'équidés du pléistocène y ont été découverts ${ }^{10}$, montrant qu'un "cheval blanc de la toundra " avait côtoyé le mammouth dans les régions septentrionales ${ }^{11}$. En 1901 dans la Kolyma, E. W. Pfizenmayer trouva, outre le mammouth Berezovka près de la rivière du même nom, des restes de rhinocéros et de chevaux, qu'il estimait, pour ces derniers, fort nombreux en Iakoutie centrale (1939, pp. 233-235). 


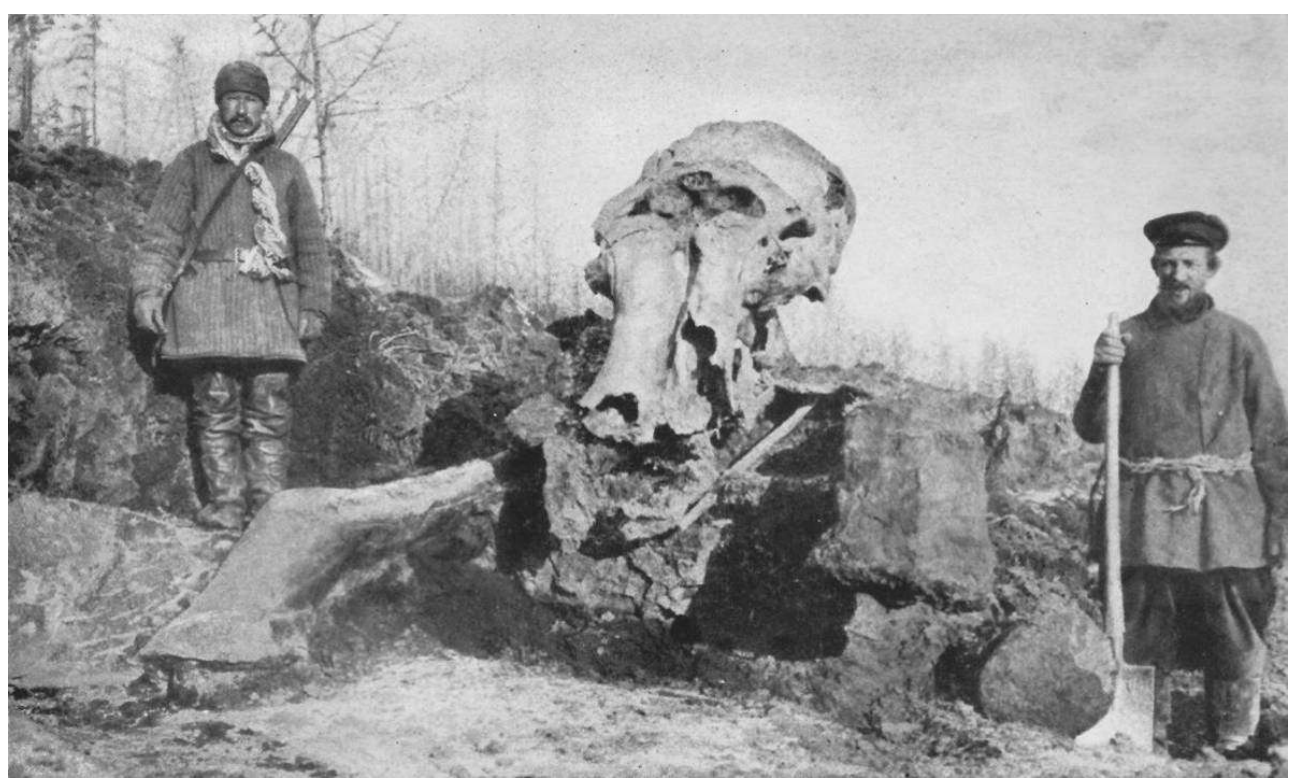

D'après Pfizenmayer 1939

10 Cet animal aurait-il pu survivre aux dernières glaciations ? Certaines légendes iakoutes font mention de chevaux sauvages ${ }^{12}$. Si quelques auteurs relatent l'effroi des peuples autochtones, evenks, evènes et ioukaguirs, à la vue de chevaux amenés par les colons iakoutes et russes ${ }^{13}$, animaux dont ils trouvaient le corps énorme, le hennissement abominable, et qu'ils appelèrent parfois «rennes iakoutes ${ }^{14}$, d'autres récits font pourtant état d'Evènes chassant le cheval dans la région du bassin inférieur de la Kolyma (Pfizenmayer 1939, p. 153). La grande extensivité de l'élevage actuel, avec une intervention humaine minime et ponctuelle (Ferret 2006), sur un animal conservé dans un état apparemment proche de la sauvagerie, semble, de prime abord, confirmer la possibilité de survie d'un cheval sauvage en Iakoutie.

11 Les chevaux étant plus grands et plus clairs dans le nord du pays, il est possible qu'on ait affaire non à un cheval iakoute, mais à deux : le premier, habitant dans le bassin de la moyenne Lena, serait venu du Sud et le second, plus grand et de robe plus claire, descendrait d'un cheval sauvage aborigène ayant survécu au refroidissement du climat (Lipping 1937, p. 31). Certaines classifications actuelles, notamment celle de la Food and Agriculture Organization, recensent d'ailleurs deux races (breed) distinctes, appelées respectivement srednekolymskaya et yakutskaya $a^{15}$. Ces vues furent confortées par la découverte, en 1968, du cheval de Selerikan, un étalon vieux de 33000 ans, dans le bassin supérieur de l'Indigirka, candidat idéal au titre de chaînon manquant entre les équidés nord-sibériens du pléistocène supérieur et le cheval domestique iakoute actuel (Lazarev 1977 ; Lazarev 1980).

12 Le cheval iakoute serait donc « le contemporain du mammouth " (Lazarev ${ }^{16} 1971$, p. 16). Aussi, dans l'attente de clones de mammouths (cf. Grison 2006), le Pleistocene park, projet de reconstitution d'un écosystème steppique initié par S. Zimov près de Čerskij dans la basse $\mathrm{Kolyma}^{17}$, commença par abriter, dès 1988, des chevaux iakoutes, comme les plus dignes représentants de la faune du pléistocène tardif (Zimov 2005; Randrianarimanana 2006). En 2006, des bisons ont été importés en République Sakha 
depuis l'Alberta, mais ils ont d'abord été placés en un lieu moins excentré, à Ust' Buotam, près du site touristique de Lenskie Stolby (Ivancova 2006 ; Ivancova 2009).

Une si extraordinaire et si vénérable pérennité fit gagner au cheval iakoute ses lettres de noblesse ${ }^{18}$. En même temps, l'ancienneté de son ancrage sur le territoire permettait de pallier l'arrivée récente de l'ethnie éponyme, pour mieux asseoir l'autochtonie de celle-ci et assurer sa légitimité. En effet, selon une hypothèse basse sur les dates de la migration, les Iakoutes ne seraient arrivés dans la contrée que deux siècles avant les Russes. Et de toutes façons, ils n'occupaient, au moment de la conquête, qu'une infime partie du territoire ( $\left(\right.$ des îlots iakoutes dans un océan toungouse $»^{19}$ ), concentrés sur le plateau de l'interfluve situé entre la Lena et l'Amga, affluent de l'Aldan - avec quelques groupes situés dans le bassin de la basse Viljuj, et d'autres sur la haute et la moyenne Jana. C'est la colonisation russe qui leur a donné l'occasion de s'étendre au-delà. Mais si les Iakoutes sont venus d'ailleurs, ils confortent leur position en postulant que leurs chevaux, eux, sont bien d'ici, et en outre de très longue date.

Cette hypothèse ne rallia cependant pas tous les suffrages. En effet, les restes osseux chevalins sont quasiment absents des sites mésolithiques ou néolithiques (Gogolev 1993, pp. 113-114; Ermolova 1983), ce qui tend à appuyer l'idée que les équidés ont disparu du Nord-Est asiatique lors des glaciations (Kuz'mina 1977, pp. 37-38). Par ailleurs, un examen plus affiné de l'élevage montre que, malgré un apparent laisserfaire, l'intervention humaine est nécessaire à la survie sur le long terme du cheval domestique en Iakoutie. Un affouragement complémentaire et temporaire s'avère indispensable, en particulier pour les plus jeunes, et pour tous lors des mauvaises années (Ferret 2006, pp. 281-282). Aussi l'Institut iakoute de recherche agronomique continue à reconnaître cinq types de chevaux iakoutes à l'intérieur d'une seule et unique race, en soulignant que les particularités des chevaux septentrionaux peuvent s'expliquer par une grande rapidité d'adaptation, généralement sous-estimée (Alekseev, Neustroev \& Ivanov 2006, pp. 8-21).

Enfin, des études génétiques soulignèrent la similitude du cheval iakoute avec d'autres races eurasiatiques - au centre et à l'est, dans les bassins de l'Amga et de la Léna, ainsi que dans le Nord, avec le kazakh de type džabe; à l'ouest, dans la région de la Viljuj, avec le mongol et l'akhal-téké (Gur'ev 1983; Gur'ev \& Ahremenko 1992). Ces deux chevaux auraient été importés en Iakoutie par des vagues successives d'immigration, le premier par les Kourykanes, qui formèrent la tribu des Namcy, le second par des peuples turcs de langue kiptchak, qui formèrent la tribu Kangalas (Gur'ev \& Ahremenko 1992, pp. 78-83). Cependant, loin de renoncer à la thèse de l'ancienneté du cheval iakoute, I. P. Gur'ev et A.K. Ahremenko, chercheurs à l'Institut d'agriculture et à l'Institut de biologie de Iakoutsk, ne firent que la redoubler et l'amplifier. En effet, reprenant l'hypothèse d'I. D.Čerskij selon laquelle le Nord-Est asiatique aurait représenté un berceau important de la faune post-tertiaire, ils affirment que le cheval du pléistocène supérieur, Equus caballus Lenensis, aurait quitté le bassin de la Léna il y a environ 10000 ou 1100 ans et serait parti vers l'Ouest, pour donner naissance au Tarpan, Equus caballus gmelini Antonius, lui-même père du cheval domestique, Equus caballus Linné. Ce cheval « iakoute » ancien serait donc, par l'intermédiaire du Tarpan, rien moins que l'ancêtre de tous les chevaux !

L'une comme l'autre, ces deux hypothèses s'attachent à mettre en valeur le cheval iakoute par son ancienneté (le cheval iakoute remonte au pléistocène) en y adjoignant soit, pour la première, son originalité (exceptionnel, il ne ressemble à aucun autre) soit, 
pour la seconde, son universalité (il est le père de tous les autres). De telles conjectures, tout en se voulant scientifiques, sont trop manifestement portées par une intention idéologique pour ne pas être suspectes. Non seulement, elles expriment une obsession des origines présente dans toute l'ex-URSS, où l'ethnogenèse constitue la préoccupation essentielle des ethnographes puis des ethnologues (cf. Laruelle 2004, pp.55-56 et passim). Mais encore elles témoignent d'une étrange confusion entre l'histoire des hommes et celle des chevaux. S'il parait important, pour ces chercheurs, de connaître l'origine de ce cheval, c'est parce qu'il représente l'ethnie éponyme. Plus ce cheval sera ancien et original - ou, à l'inverse, universel - plus le peuple qui l'élève le sera également car le prestige du premier rejaillit sur le second.

17 Archéologues et biologistes passent inconsidérément du cheval à l'homme et de l'homme au cheval. Ainsi, l'académicien V. P. Alekseev, archéologue et spécialiste d'anthropologie physique, écrit, par exemple :

« des matériaux paléoanthropologiques obtenus plus récemment témoignent de la parenté du peuple iakoute actuel avec les populations qui vivaient sur le territoire de la Iakoutie au néolithique. Des éléments autochtones sont donc intervenus de manière significative dans l'ethnogenèse iakoute, ce qui renforce l'hypothèse selon laquelle le cheval iakoute domestique a de profondes racines aborigènes » (1990).

I. P. Gur'ev ne craint pas d'intituler un de ses articles Les types de protéines du sang $d u$ cheval iakoute et l'origine des Iakoutes, estimant que :

"puisque les animaux domestiques sont les compagnons inséparables de leurs maîtres, l'établissement de la microévolution et des liens génétiques des races aborigènes et des populations d'animaux domestiques peut aider les historiens à établir l'origine des différents peuples et leurs liens historiques » (Gur'ev \& Ahremenko 1992, p. 78 ; voir aussi Gur'ev \& Ahremenko2008, p. 117).

Le rapprochement est implicite dans le titre d'un autre de ses articles L'origine du cheval iakoute et du peuple sakha à la lumière de l'archéologie génétique et de l'histoire (Gur'ev \& Ahremenko 2008), où, curieusement, le peuple est devenu sakha alors que le cheval demeure iakoute, une divergence terminologique qui ne paraît pourtant pas troubler l'évidence et la solidité de leurs liens.

20 Or ceux-ci ne sont basés sur aucun fondement scientifique. Il va sans dire que, premièrement, les Iakoutes n'ont pas nécessairement la même origine que leurs chevaux et, deuxièmement, le fait que les ancêtres des Iakoutes aient, comme leurs descendants, élevé des chevaux ne suffit à prouver qu'il s'agit des mêmes animaux. Tout en n'étant pas toujours aussi clairement notifiée, cette confusion entre les hommes et les chevaux est savamment entretenue, dans la mesure où elle permet aux Iakoutes de pallier leur manque d'autochtonie grâce à un cheval «vieux comme le mammouth ».

\section{Une chair grasse, saine et savoureuse}

21 Les Iakoutes aiment les chevaux et ils aiment le cheval. Ils les élèvent davantage pour les manger que pour les monter. La boucherie est le principal débouché de la filière équine. J'ai montré dans un autre article (Ferret 2010) que, pour eux, il n'y a aucune contradiction entre le fait de vénérer les chevaux et celui d'en manger.

«Le cheval est pour moi comme un dieu. Je l'admire et j'ai vécu toute ma vie avec

les chevaux. C'est mon meilleur ami, mon partenaire, et il me nourrit, moi et ma 
famille : en même temps par son travail et parce que je mange sa viande », dit un certain Vassili à un voyageur suédois à Nalimsk, dans la Kolyma (Strandberg 2008). tenus sur cette dernière, dénués de tout complexe, et dans les pratiques alimentaires : le vaste éventail des morceaux consommés, leur présentation anatomique (avec la tête et les os), le caractère festif de la viande chevaline, ainsi que dans la consommation de poulain.

En effet, une autre particularité de l'élevage iakoute tient à ce que les chevaux sont consommés très jeunes, afin éviter l'affouragement hivernal, indispensable pour les poulains sevrés. La majorité des poulains est abattue au premier automne, vers l'âge de six mois, immédiatement après le sevrage ${ }^{20}$. Ce sont donc, selon la terminologie des éleveurs français, des «laitons ». Tout propriétaire attend de chacune de ses juments qu'elle mette bas chaque printemps et lui fournisse ainsi, par l'intermédiaire de ses poulains, $100 \mathrm{~kg}$ de viande tous les ans. L'abattage d'un cheval adulte procure environ le double.

"Même si le cheval iakoute est petit, il donne beaucoup de viande. La taille moyenne du cheval iakoute est $135 \mathrm{~cm}$; son poids vif de $460-490 \mathrm{~kg}$, jusqu'à $513 \mathrm{~kg}$ pour étalon. Moi, j'en ai eu un qui m'a donné $295 \mathrm{~kg}$ de viande. C'est le record. Les chevaux croisés ne donnent jamais plus de $275 \mathrm{~kg}$ ».

«L'année dernière, mes juments m'ont donné vingt-quatre poulains. J'en ai vendu vingt vivants, j'en ai gardé deux pour la remonte et j'ai mangé les deux derniers. Mes poulains sont gras, ils donnent $120 \mathrm{~kg}$ de viande. Ceux des autres n'en donnent habituellement que $100 \mathrm{~kg}^{21}$. Ce serait plus rentable de les abattre, parce qu'avec la viande et les viscères, j'en tirerais 25000 roubles, au lieu de 20000 roubles en les vendant vivants. Mais je préfère qu'ils restent en vie car ce sont de purs chevaux iakoutes, de bonne qualité » m'a expliqué M. A. Artamonov, en 1994 puis 2008.

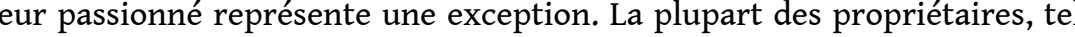
A. N. Okoëmov à Kurbusah, ne possède que quelques têtes de bétail et abat chaque automne tous les poulains que ses juments ont mis bas au printemps, sans en garder pour le renouvellement du cheptel. Et dès qu'une poulinière devient trop vieille pour faire un poulain chaque année, on la réforme. La viande ainsi obtenue est généralement entièrement consommée au sein de la famille étendue, souvent distribuée à des parents citadins, rarement vendue en dehors du cercle familial. L'hiver est long et on mange beaucoup de viande ${ }^{22}$.

Le cheval occupe une place de choix dans la cuisine iakoute. E. W. Pfizenmayer note que le poulain est « le mets préféré des iakoutes » $(1939$, p. 91). « La viande de cheval, on ne peut pas s'en passer ", m'a dit la directrice du musée du Pôle du froid à Verhojansk, V.Z. Kirillina. Elle représentait environ $20 \%$ de la production totale de viande en Iakoutie - après le bœuf, qui en constituait près de $60 \%{ }^{23}$, mais la part de la viande de poulain tend actuellement à augmenter, atteignant près des $40 \%$ de la viande consommée.

Parmi les sept recettes les plus typiques de la cuisine iakoute présentées sur le site internet de l'Université de Iakoutsk consacré à la culture du pays ${ }^{24}$, trois plats sont à base de cheval (poulain bouilli, ojogos «côte» de cheval et haan "boudin "-appelé subaj, lorsqu'il est fait avec le sérum additionné de lait de vache). Il conviendrait d'y ajouter plusieurs mets fins fort appréciés: la viande gelée (ton èt), prélevée sur l'abdomen avec la graisse et coupée en petits morceaux, semblables à nos lardons, le foie dégusté également cru et gelé, les pieds en gelée, la soupe de tripes, le saal « graisse

Études mongoles et sibériennes, centrasiatiques et tibétaines, 41 | 2010 
de la crête de l'encolure ", le harta «rectum », entre autres ${ }^{25}$. La viande de cheval est jugée plus goûteuse et le poulain, plus tendre.

La viande chevaline est plus prisée que la bovine, mais aussi, paradoxalement, plus rare et moins chère ${ }^{26}$. En effet, les bovins étant gardés dans le hoton « étable » tout l'hiver et nourris au foin, le coût de revient du bœuf est nettement plus élevé27. Dans l'ensemble des régions d'élevage en troupeaux, le coût de production de la viande de cheval est deux à cinq fois inférieur à celui de la viande bovine ${ }^{28}$.

De nos jours, l'objectif de l'élevage équin s'affiche ainsi clairement en Iakoutie: " fournir à la population des aliments sains et écologiquement propres [bio, dirait-on ici], produits avec une rentabilité maximale " (Kozlov \& Borisov 2008, p. 164). Pour justifier leur hippophagie face à des Russes qui ne mangent pas de cheval ${ }^{29}$, les Iakoutes expliquent que le mode de vie semi-sauvage du cheval iakoute, avec un pacage en liberté l'année durant, confère à sa viande une incomparable saveur et des qualités nutritionnelles exceptionnelles.

"Sur le marché européen, la viande de cheval provient pour la majeure partie des races de trait lourd. Or à mon avis, la viande des chevaux élevés en troupeaux, qui paissent toute l'année sur des pâtures naturelles est supérieure, tant par son goût que par ses qualités nutritionnelles, à la viande des autres chevaux » (Ivanov 2008, p. 67).

Le cheval iakoute est délicieux parce qu'il vit dehors et ne travaille pas, se contentant de brouter pour engraisser ${ }^{30}$ tandis qu'en Occident, le confinement en écurie, le labeur et la sudation qui s'ensuit gâtent sa chair. Pour les Iakoutes, le débat sur l'hippophagie, c'est d'abord et avant tout une question de palais, bien plus qu'une question de principe.

Un autre élément entre en ligne de compte : la santé. Le cheval est jugé aussi bénéfique pour la santé que bon au goût. De multiples vertus médicinales sont attribuées à cette viande. Consommée crue et gelée, elle serait un remède efficace contre l'anémie. Riche en graisse, elle a été utilisée pour soigner la tuberculose (Gabyšev 1972, p. 344). Grâce à ses acides gras polyinsaturés (oméga 3), elle est pauvre en cholestérol malgré une teneur lipidique élevée et protège des maladies cardiovasculaires (Krivošapkin \& Mordovskaja 2008). Très appréciés, les abats chevalins sont riches en fer, en calcium, en phosphore et en micro-éléments (Abramov 2008, p. 133). Pour remédier à l'impuissance sexuelle, les Iakoutes avaient l'habitude, selon D. Nikolaeva, d'avaler un petit morceau situé au-dessus des reins, sorte de Viagra local. On raconte même que manger du cheval atténuerait les effets des radiations atomiques.

31 De même, le kumys «lait de jument fermenté » (iak. kymys) est paré de toutes les qualités: il est riche en vitamine $C$, revigorant, stimule la circulation sanguine (Seroševskij 1896, p. 206) et le transit intestinal, freine la dégradation des dents (Nikolaeva 2009), fait tomber la fièvre, est un bon vermifuge (Savvin 2005, pp. 22, 29, 34), favorise le développement d'une immunité contre la tuberculose ou, à défaut, permet de soigner les personnes atteintes de cette maladie. C'est pour cette raison qu'il a été utilisé dans les sanatoriums et qu'il a fait l'objet d'une propagande active à partir des années 1950 en URSS (Ferret 2009, p. 105). Ses vertus sont si nombreuses que des chercheurs attribuent à la consommation de produits laitiers, et notamment de kumys, l'espérance de vie élevée des Iakoutes et la longévité exceptionnelle de certaines personnes (Savvin 2005, p. 23 ; Nikolaeva 2009). Cette opinion ne s'appuie que sur quelques cas isolés car, en réalité, l'espérance de vie à la naissance n'est pas très élevée 
dans la République Sakha: 65,8 ans en 2008 (71,9 pour les femmes; 60,2 pour les hommes) contre 67,9 (74,2 pour les femmes ; 61,8 pour les hommes) dans l'ensemble de la Fédération de Russie ${ }^{31}$. Il convient également de noter que, tout en ayant fait de l'yhyah «la fête des libations de kumys " leur fête nationale ${ }^{32}$ et tout en continuant à louer les vertus de ce breuvage, les Iakoutes n'en consomment désormais que de très petites quantités, uniquement au moment du solstice d'été33, et qu'ils le remplacent souvent par un ersatz, fait à base de lait de vache et appelé byppah. Après un grand déclin, la production de kumys semble cependant aujourd'hui être repartie légèrement à la hausse ${ }^{34}$.

Véritable panacée par sa viande et son lait ${ }^{35}$, le cheval iakoute est qualifié de "pharmacie sur pattes» (Mizgirev 2006). L'argumentaire de ces discours revêt parfois une étrange tournure, si bien que la prose de certains docteurs en sciences de l'agriculture prend l'allure d'une rhétorique publicitaire.

« Les produits du bétail [bovin et équin] aborigène iakoute, génétiquement adapté à des conditions climatiques difficiles, sont riches en Oméga-3 et Oméga-6. Ils donnent force, intelligence et santé aux gens de toutes nationalités » (Nikolaeva 2009).

Pourvu que le produit soit certifié «pur iakoute», il peut sauver tout un chacun, iakoute ou non!

La qualité médicinale de cette viande est explicitement liée au mode de vie « sauvage » de l'animal qui la fournit.

"Sur le marché mondial, on observe actuellement un engouement pour la viande des animaux sauvages, bien supérieure à celle des animaux de la production agricole industrielle par ses acides gras, ses acides aminés et d'autres indicateurs. La viande de cheval, par ses acides gras insaturés, se distingue nettement de la viande des autres espèces agricoles (bœuf, porc et mouton)» (Ivanov 2008, p. 67).

Ici apparaît une ambiguïté récurrente, qui confond liberté et sauvagerie, faisant mine d'oublier qu'en Iakoutie, plus de la moitié des poulains sont abattus à six mois, qu'une bonne partie des mâles survivants est dressée, castrée, que les troupeaux sont formés par l'homme, puis subtilement dirigés et qu'ils bénéficient de temps à autre d'une alimentation complémentaire (Ferret 2006). Pour toutes ces raisons, il n'est objectivement pas possible d'affirmer que le cheval iakoute est un animal sauvage - au sens où il croitrait et multiplierait indépendamment de toute intervention humaine.

Outre son importance considérable dans l'alimentation, l'hippophagie iakoute se distingue de la nôtre par le large éventail des morceaux consommés. «On mange tout dans le cheval » m'a dit N. A. Slepcov à Stolby, dans la région de Verhojansk. Tout, c'est-à-dire les différentes pièces de viande, mais aussi quasiment tout le cinquième quartier : le foie, les reins, les intestins, le cœur, ainsi que les poumons, les mamelles, les testicules, l'estomac, la rate, de même que la tête, les extrémités, le sang (Atlasov 1992, p. 57). Même la cervelle qui faisait naguère l'objet d'un interdit (Priklonskij 1888, p. 30 ; Seroševskij 1896, p. 311 ; Savvin 2005, p. 54) est désormais cuisinée. Toutes les parties de l'animal étant utilisées, cet élevage est une activité particulièrement écologique, «sans déchets » (Vladimirov 2008, p. 91).

37 La graisse est grandement valorisée (Ferret 2010) car elle est considérée comme la première arme contre le froid, permettant la survie, d'abord des chevaux - dont l'embonpoint est le principal indice de qualité -, ensuite des hommes qui s'en nourrissent. Le vaste éventail des morceaux utilisés, l'importance de la graisse, l'usage 
du sang, la fabrication de semi-conserves relevant ce qu'on appelle chez nous la charcuterie, tendent à rapprocher le cheval iakoute du porc occidental. Pour nous, « dans le cochon, tout est bon »; pour eux, « dans le cheval, tout est régal ».

Plusieurs auteurs dressent explicitement cette comparaison entre le cheval iakoute et le porc occidental - en rapprochant notamment la graisse chevaline du lard porcin ${ }^{36}$. Gras comme un cochon, le cheval iakoute peut se révéler aussi délicieux que lui. Il convient néanmoins de noter que cette comparaison entre cheval et cochon a surtout été faite par des observateurs allogènes, russes ou polonais. Une telle analogie auraitelle pu venir à l'esprit des Iakoutes eux-mêmes? Pour tenter de répondre à cette question, il convient d'analyser la situation du porc dans le pays et de voir dans quelle mesure le suidé a pu s'insérer dans le système alimentaire iakoute, alors que sa place était déjà en partie occupée par l'équidé.

Le porc a été importé par les Russes en Iakoutie. Le nom iakoute du cochon, sibiinn'è, est également emprunté du russe svin'ja. È. K. Pekarskij atteste un emploi péjoratif du mot (1907-1930, p. 2202), analogue à ceux qui existent en russe et en français. Le nom mongol du porc, gahaj, est connu des Iakoutes sous la forme hahaj mais, chez eux, il désigne le lion, la panthère (Böhtlingk 1851, p. 637), voire parfois l'aigle, le grand duc, le chameau ou encore le serpent (Pekarskij 1907-1930, p. 3414-5).

Longtemps dédaigné par les Iakoutes, bien qu'aucun interdit religieux ne prohibe la consommation de sa chair (Gmelin 1767 [1751], I, p. 188), le cochon est petit à petit devenu plus populaire. Au XIX ${ }^{e}$ siècle, les Iakoutes ne mangeaient pas de porc. D'après V. L. Priklonskij, ils considéraient ces animaux, avec la volaille, comme impurs car trop proches du fumier $(1888$, p. 31). Dans les années 1880 , les exilés politiques Strandin et Jurasov s'étant lancés dans l'élevage porcin, les jambons et saucissons "strandinovskie " étaient fameux. Alléchés, de riches Iakoutes se sont mis à acheter des porcs pour les élever, d'abord sans succès, car ils ne savaient pas soigner ces animaux (Seroševskij 1896, pp. 171-172). La Iakoutie ne comptait que 51 porcs en 1870. Le recensement de 1917 en dénombre 1 148, dont 1020 dans le district de Iakoutsk (Jochelson 1933, p. 191). «Au début $\mathrm{du} \mathrm{xx}^{\mathrm{e}}$ siècle, l'élevage du cochon n'était pas développé [en Iakoutie]. Seuls les paysans russes et les koulaks iakoutes en élevaient. Ils les engraissaient et les vendaient aux travailleurs des mines" (Gogolev 1970, p. 67). Dans les années 1920, N. K. Nedokučaev prédisait avec justesse que, parmi tous les animaux "exotiques " importés en Iakoutie, le porc était celui dont l'élevage avait le plus de chances de prospérer (1927, p. 511). Au commencement de la collectivisation, dans les années 1930, furent créés les premiers kolkhozes dédiés à l'élevage porcin (Antipin \& al. 1963, p. 173).

41 Le cheptel porcin a connu une progression spectaculaire: ne dépassant guère la centaine de têtes au XIX ${ }^{e}$ siècle, il se montait à un millier à la Révolution et à $110000 \mathrm{au}$ début des années 1990 - mais il été divisé par quatre depuis. 


\section{Évolution du cheptel porcin en lakoutie}

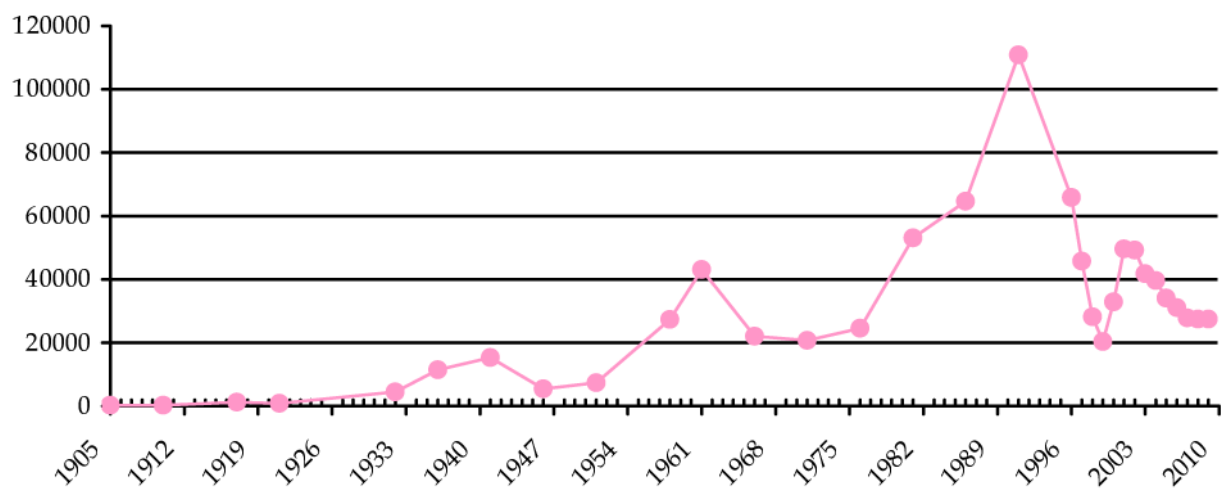

Schéma de Carole Ferret

Cette croissance vigoureuse peut être mise en parallèle avec les vagues de migration russe et soviétique sur le territoire. En regroupant la population de Iakoutie relevée par les recensements successifs en trois grandes catégories: Iakoutes, allochtones (Russes, Ukrainiens, Tatares, etc.) et autochtones (peuples toungouses, ouraliens et paléosibériens), on obtient le graphique suivant :

Évolution de la population en République de lakoutie

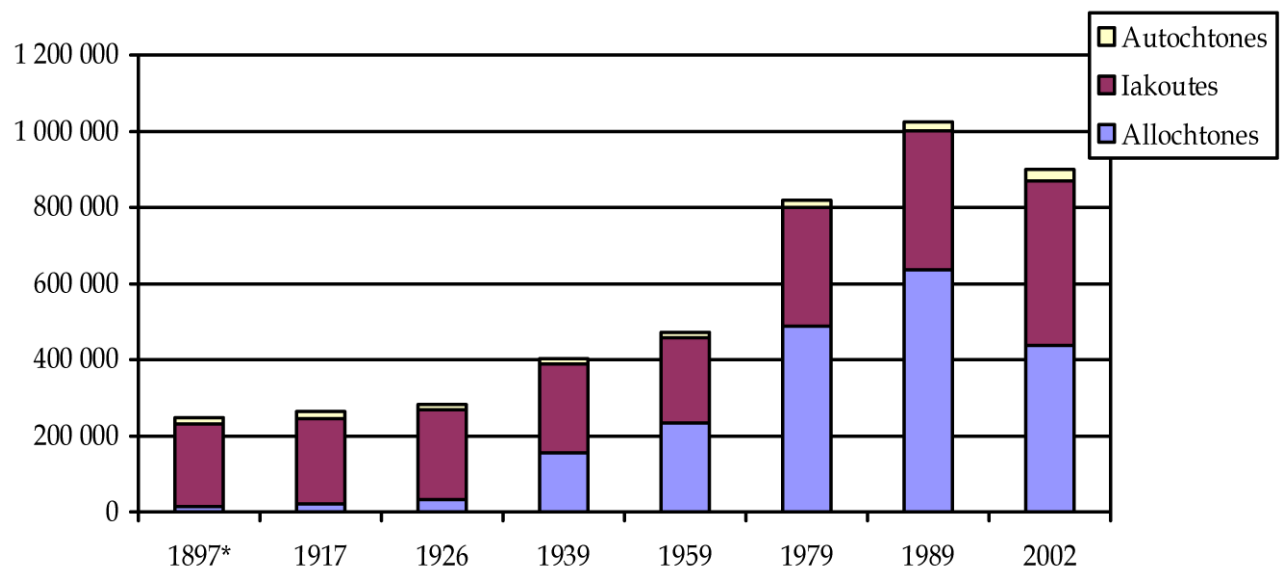

Schéma de Carole Ferret

Les allochtones, qui n'étaient que quelques dizaines de milliers au XIXe siècle et jusqu'en 1926, se sont vite comptés en centaines de milliers (155 000 en 1926, 500000 en 1989). Ce flux migratoire massif est liée à l'exploitation des précieuses et gigantesques ressources minières du pays (or, diamants, charbon, gaz, entre autres), mais le mouvement s'est inversé à partir de 1990. Entre les recensements de 1989 et de 2002, le nombre de Russes a diminué d'un tiers, celui des Ukrainiens de plus de la moitié, tandis que celui des Iakoutes et des Evenks augmentait de 20 à $30 \%$.

La répartition géographique révèle également une nette corrélation entre l'importance $\mathrm{du}$ cheptel porcin et l'implantation slave dans la République. Les porcs sont particulièrement nombreux dans les arrondissements industriels ou urbains, dont la population est majoritairement allochtone (Iakoutsk, Nerjungri, Mirninskij, Leninskij). 


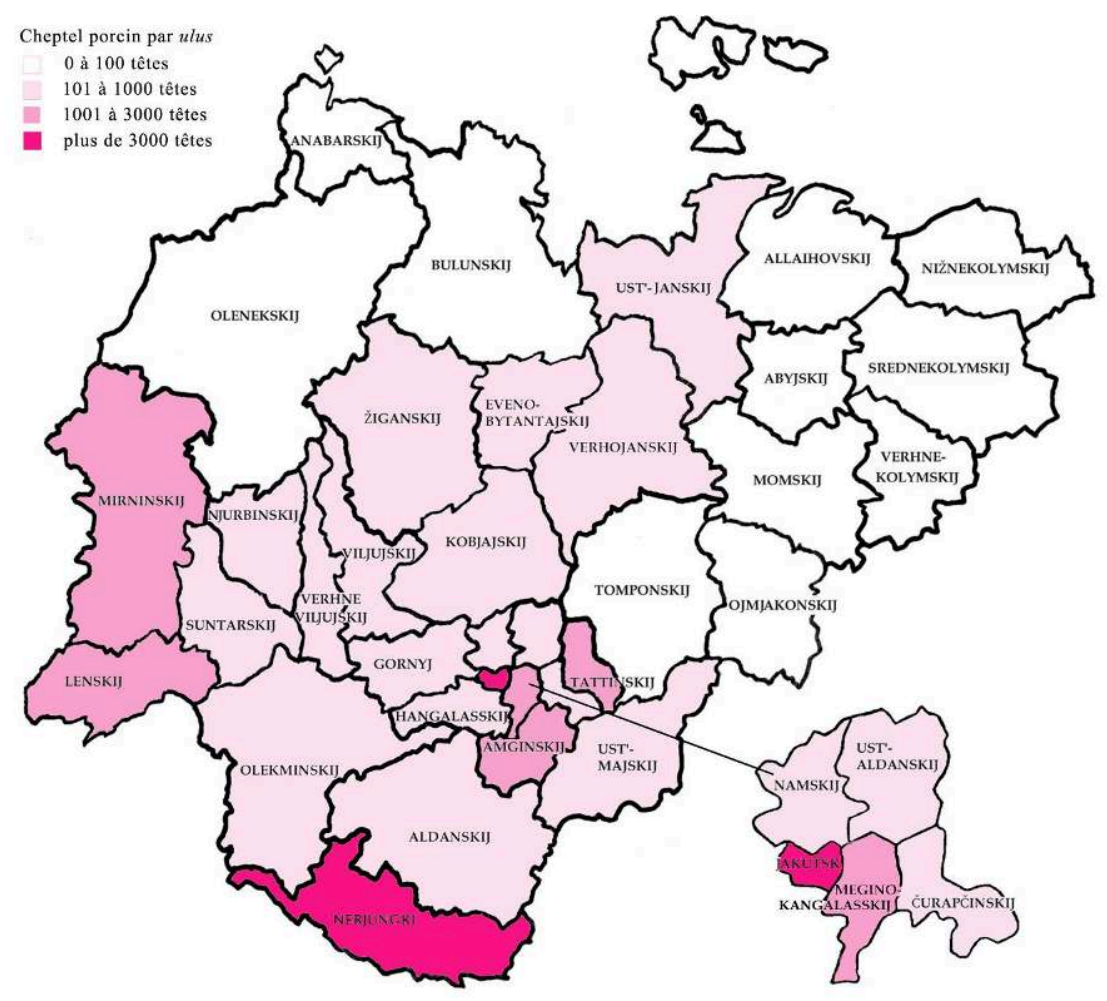

Carte de Carole Ferret

Il ne faudrait pas en conclure qu'en Iakoutie, seuls les Russes élèvent et consomment du porc. Certes, on connait l'importance du lard (rus. salo) dans l'alimentation russe (Kerblay 1962, p. 903). Avec près de 16 millions de têtes, la Fédération de Russie occupe le $8^{\mathrm{e}}$ rang mondial pour l'élevage porcin ${ }^{37}$ et $\mathrm{c}^{\prime}$ est, après la Japon, le deuxième importateur de viande porcine. Il faut d'ailleurs noter que, pour l'ensemble de la Russie, le porc est le seul animal dont le cheptel a augmenté depuis un siècle - tandis que le cheptel équin a été décimé.

Évolution du cheptel dans la Fédération de Russie (en millions de têtes)

\begin{tabular}{|l|l|l|l|l|}
\hline & bovins & porcs & caprins et ovins & chevaux \\
\hline 1916 & 33 & 11,3 & 47,0 & 35,0 \\
\hline 1954 & 28,4 & 16,6 & 56,5 & 7,9 \\
\hline 2005 & 23,1 & 14,2 & 16,9 & 1,4 \\
\hline Évolution entre 1916 et 2005 & $70 \%$ & $125 \%$ & $35,9 \%$ & $4,3 \%$ \\
\hline
\end{tabular}

\section{D’après Kalašnikov 2008, p. 20}

Néanmoins on ne peut ignorer que de nombreux Iakoutes se sont également mis à l'élevage du porc. Dès les années 1930, la demande en bétail et produits porcins était élevée dans la population (Šubskaja \& Saltykov 1931, p. 39). À Bèjdinè, dans l'Ust'- 
Aldan, jusqu'à récemment, presque toutes les maisonnées avaient un cochon, gardé dans un coin du hoton en hiver, et dans un petit enclos dans la cour en été (Bašarin 1962, p. 75). Il y en avait 138 dans le village, qui comptait même une ferme porcine. Or en 2008, il n'en restait plus que 14 (pour 1005 habitants, 1254 bovins et 606 chevaux d'après P. I. Doktorov). Le même phénomène a été observé par le couple BychkovaJordan au village de Djarkhan, dans la Viljuj (2001, p. 97). Comme en témoignent un peu partout des porcheries vides, cet élevage a fortement décliné. Sa chute est d'abord attribuée à la cherté des aliments, un mélange de céréales appelé kombikorm ${ }^{38}$. Plusieurs Iakoutes m'ont dit ne plus élever de cochons faute de quoi les nourrir. Leur donner les restes du repas familial ne suffit pas car ils sont réservés au chien de la maison.

Enclos à cochons vide

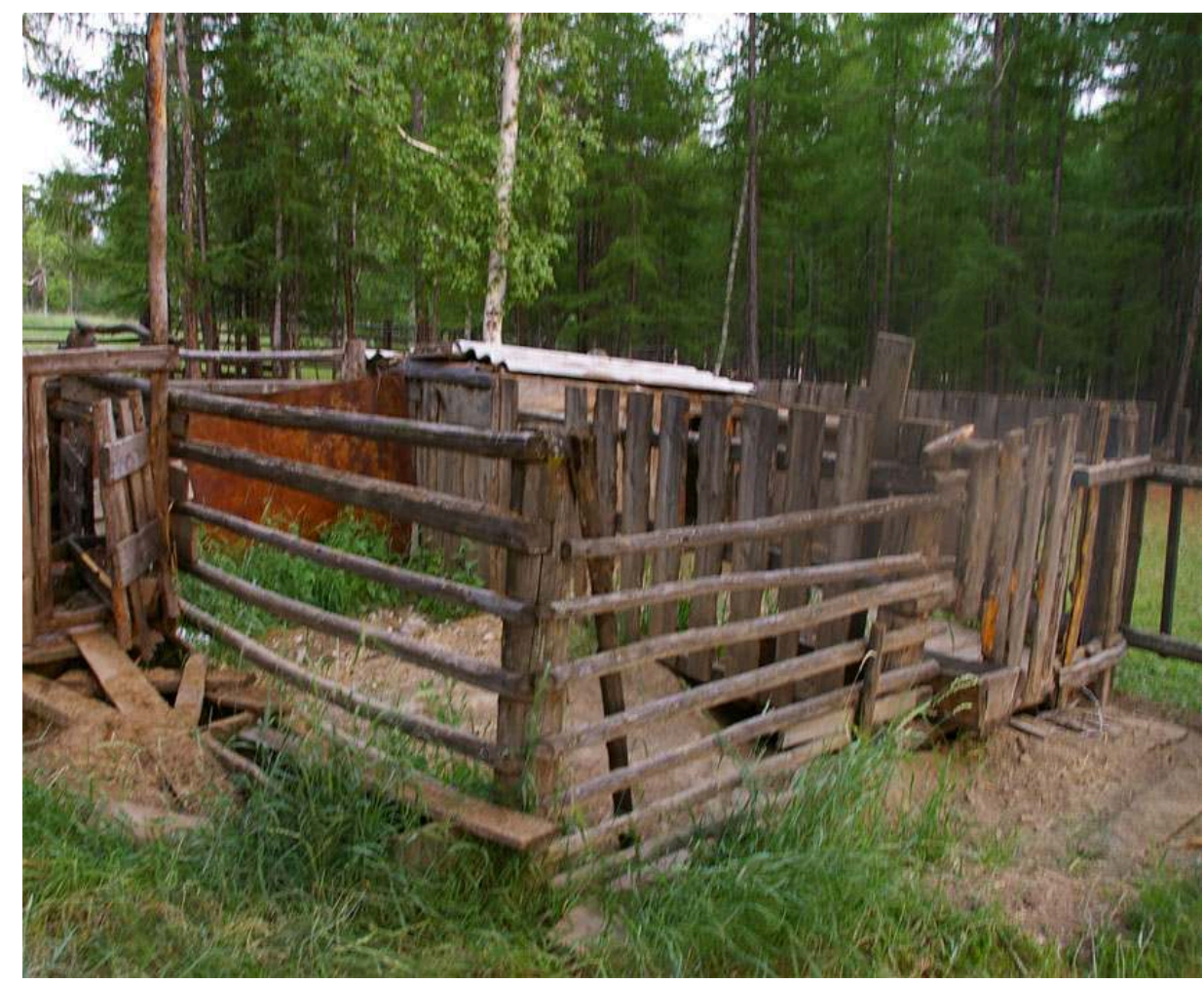

Ust'-Aldan, (chez V. V. Okoëmov), 2008

Photographie de Carole Ferret

En Russie, 2005 a été proclamé " année du cochon », mais cet événement n'a eu que peu d'écho chez l'un de ses "sujets ", la République Sakha où, comme le dit un journaliste économique, «il manque un projet de développement de l'élevage porcin » (Zarickaja 2009). Aussi l'intermède porcin n'aura-t-il peut-être été, pour les Iakoutes, que de courte durée. À Bèjdiyè, les Artamonov, m'ont dit qu'ils n'avaient jamais possédé, en tout et pour tout, qu'un seul porc et qu'ils n'en auront probablement plus.

Même si les Iakoutes ne rechignent pas à élever et manger du porc, ils n'ont laissé qu'une place mineure à cet animal, adopté récemment. Il est peu présent dans le folklore, hormis quelques rares mentions dans des devinettes. Par exemple, muoh isigèr sibiinnèr baallar « il y a des cochons dans la mousse " (des poux sur la tête) (Pekarskij 1907-1930, p. 2202). Rapprocher cheval et cochon est difficilement concevable pour les Iakoutes, non qu'ils souhaitent dissimuler la dimension bouchère de leur élevage équin 
- car pour eux, le cheval n'a rien d'une viande honteuse -, ni uniquement parce que l'image du suidé demeure entachée d'un préjugé défavorable, mais avant tout parce qu'il n'est pas opportun d'assimiler un animal domestique, omnivore et qui demeure constamment dans la cour de la maison, avec un animal dit sauvage, dont l'indépendance et la liberté de mouvement sont soigneusement cultivés.

\section{Un animal à fourrure}

Le climat exceptionnellement rigoureux de la Iakoutie a donné au cheval une caractéristique extraordinaire : c'est un animal à fourrure! Certes, la qualité de son pelage ne lui permet pas de concurrencer la zibeline, cet «or brun» qui attira les Cosaques en Sibérie et dans lequel ils exigeaient des populations locales qu'elles acquittent le jasak. Néanmoins, la peau du cheval iakoute est couramment utilisée en pelleterie.

Son système pileux est particulièrement développé, avec des crins longs, un duvet dense et des poils fournis (Alekseev, Andreev \& Andreevna 1976, p. 175). A. F. Middendorf décrit ainsi son épais manteau :

«Son aspect est fort peu attrayant au printemps, quand il lui reste encore de grosses touffes de poil d'hiver [...] il est vain de tenter alors de deviner les formes de son corps. Sa fourrure est non seulement longue, mais aussi hirsute, car sous les poils a poussé un duvet épais et laineux qu'il perd en été, où son poil est relativement court et lisse. Ce sont surtout les poulains qui sont vêtus de telles pelisses d'ours. Le cheval iakoute a une aptitude extraordinaire à produire du poil » (1869-1877, p. 537).

R. K. Maak renchérit :

«Tout au long de l'hiver pousse sous les poils un duvet si long et si laineux que certaines parties du corps perdent la forme qu'on a l'habitude de voir chez les chevaux. Plus le cheval est jeune, plus son poil d'hiver est épais, si bien que les poulains ont des allures d'oursons aux longues pattes» (1887, p. 151).

52 Mais là encore, si l'explorateur dresse cette comparaison, elle n'est pas usuelle chez les Iakoutes, où l'ours jouit d'un statut bien particulier, très anthropomorphisé comme le montre son nom ${ }^{39}$. 
Les rondeurs poilues de l'étalon D'ükèèbil « aurore boréale », accompagné de ses juments

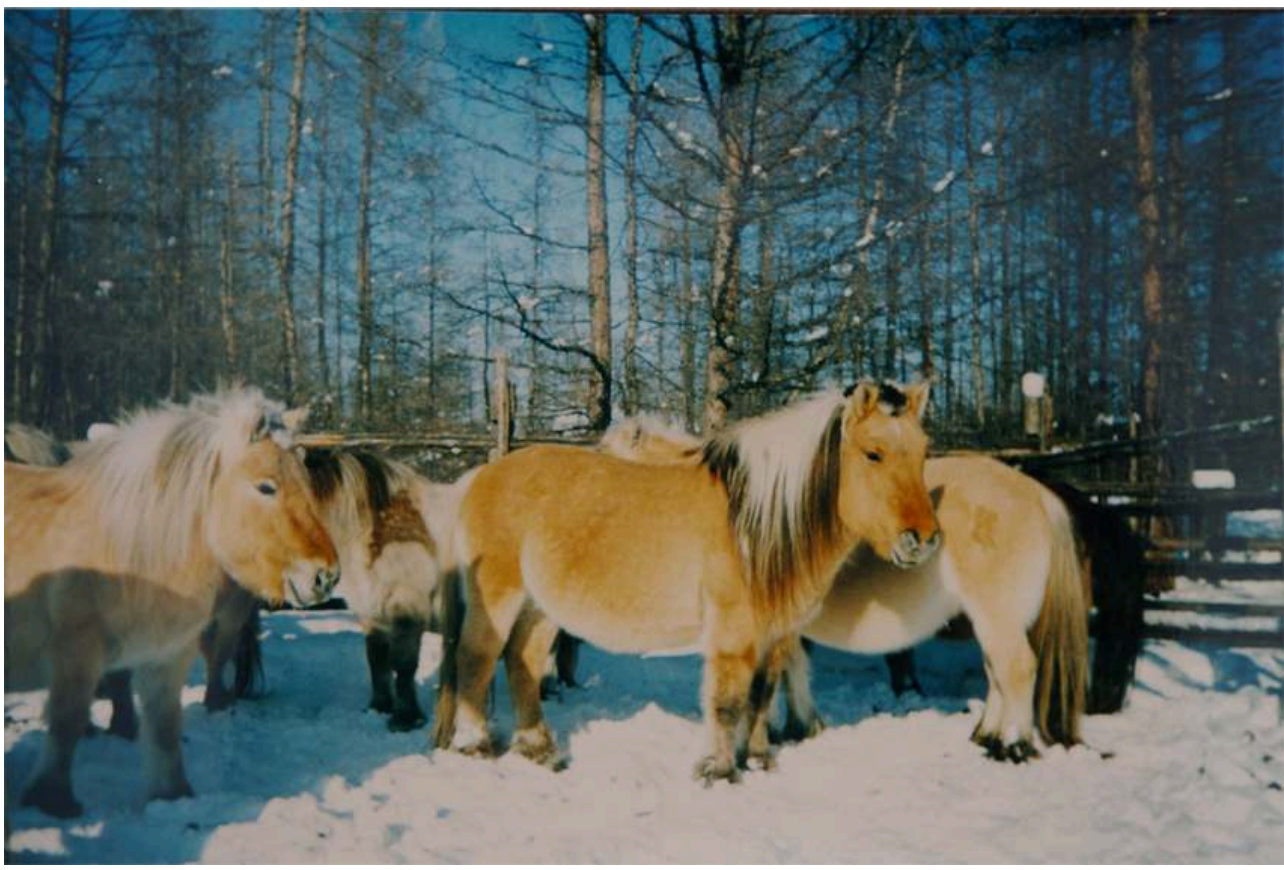

Ust'-Aldan

Photographie de M. A. Artamonov

La qualité du poil constitue l'un des principaux critères de sélection pour les éleveurs iakoutes, une suprématie évidemment dictée par la nécessité de supporter les froids les plus rigoureux. M. A. Artamonov est convaincu que « le plus important, pour choisir un bon cheval, c'est le poil » (le mot utilisé en russe est puh « duvet » et non šerst' « laine, pelage »). Non tant l'épaisseur ni la longueur du poil que sa densité, qui protège efficacement le cheval du froid. Le bon poil doit être doux, fin et serré, transformant le cheval iakoute en véritable bête à fourrure.

«L'augmentation des propriétés d'isolation de la fourrure hivernale du cheval iakoute est due à l'allongement des poils, à l'augmentation de leur densité, mais aussi principalement, à la présence, parmi les différentes sortes de poils [bourre et jarre] d'une couche en forme de cœur. Cette couche de poils en forme de cœur, comme soudée à ces deux extrémités et remplie d'air joue le rôle d'un excellent isolant thermique » (Alekseev, Neustroev \& Ivanov 2006, p. 9).

54 Par la finesse de son poil, le cheval se rapproche du mouton. "En hiver, les poulains ressemblent à de gros moutons. La laine de poulain, par ses qualités, est très proche de la laine de mouton ou de chameau "(Naumov 1953, p. 24).

Cette analogie s'arrête cependant là car, en dehors de quelques expériences avortées, le poil n'est jamais tondu. Simplement, au moment de la mue printanière, il pouvait être récupéré pour faire du feutre, nécessaire à la confection des tapis de selle et des valenki, grosses bottes de feutre russes (Gabyšev 1972, pp. 353-354; Dabrasov 1982, p. 12). La production de feutre demeure néanmoins très mineure chez les Iakoutes ${ }^{40}$, vis-à-vis de l'importance qu'elle revêt chez les bergers centrasiatiques. À la différence du mouton, le poil du cheval iakoute est le plus souvent prélevé avec la peau, sur un animal mort.

Il convient de souligner que la Iakoutie se distingue des autres civilisations pastorales de Sibérie méridionale et d'Asie centrale par l'absence de petit bétail. Plusieurs tentatives d'introduction d'élevage ovin se sont soldées par des échecs (Bašarin 1962, 
p. 75 ; Šubskaja \& Saltykov 1931, pp. 38-39), parce que cet animal n'a pas pu s'adapter au climat, mais aussi parce qu'il nécessite des soins trop assidus et surtout une surveillance constante (Gmelin 1767 [1751], I, p. 188 ; Seroševskij 1896, p. 171). Laissés à eux-mêmes comme l'est habituellement le bétail iakoute, les spécimens importés étaient souvent la proie des chiens ${ }^{41}$. Le cheptel ovin de Iakoutie atteignit son maximum en 1875, avec 786 têtes (Bašarin, 1962, p. 46), puis déclina définitivement. Les quelques chèvres arrivées là disparurent également à la fin $\mathrm{du} \mathrm{XIX}^{\mathrm{e}}$ siècle, mais certains projets visent actuellement à relancer cet élevage (Savvinov 2000) ${ }^{42}$.

Il est d'ailleurs étonnant de voir à quel point, au moment de la collectivisation, les autorisations permettant aux kolkhoziens de conserver quelques têtes de bétail ignoraient la réalité du terrain puisque, dans la majorité des arrondissements de la République autonome de Iakoutie, en 1935, chaque foyer pouvait officiellement disposer de :

« quatre ou cinq vaches, trente à quarante moutons et chèvres [sic], deux à trois truies avec leurs petits, un cheval ou un bœuf de travail, et trois juments avec leur poulain » (ainsi que deux cents à trois cent cinquante rennes et un nombre illimité de chiens de traîneaux dans les arrondissements de renniculture) (Antipin \& al. 1963, pp. 114-115)

La fourrure (iak. tiiri) chevaline fournissait et fournit encore parfois la matière première de nombreux objets: des bottes, fabriquées avec la peau des membres chevalins $^{43}$, mais aussi divers types de chaussures (iak. oloočču) en peau, le poil vers l'extérieur, et des galoches, portées au-dessus des bottes lors des voyages en traîneau; des chapkas, fabriquées avec la peau du front et du ventre, où le poil est le plus fin, des cols, manchettes et moufles; des manteaux, dont de superbes pardessus (iak. sayajah), où alternent des pièces en fourrure de poulain sombres et claires, mais aussi des pelisses (iak. son), avec la fourrure à l'intérieur; des vestes, des caleçons pour l'hiver (iak. syalyja), avec les cuissards (iak. suturuo) qui s'y attachent; des sangles pour les selles; divers sacs (iak. haa), dont de grands fourre-tout pour les voyages (iak. bèrèmèdèj); des soufflets de forgeron (iak. küört) ; des sacs de couchage; des tapis ${ }^{44}$, composés d'une mosaïque de fourrures de couleurs ou d'origines différentes; des couvertures (iak. suorġan); des matelas (iak. tèllèh) pour les berceaux ${ }^{45}$.

Tapis en mosaïque de fourrure de vache et de cheval

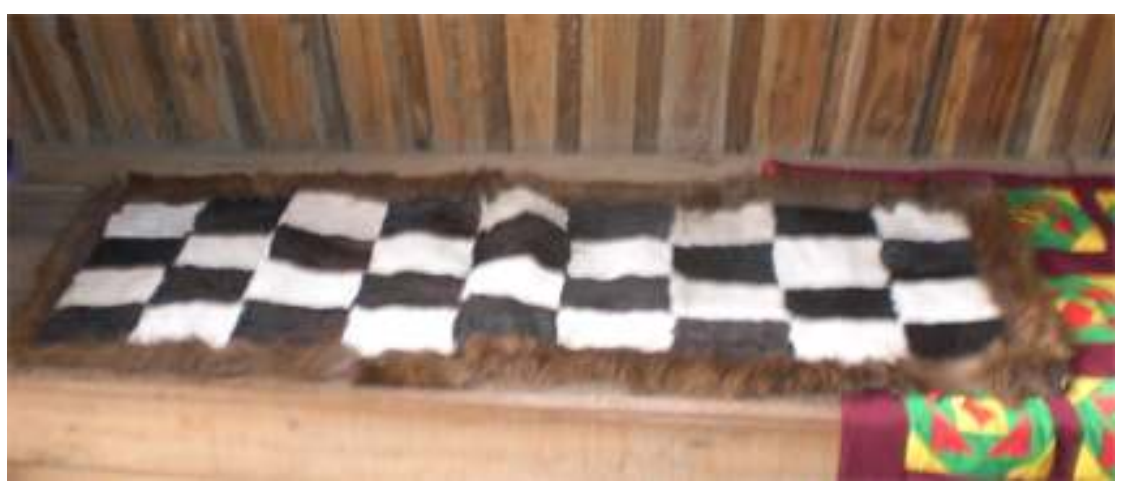

Ust'-Aldan, 2008

Photographie de Carole Ferret

Épilées, écharnées, puis fumées, corroyées, enduites de beurre ou de crème, les peaux chevalines sont transformées en cuir qui sert à fabriquer des vêtements, des 
chaussures, des récipients (notamment des outres à kumys), ainsi que des pièces de harnais et des courroies ${ }^{46}$. Les saary ètèrbès sont des bottes imperméables pour l'été, faites avec la peau de la croupe séparée en deux couches ${ }^{47}$.

L'absence de tissage et la rareté des tissus expliquent l'importance première des habits de peau, particularité qui s'est considérablement amoindrie avec la modernisation. Naguère, les vêtements en peau de cheval étaient plutôt réservés aux pauvres, aux enfants et aux femmes, tandis que les plus riches préféraient se vêtir de renne (Cochrane 1824, p. 217 ; Hudjakov 1969, pp. 25, 123, 177).

61 Si l'utilisation de la fourrure et de la peau chevalines nécessite l'abattage de l'animal, le crin peut, lui, être prélevé sur l'animal vivant. La langue iakoute différencie le crin de la queue (kyl) de celui de la crinière (sièl) (Pekarskij 1907-1930, pp.1375, 2187). Cet artisanat a grandement décliné ${ }^{48}$, mais les crins servaient à fabriquer un grand nombre d'objets : du fil à coudre et à broder, des cordes et des cordelettes, des pièces de harnais, des pièges pour la chasse et des instruments de pêche, des tapis de selle, des paillassons, des pompons, des bas, des moustiquaires, des tamis, des chapeaux et même des lunettes de soleil ${ }^{49}$.

\section{Fillettes maniant de mini-émouchoirs en crin}

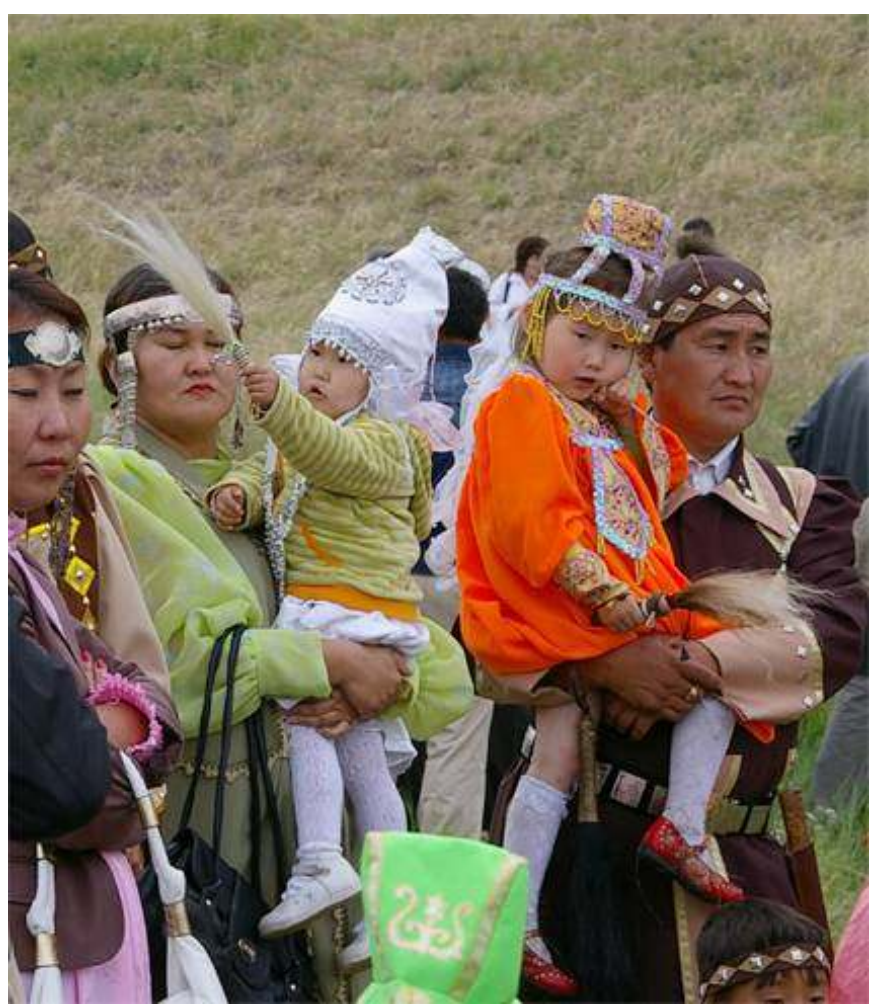

Fête de l'yhyah à Orto Dojdu, environs de lakoutsk, juillet 2008

Photographie de Carole Ferret 
Homme muni d'un émouchoir en crin

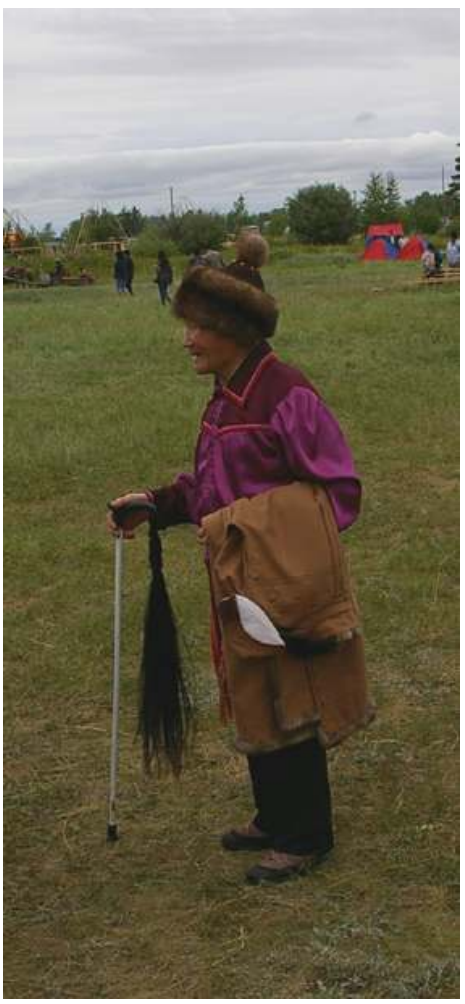

Fête de l'yhyah à Orto Dojdu, environs de lakoutsk, juillet 2008

Photographie de Carole Ferret

62 Des émouchoirs (iak. dèjbiir ou döjbüür) confectionnés à partir d'un morceau de queue fixé sur un manche en bois servent à chasser moustiques et mauvais esprits ${ }^{50}$. Les cordelettes d'offrande utilisées lors des rituels sont en crin blanc (dèlbèrgè) ou souvent bigarrées, mêlées de crins noirs et de crins blancs (salama $\left.a^{51}\right)$, et portent elles-mêmes des rubans ou des touffes de crins blancs ${ }^{52}$. 


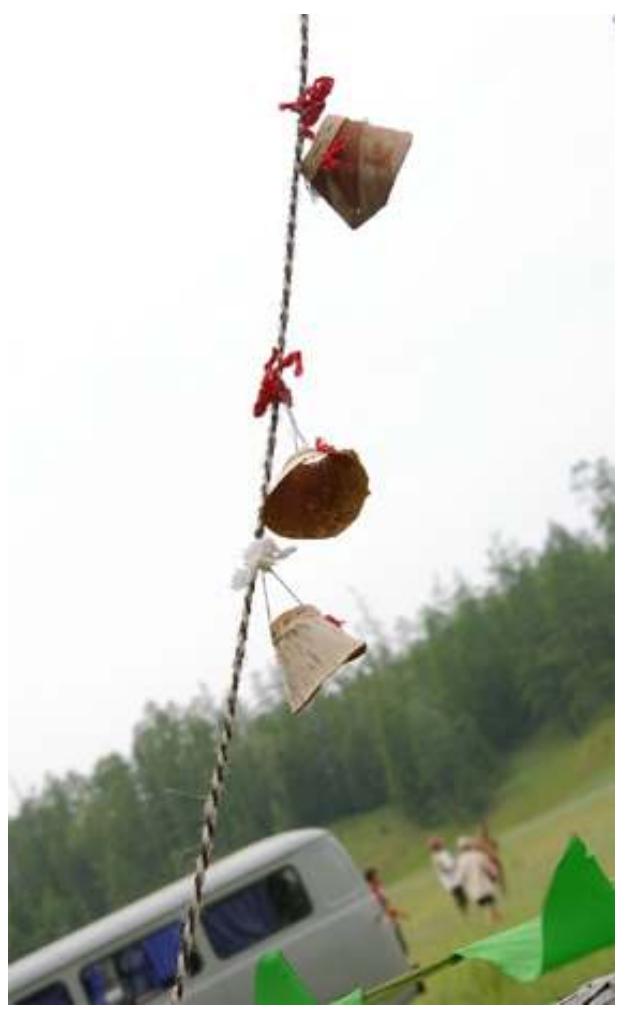

Fête de l'yhyah à Kurbusah, Ust'-Aldan, juillet 2008 Photographie de Carole Ferret

Métonymie du cheval, les crins constituent une forme d'offrande privilégiée - et particulièrement économique, puisque leur coupe n'entraîne qu'un dommage minime et temporaire pour l'animal. Des touffes de crins sont ainsi déposées sous les piliers des demeures ou au pied des sèrgè "piquet d'attache " ${ }^{53}$, enterrées avec le placenta (D'jačenko 1988, pp. 187, 189), jetées dans le feu ${ }^{54}$, accrochées sur les arbres sacrés (Gmelin 1767 [1751], I, p. 398), à la croisée des chemins, au lieu dit sièl yjyyr "d'accrochage des crins de crinière " ${ }^{55}$, etc. Quand ils partaient en voyage - même sur des rennes -, les Iakoutes ne manquaient jamais d'emporter une petite réserve de crins, qu'ils accrocheraient ici ou là (Middendorf 1869-1877, p. 788), une habitude imitée par les Russes eux-mêmes (Priklonskij 1886, p. 90).

Tortillé à la main, sur une cuisse, le crin forme des cordes solides ${ }^{56}$, appelées örgön $(\ddot{u} n e n)^{57}$. Des mèches de crins blancs ornent le bâton de chamane (d'albyyr $)^{58}$, ainsi que les cuillères, les outres et les coupes à kumys (čoroon) ou les sèrgè, tous objets qualifiés de sièllè̀h « ornés de crins de crinière " ${ }^{59}$.

De nos jours, cette utilisation du cheval tend à disparaître, les femmes qui savent rouler les crins pour en faire des cordelettes se font de plus en plus rares et ces objets deviennent des pièces de musée, en dehors de quelques tentatives visant à développer un artisanat iakoute à base de crin ${ }^{60}$. Néanmoins, pour poursuivre la comparaison avec le mouton centrasiatique, on peut noter qu'il en va de même dans certains élevages ovins. Dans le Sud kazakh, les éleveurs ont cessé d'utiliser la laine de leurs moutons. Ils ne savent plus qu'en faire car son prix de vente a tant baissé qu'il ne vaut pas la peine d'aller la porter au marché ${ }^{1}$. En effet, la laine de la race locale, des moutons à queue grasse, élevés pour leur viande, est peu appréciée. Sa qualité est bien inférieure à celle 
du Mérinos, naguère élevé dans les sovkhozes. Si aujourd'hui, les éleveurs continuent à tondre leurs bêtes à la fin du printemps, ce n'est plus pour récupérer la laine, mais simplement pour que les animaux ne souffrent pas d'une chaleur excessive et que leur viande n'en pâtisse pas ${ }^{62}$.

\section{Plus endurant que les porteurs de bosses et de bois}

Le cheval iakoute est un animal de transport, qui a été largement utilisé, d'abord pour le portage, sous la selle et le bât, ensuite pour le trait, attelé à un traîneau ou un chariot. Dans la seconde moitié du $\mathrm{xx}^{\mathrm{e}}$ siècle, la mécanisation a restreint son usage moteur, mais son rôle dans la conquête et l'exploitation du territoire a été si décisif, aussi bien pour le déplacement des hommes que le transport des marchandises ${ }^{63}$, que le qualificatif de "vaisseau de la taïga » ne serait pas usurpé, adaptation d'une expression créée à propos du dromadaire dans le désert (Finbert 1938) ${ }^{64}$.

Cavalier dans la taïga

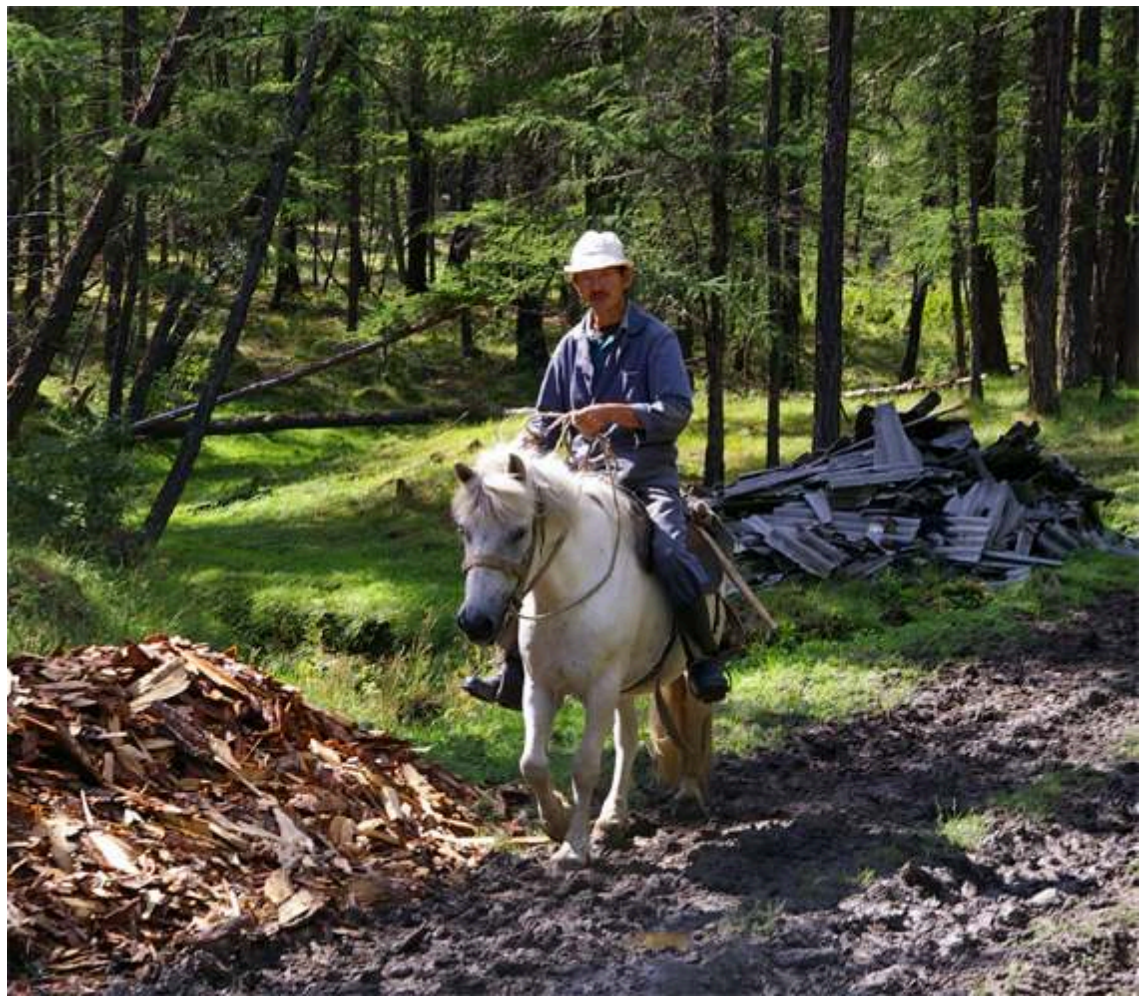

Ust'-Aldan, juillet 2008

Photographie de Carole Ferret

67 En iakoute, le chameau s'appelle tèbièn - ou encore parfois mörbölüt (du rus. verbljud " chameau, dromadaire »). Le premier terme, proche du turc ancien täbä " chameau» (Roux 1959-1960, pp. 36-39), est généralement interprété comme un signe de l'origine méridionale des Iakoutes qui, tout en abandonnant l'élevage de certains animaux lors de leur migration vers le Nord, auraient conservé leurs noms. Outre le chameau, ce serait également le cas du mouton (iak. hoj, à comparer, par exemple, au kazakh qoj) ${ }^{65}$. Aussi une partie des dénominations iakoutes des rennes correspond à des termes désignant les chameaux ou les moutons dans les autres langues turques : par exemple, 
iak. tugut « jeune renne de moins d'un an ", à rapprocher de kaz. toqy « agneau de six mois à un an » (Antonov 1971, pp. 56-60).

Cette interprétation perd un peu de sa crédibilité si on remarque que l'animal est parfois qualifié de sauvage ( $k y y l)$, le chameau étant appelé tèbièn kyyl (ou mörbölüt kyyl). Dans ce cas, il semble que kyyl doive être compris non comme "sauvage" par opposition à « domestique » mais plutôt comme « extraordinaire » ${ }^{66}$.

La littérature orale iakoute conserve quelques rares mentions du camélidé, telles zaqtar sebe a:l curumcuta bolar (ebeter tebien curumcuta bolar) « le sexe des femmes est si solide qu'il pourrait servir de nœud d'attache pour le halage d'un navire / d'anneau nasal pour la conduite d'un chameau »; a:ta tebien ku:l ete b@llafa « serait-ce de la viande de chameau ? ", expression qui se dit à propos d'un objet qu'on chérit excessivement ${ }^{67}$; ou tebien safa qara sana:ta: $\int a r$ twn safa yryn sana: Jrduk « mieux vaut une idée sombre d'un chameau plutôt qu'une idée claire d'une pointe de feu [tüön $\left.{ }^{68}\right]$ » (Kulakovskij 1925, proverbes Z.6 p. 32, A.69 p. 18 et T.84 p. 86, dans l'alphabet latin alors en usage pour l'écriture du iakoute). Dans les épopées, horo-tèbièn est une terrifiante monture à deux bosses, chevauchée par les ennemis des preux (Okladnikov 1970 [1955], p. 232).

L'emblème de la République Sakha (de Iakoutie) vient d'un pétroglyphe trouvé près du village de Šiškino, dans le bassin supérieur de la Lena (actuelle région d'Irkoutsk) et attribué aux Kourykanes. Il représente un cavalier, suivant deux chameaux en liberté 6 . Or les deux camélidés, pourtant bien présents sur la roche, ont été gommés du médaillon symbolisant la nation, vraisemblablement car ils paraissaient trop exotiques.

Pétroglyphe de Šiškino représentant deux chameaux et un cavalier

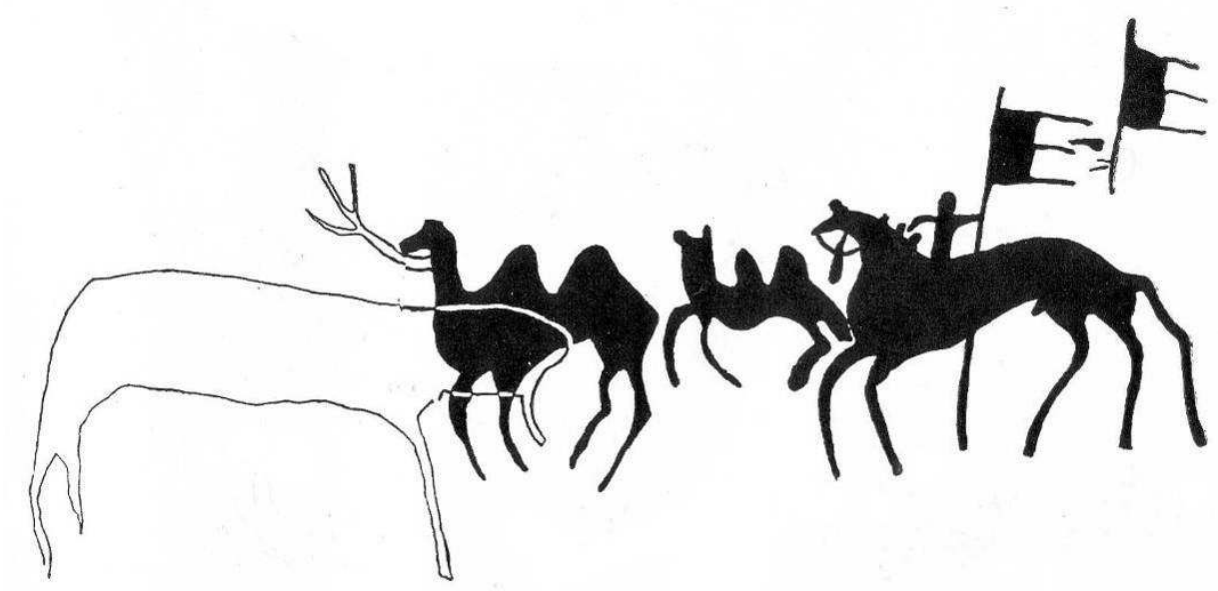

Okladnikov 1959 tab. XX fig. 536

71 Les quelques essais d'importation de chameaux en Iakoutie ont échoué.

«Il y a quelques années que l'on essaya de faire cette route avec des chameaux : on en fit amener un à Iakoutsk, et les Iakoutes furent très étonnés à la vue de ce monstre. Il arriva par hasard dans la même année que plusieurs personnes de cette ville eurent la petite vérole; les Iakoutes accusèrent le dromadaire de l'avoir donnée. Ils savaient bien que cette maladie avaient auparavant régné dans Iakoutsk, sans qu'elle y eut été apportée par un pareil animal, et pouvaient croire que celle-ci était aussi naturelle que les précédentes, mais un raisonnement philosophique leur persuada le contraire [...] Le nouveau démon de la petite vérole chargé de provisions et de marchandises partit de Iakoutsk, à la grande satisfaction des 
Iakoutes, mais il ne put pas aller jusqu'à Okotsk; le pauvre diable mourut auprès d'un ruisseau, que depuis cet événement on nomme verblioucha, c'est-à-dire ruisseau du chameau. Le climat est trop froid pour ces animaux, et les montagnes ne leur conviennent pas ; il paraît que la nature les a destinés à des plaines désertes, où l'on éprouve peu de froid » (Gmelin 1767 [1751], I, pp. 419-421)

Dans les années 1920, des chameaux furent utilisés dans le sud de la Iakoutie pour assurer le transport jusqu'aux mines de l'Aldan (Šubskaja \& Saltykov 1931, pp. 38-39 et 41 ; Molodyh 1927, pp. 643-650). Mais ces expériences ne connurent pas de suite.

L'animal de transport qui peut concurrencer le cheval dans la taïga iakoute, ce n'est pas le chameau, mais le renne. Selon N.K. Antonov, les ancêtres des Iakoutes auraient d'abord nommé le renne "chameau céleste» (1971, p. 155), une expression ensuite devenue obsolète, mais leurs descendants ont gardé, pour désigner le renne, un dérivé (taba) du nom turc du chameau (täbä) (ibid., p. 58). En Eurasie, la répartition géographique de ces trois animaux peut être reliée aux variations du milieu naturel avec, grossièrement, le chameau dans les zones de désert et de steppe, le cheval dans la steppe et la taïga, le renne dans la taïga et la toundra. L'usage de l'équidé est néanmoins le plus largement diffusé, à telle enseigne que, pour A. Leroi-Gourhan,

«il n'est pas possible d'étudier le cas du cheval dont la diffusion, comme celle du chien est universellement humaine et dont la plasticité est telle qu'on les élève aussi bien sous l'équateur que sous le cercle arctique. Il reste le cas du chameau et celui du renne qui offrent la possibilité d'une curieuse série de comparaisons. On entre avec eux dans le système des zones parallèles qui ont joué un rôle prépondérant dans la constitution physique et politique du monde asiatiqueeuropéen. Ces zones, en remontant vers le pôle, sont la steppe, la forêt, la taïga et la toundra qui s'étend jusqu'à l'Océan glacial [...] La taïga et la forêt, de pénétration difficile, n'ont pas eu la première place dans les déplacements humains, alors que la steppe, territoire du chameau, et la toundra, domaine du renne, forment les couloirs horizontaux par lesquels les grands mouvements se sont produits. On verra, pour le renne, que celui-ci n'a que peu ou pas besoin de l'homme, alors que la diffusion du chameau est exclusivement humaine » (1936, pp. 19-20).

Durant plusieurs siècles, pour cheminer dans la taïga iakoute, le voyageur avait donc le choix entre chevaux et rennes.

« On peut aller par terre et par eau de Iakoutsk à Okotsk [...] Comme il [le chemin de terre près de la rivière Ourak ou Ourom] traverse de hautes montagnes, il est impraticable pour les voitures, et l'on est obligé de mettre ses bagages sur des chevaux ou des rennes » (Gmelin 1767 [1751], I, 415-416; voir aussi par exemple, Jochelson 1933, p. 187).

Les avantages respectifs des deux animaux de transport sont ainsi jaugés : le renne a pour lui sa frugalité, son habileté à traverser les cours d'eau (Middendorf 1869-1877, p. 542), à avancer sur la neige ou la glace (Watkin 1905, p. 18 ; Leroi-Gourhan 1936, p. 154); mais le cheval demeure indubitablement plus puissant, pour porter de lourdes charges ou des cavaliers (Cochrane 1824, 176). Aussi, en fonction des circonstances, sera-t-il plus judicieux d'opter pour l'une ou l'autre des deux espèces. 


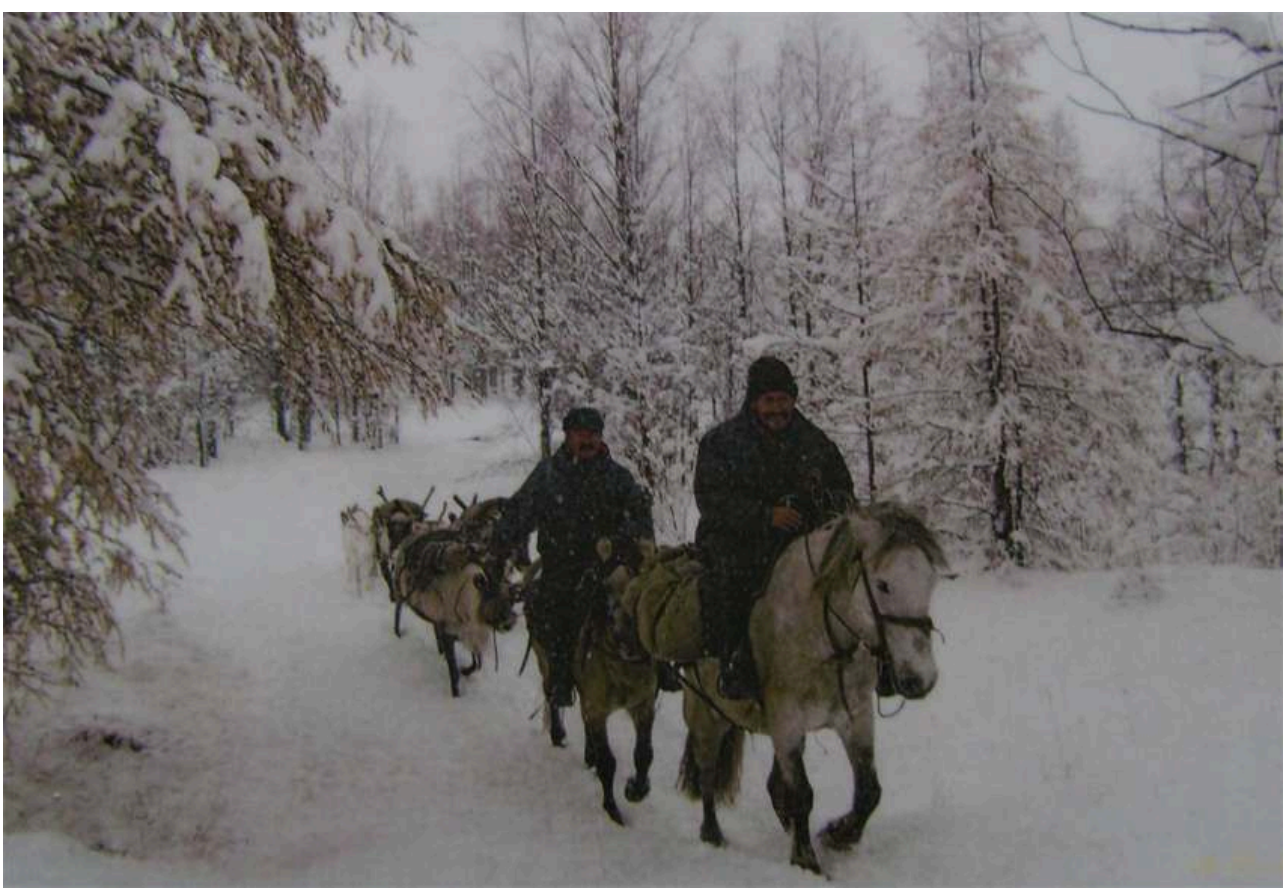

Ulus de Kobjaj

Photographie de L. V. Burceva

La place du renne dans l'économie iakoute est controversée. L'image classique des Iakoutes, telle que nous l'ont transmise les explorateurs et les ethnographes ${ }^{70}$, les décrit comme un peuple de pasteurs, éleveurs de chevaux et de vaches, qui, en migrant vers le Nord, a rencontré d'autres peuples, evenks, evènes et ioukaguirs, chasseurs et éleveurs de rennes. I. A. Hudjakov va jusqu'à affirmer que seuls les chevaux sont élevés de longue date par les Iakoutes, l'élevage du renne ayant été emprunté aux Toungouses, et celui des bovins aux Russes $(1969$, p. 229) - cette dernière affirmation n'étant pas exacte.

Dans cette perspective, il n'y a guère de place pour le renne chez les Iakoutes. « Reindeer breeding is, nevertheless, a secondary occupation » (Jochelson 1933, p. 191 ; voir aussi Seroševskij 1896, p. 295 ; Tokarev 1945, p. 35). Comptabilisant les activités décrites dans les légendes et les épopées recueillies par I. A. Hudjakov, N. V. Volens trouve que l'élevage du cheval est cité dix fois, celui des bovins sept fois, celui des rennes deux fois $(1927$, p. 676). Il va de soi que cette proportion n'est pas nécessairement le reflet fidèle de la réalité, mais elle révèle néanmoins le rôle secondaire attribué au cervidé. Plusieurs légendes qualifient le renne de "bétail toungouse" (Seroševskij 1896, p.141). On l'appelle aussi omuk süöhütè "bétail étranger » (Pekarskij 1907-1930, p. 2399. Entretiens à Bèjdiyè et Aryylaah, Ust'-Aldan).

78 Comme l'avait relevé J. G. Gmelin dès le XviII ${ }^{e}$ siècle (1767 [1751], I, p. 272), l'espèce élevée a longtemps servi de marqueur ethnique, suivant la logique « dis-moi quel bétail tu élèves, je te dirai qui tu es ». Des rituels analogues s'effectuent, chez les Iakoutes avec un cheval et chez les Evenks et les Evènes, avec un renne (Hamayon 1997, p. 189). Le mode d'élevage et les usages des deux animaux sont parallèles chez les uns et les autres. 
Répartition du cheptel (chevaux, bovins et rennes) par ethnies en 1917 dans les districts centraux et méridionaux (Jakutskij, Olekminskij et Viljujskij)

\begin{tabular}{|c|c|c|c|c|c|c|c|c|c|c|}
\hline & \multicolumn{2}{|c|}{ habitants } & \multicolumn{4}{|c|}{ chevaux } & \multicolumn{2}{|c|}{ bovins } & \multicolumn{2}{|c|}{ remues } \\
\hline & \begin{tabular}{l|l} 
nb \\
\end{tabular} & $\begin{array}{c}\text { par } \\
\text { foyer }\end{array}$ & nb & $\begin{array}{c}\text { par } \\
\text { foyer }\end{array}$ & $\begin{array}{l}\text { \% chevaux } \\
\text { de truvail }\end{array}$ & $\begin{array}{l}\text { ch. de travail } \\
\text { par foyer }\end{array}$ & $\mathrm{nb}$ & $\begin{array}{c}\text { par } \\
\text { foyer }\end{array}$ & $\mathbf{n b}$ & $\begin{array}{c}\text { par } \\
\text { foyer }\end{array}$ \\
\hline $\begin{array}{l}\text { paysans } \\
\text { russes et } \\
\text { Cosaques }\end{array}$ & 10743 & 5,51 & 6754 & 3,46 & 82 & 2,85 & 12792 & 6,56 & 0 & 0 \\
\hline $\begin{array}{l}\text { Iakoutes } \\
\text { sédentaires }\end{array}$ & 8651 & 4,58 & 8515 & 4,51 & 76 & 3,42 & 17226 & 9,11 & 244 & 0,13 \\
\hline $\begin{array}{l}\text { Iakoutes } \\
\text { nomades }\end{array}$ & 198462 & 4,29 & 108216 & 2,34 & 71 & 1,66 & 437345 & 9,46 & 4632 & 0,1 \\
\hline $\begin{array}{l}\text { Toungouses } \\
\text { nomades }\end{array}$ & 2372 & 4,71 & 1018 & 2,02 & 74 & 1,5 & 4136 & 8,22 & 1115 & 2,22 \\
\hline $\begin{array}{l}\text { Toungouses } \\
\text { errants }\end{array}$ & 96 & 4,33 & 5 & 0,27 & 100 & 0,27 & 10 & 0,56 & 386 & 21,44 \\
\hline autres & 4638 & 3,69 & 2078 & 1,65 & 78 & 1,3 & 7857 & 6,26 & 468 & 0,37 \\
\hline
\end{tabular}

D'aprèsBašarin 1962, p. 35 ; Gogolev 1970, pp. 66-69

79 Cette distribution ethnique et géographique était claire dans les régions centrales et la Viljuj et elle le demeure jusqu'à nos jours. Nombre de Iakoutes considèrent « celui qui porte la forêt sur lui » (Solov'eva-Ojunskaja 1992, p. 30) avec un certain mépris.

" These [horse] herds are among the northern most in the entire world, and only a short distance poleward lies the domain of reindeer herding, an activity the Vilyui Sakhalar consistently rejected, regarding it as an enterprise for Evenks, Evens, and Yukagir.»

« Budyonny also experimented early with a herd of twenty-one reindeer, a venture doomed to failure, since the Vilyui Bend Yakuts regarded them as livestock fit only for Evens, Evenks, or Yukagirs. By 1950 reindeer had virtually disappeared, and the cattle-horse ratio had shifted even more in favour of bovines. »

«To another interviewer Artamonov said the Sakha government should bring the Even reindeer herders closer to Yakutsk, so they "could abandon this Stone Age life.” (Bychkova \& Jordan 2001, pp. 46, 73, 107).

Ce dernier cliché est lié à un paradigme évolutionniste, qui dominait au $\mathrm{XIX}^{\mathrm{e}}$ siècle et encore dans l'idéologie soviétique, voulant que l'élevage du renne, particulièrement extensif, peu interventionniste et de surcroît complété par la chasse, corresponde à un stade antérieur du développement de l'humanité. C'est pour cette raison que, sous le régime tsariste, les Toungouses, chasseurs et éleveurs de rennes nomades, étaient recensés comme «errants» (rus. brodačie), tandis que les Iakoutes semi-sédentaires, éleveurs de gros bétail bovin et équin, étaient classés comme "nomades» (kočevye). Les Français trahissent d'ailleurs une appréciation similaire, lorsqu'ils parlent de renniculture plutôt que d'élevage du renne.

D'un autre côté, quelques auteurs estiment que l'élevage iakoute du renne est largement méconnu. Pour G. V. Ksenofontov, l'avant-garde de la migration iakoute fut nécessairement formée par des Iakoutes éleveurs de rennes, car des populations ignorant tout de cette activité n'auraient jamais pu coloniser ces terres. Leur rôle a été, selon lui, sous-estimé dans la littérature ethnographique au profit des Iakoutes éleveurs de chevaux et de bovins, parce qu'ils ont souvent été confondus avec des Toungouses et qu'aucune monographie n'a été consacrée au territoire où ils se sont établis, au nord-ouest de la Iakoutie (1937, pp. 269-275). Cette lacune a ensuite été comblée grâce à l'ouvrage d'I. S. Gurvič, sur La culture des Iakoutes septentrionaux éleveurs de rennes (1977) - qui infirme néanmoins la thèse de Ksenofontov sur une migration précoce des Iakoutes. 
Cette polémique sur la place du renne dans l'économie iakoute est instructive dans la mesure où elle montre que l'espèce animale élevée, souvent considérée comme le reflet du peuple qui l'a domestiquée, peut être une composante essentielle de l'identité collective, pour soi-même comme pour autrui.

Nombre de rennes par ulus en 2006

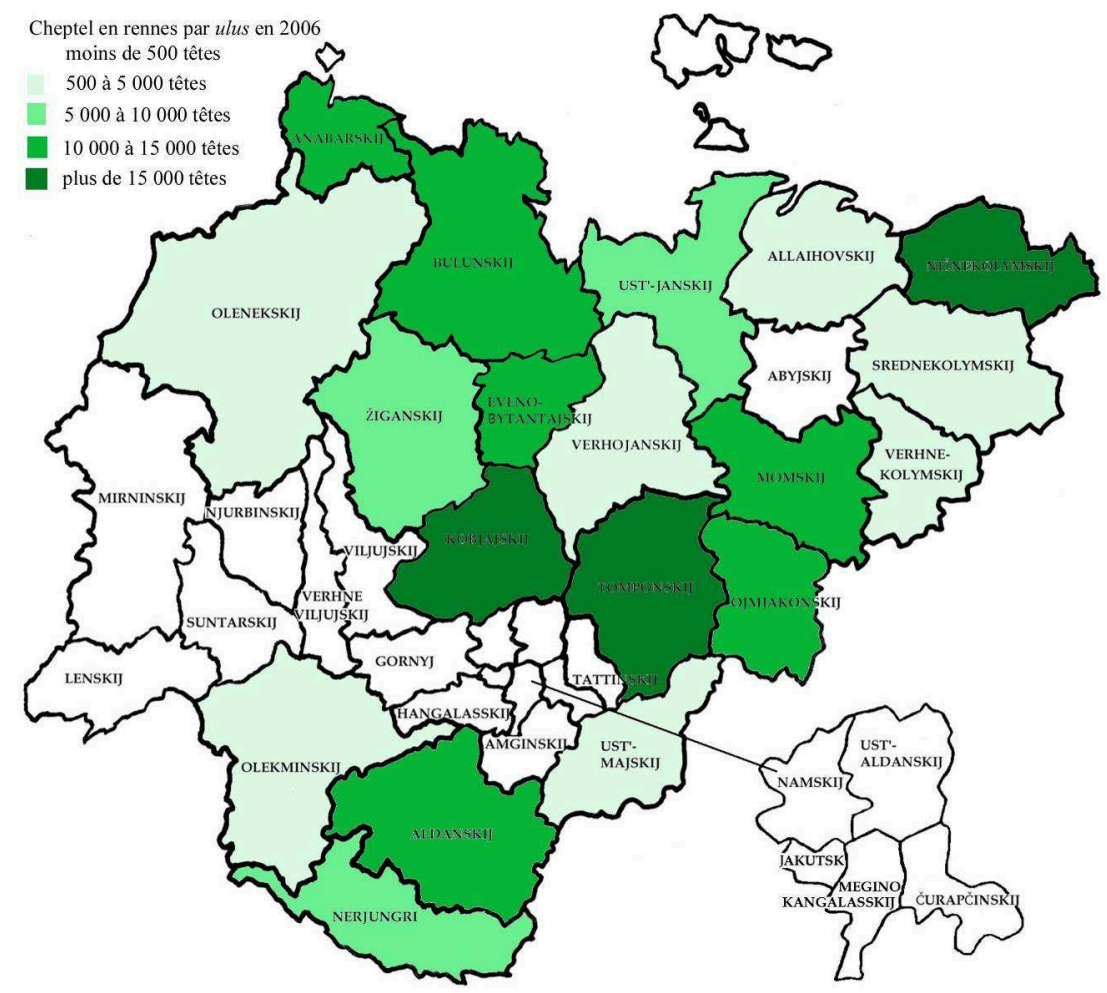

Carte de Carole Ferret 


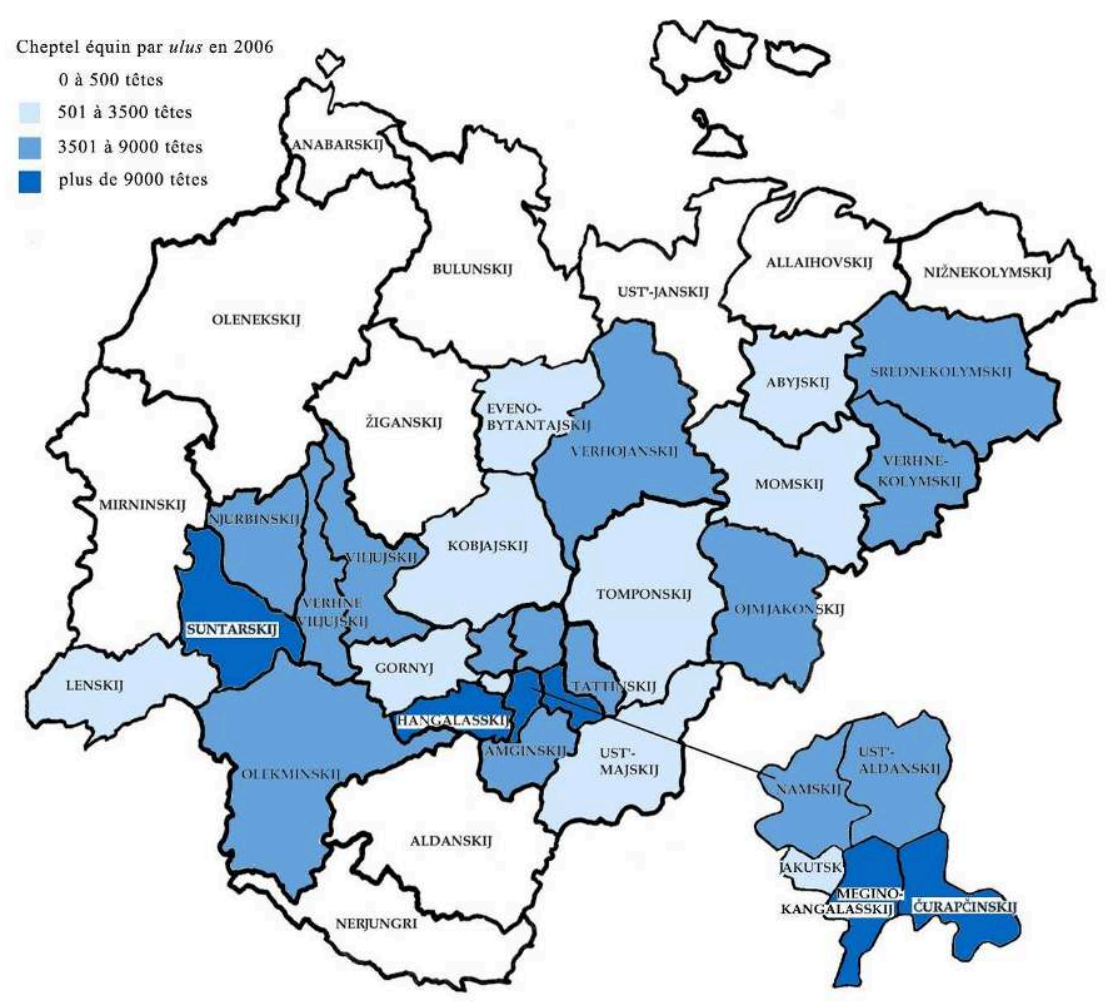

Carte de Carole Ferret

Le renne est très inégalement réparti dans le pays, et surtout présent là où il n'y a pas ou peu de chevaux. Espèce prépondérante dans la moitié Nord ${ }^{71}$, également élevé dans l'extrême Sud, le cervidé est totalement absent des régions centrales et de la Viljuj. Rennes et chevaux se partagent le territoire de la Iakoutie. Ces deux espèces polyvalentes qui constituaient les deux principales forces de portage et de trait se substituent l'une à l'autre. Partout où l'une est dominante, l'autre s'efface (Rogalevič 1941, p. 8). La carte de répartition du nombre de rennes par foyer en 1938 est le négatif presque parfait de la carte équivalente pour les chevaux. 


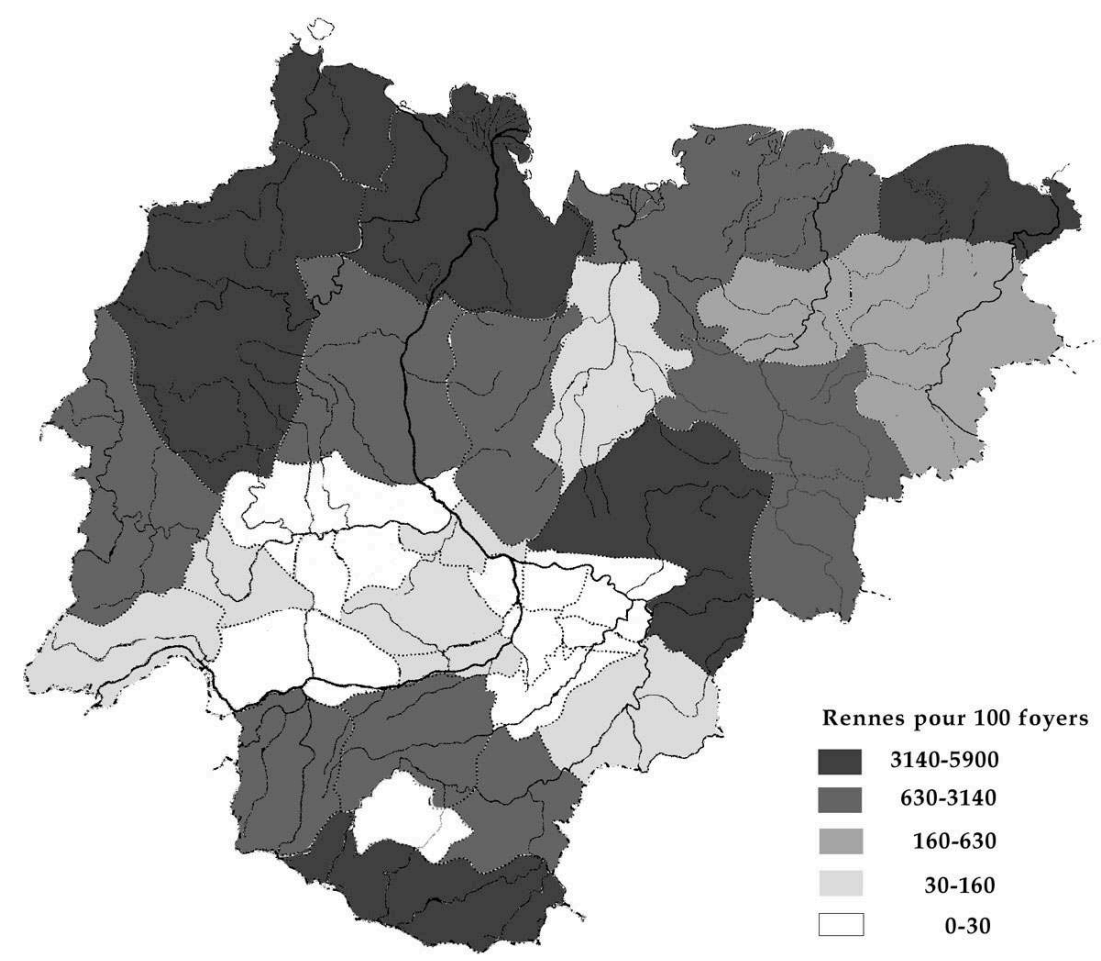

Carte de Carole Ferret

Répartition du nombre de chevaux en 1938

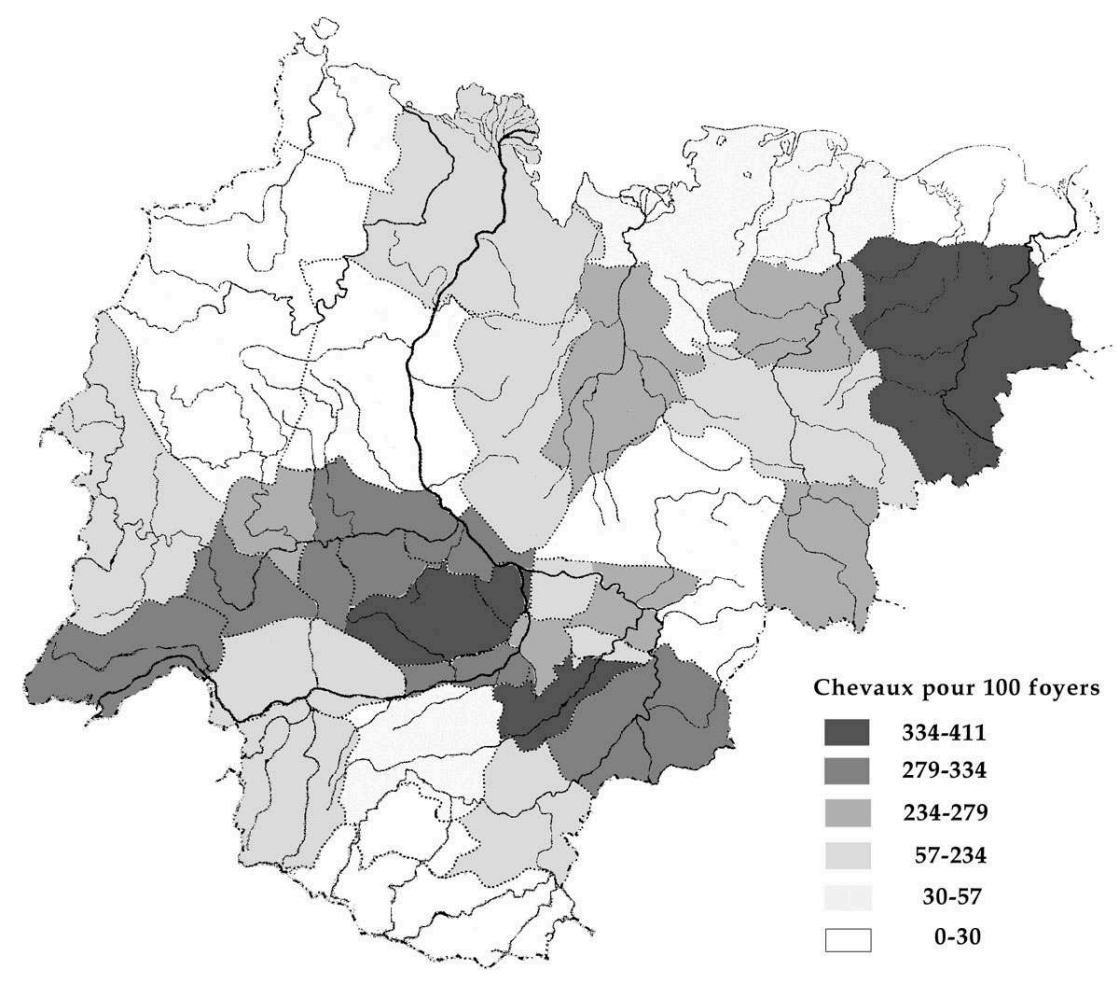

Carte de Carole Ferret 
Cela ne signifie pas qu'il n'y ait jamais coexistence des deux espèces. Les éleveurs de rennes se servent parfois de chevaux comme montures, dans l'ulus de Kobjaj par exemple $^{72}$. Mais l'inverse est rarement vrai et surtout, il n'y a pas d'élevage massif concomitant des deux animaux comme c'est le cas avec chevaux et bovins.

Évolution du nombre de rennes en lakoutie depuis 1948

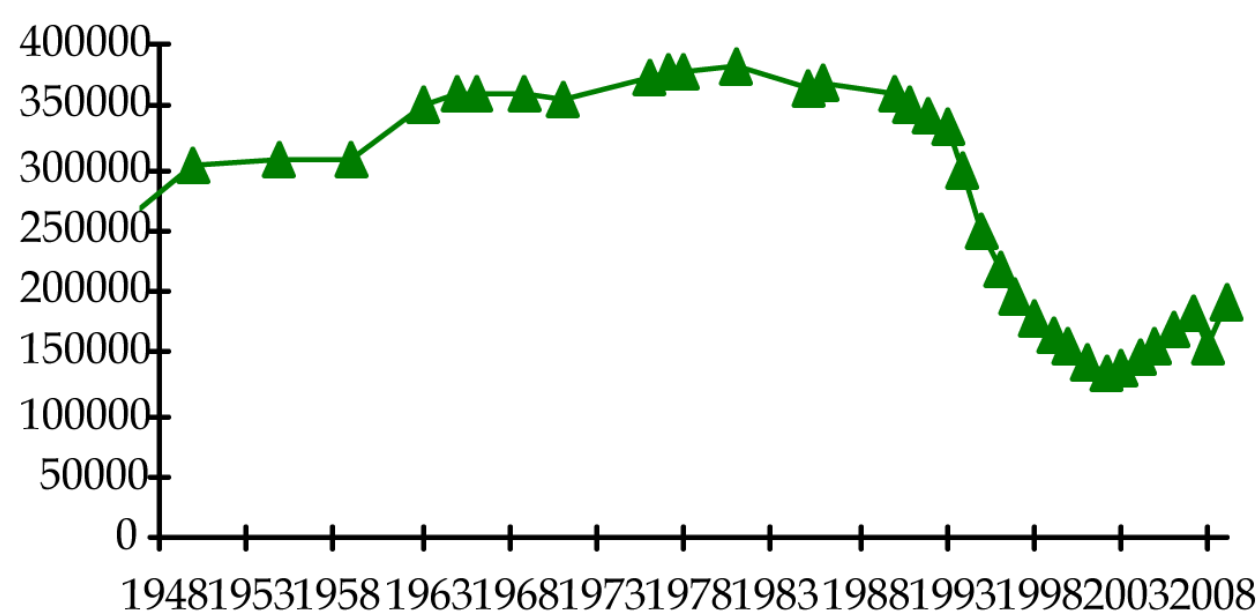

Schéma de Carole Ferret - à ceci près que celui-là bénéficie d'un affouragement en foin à certaines périodes critiques de son existence (Alekseev 2008, p. 72) et qu'il est davantage laissé à lui-même le reste du temps. Tout en étant proches par l'extensivité de leur élevage et la polyvalence de leurs usages, cheval et renne sont rarement mis en parallèle dans les représentations. Ceci est compréhensible, dans la mesure où ces deux espèces ne sont pas complémentaires mais substitutives. Jouant un rôle analogue mais ne coexistant guère, elles sont trop semblables pour entrer dans un jeu d'oppositions. L'animal qui incarne le parfait antagoniste complémentaire du cheval et qui, à ce titre, est constamment comparé à lui, c'est la vache.

\section{Un bétail radieux}

87 J'ai déjà montré à quel point la comparaison des deux principales espèces élevées par les Iakoutes brosse un tableau bipolaire et contrasté, comme si la vache représentait un cheval à l'envers, un cheval en négatif (Ferret 2009, pp. 253-305). D'un côté, un bétail familier, avec lequel on cohabite, qui donne beaucoup et qui donne aussi beaucoup de mal; de l'autre côté, un bétail lointain, libre et indépendant, qui donne également beaucoup, mais auquel on ne donne rien. Je ne reviendrai pas sur le détail de cette

Études mongoles et sibériennes, centrasiatiques et tibétaines, 41 | 2010 
démonstration, mais je me contenterai d'apporter quelques éléments nouveaux qui invitent à compléter ou à nuancer ce tableau.

Anna Okoëmova ramène les veaux dans le hoton

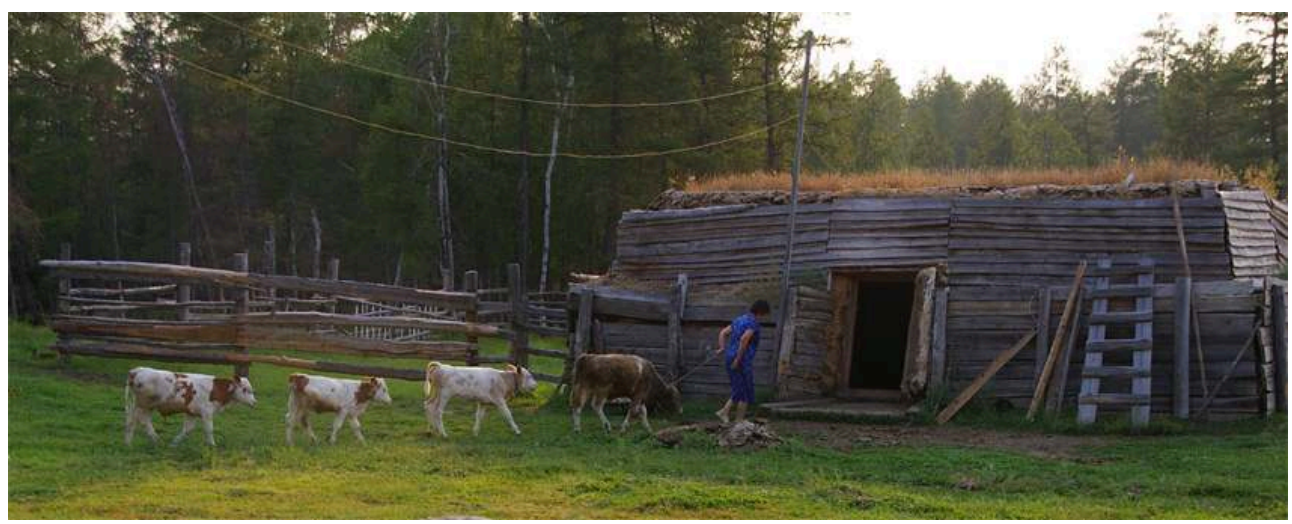

Anna Okoëmova trait une vache dans le hoton

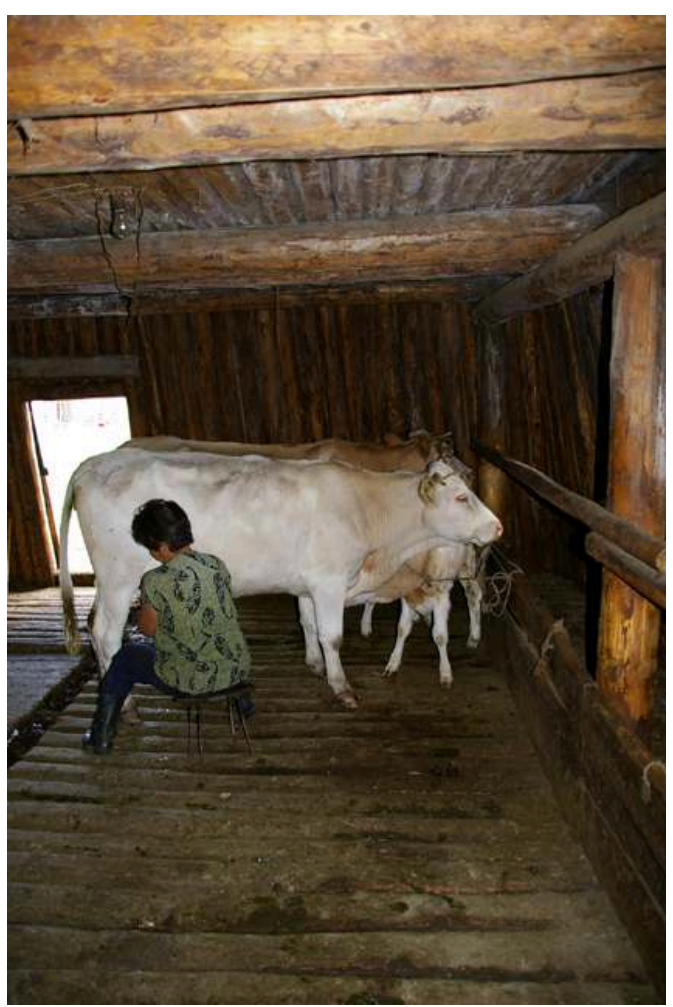

Ust'-Aldan, juillet 2008

Photographies de Carole Ferret

Maints auteurs soutiennent l'idée qu'autrefois, les Iakoutes élevaient davantage de chevaux que de bovins ${ }^{74}$, ce qui expliquerait le différentiel des valeurs attribuées à chacune de ces deux espèces. En effet, dans la littérature orale, les chevaux sont montés par des héros ou des esprits positifs et les bovins, par des adversaires du héros ou des esprits mauvais ${ }^{75}$. Dans la vie courante, les bœufs peuvent être montés ou attelés pour parcourir de courtes distances, mais ils sont considérés comme des montures moins aimables que les chevaux (Kulakovskij 1925, p. 17 proverbe A-76). Dans les incantations 
(iak. algys), les équidés sont signalés par leurs sabots pleins (bütèj tujahtaah), cependant que les bovins ont les pieds fendus (atyrd'ah tujahtaah ou ahahagas tujahtaah) (Pekarskij 1907-1930, p. 593, 203 ; Èrgis 1974, p. 171).

De façon générale, les chevaux sont considérés comme le «bétail blanc » ou plus précisément ürüy süürük « coursier blanc » (Pekarskij 1907-1930, p. 2412), tandis que les bovins sont le «bétail (coursier) noir». La langue des épopées, telles Kyys Dèbilijè, oppose ürüy tüülèègè « ceux qui ont une robe à poils blancs» (i.e. les chevaux) à hara tüülèègè « ceux qui ont une robe à poils noirs » (i.e. les vaches) ${ }^{76}$. Un passage de N'urgun Bootur illustre également ce contraste de couleurs.

« Il lui sembla apercevoir des tas de neige lumineux, c'est ainsi que les troupeaux de chevaux blancs lui apparurent. Il lui sembla discerner une masse de paillettes de glace, c'était des troupeaux de vaches noires. Ainsi lui apparut cette terre généreuse » (Guerriers célestes... 1994, p. 74).

Cette opposition se fonde sur une réalité : les chevaux iakoutes ont souvent des robes claires, tandis que les vaches iakoutes ont des robes sombres (Kulakovskij 1928, p. 37), mais elle est surtout fortement chargée symboliquement. Tout en étant plus nombreux, les bovins sont beaucoup moins valorisés que les chevaux dans la culture iakoute qui partage, dans une certaine mesure, la bipolarisation altaïque du noir et du blanc, comme le montre la polysémie des adjectifs de couleur kèrè «blanc » et «beau », ürüy « blanc » et " pur », hara « noir », « fort », « mauvais » et " simple, commun »"

91 Les Iakoutes conçoivent les chevaux comme un bétail masculin (iak. èr kiḥi süöhü «le bétail de l'homme») et les bovins, comme un bétail féminin (iak. d'ahtar süöhü «le bétail de la femme») (Seroševskij 1896, p. 506; Pekarskij 1907-1930, p. 2399). Bien qu'elle ne soit pas toujours strictement respectée, une certaine division sexuelle des tâches demeure : les femmes s'occupent des vaches et de leur traite; les hommes, des chevaux.

En revanche, les Iakoutes n'établissent pas de relation manifeste entre l'opposition des sexes et celle du chaud et du froid, ni même d'association évidente entre ces deux dernières catégories et les espèces animales, comme le font les Mongols, qui distinguent le bétail à museau chaud (cheval et mouton) du bétail à museau froid (chèvre, bovin, chameau) et ne sacrifient que le premier aux esprits bienfaisants (Vjatkina 1968, pp.117-118 ; Rintchen 1977, p. 156). Chez les Iakoutes, paradoxalement, le froid semble être moins systématiquement chargé de valeurs négatives que chez les autres peuples altaïques (Ferret 2004, p. 265). Chevaux et bovins peuvent pareillement faire l'objet de sacrifices, actifs ou passifs ${ }^{78}$, dédiés aux esprits bons ou aux esprits mauvais. La seule règle observable à ce sujet consiste en ce que les esprits du monde supérieur reçoivent des chevaux (Seroševskij 1896, p. 252, 637, note 2 ; Hudjakov 1969, p. 236).

Quelques éléments de la littérature orale rapprochent néanmoins les bovins de la catégorie du froid. Ainsi, la figure de l'hiver est incarnée par un taureau aux immenses cornes et au souffle glacial.

«Le froid [moroz] est comme un taureau à deux cornes. La première casse à la première fête de Saint-Afanasij (le 5 mars), la seconde à la deuxième Saint-Afanasij (le 24 avril), et son corps disparaît tout entier à la troisième Saint-Afanasij (le 14 mai)» (Seroševskij 1896, p. 26).

"D'yl og̉usa "le taureau de l'année", maître de l'année, apparait à l'automne sous la forme d'un oiseau. Au premier trimestre, il perd ses ailes, puis tous ses autres membres à l'approche du printemps. Quand la neige fond, il prend l'aspect définitif 
d'un taureau tigré à long poils et s'en va au-delà de l'océan jusqu'à l'automne » (Popov 1949, p. 278).

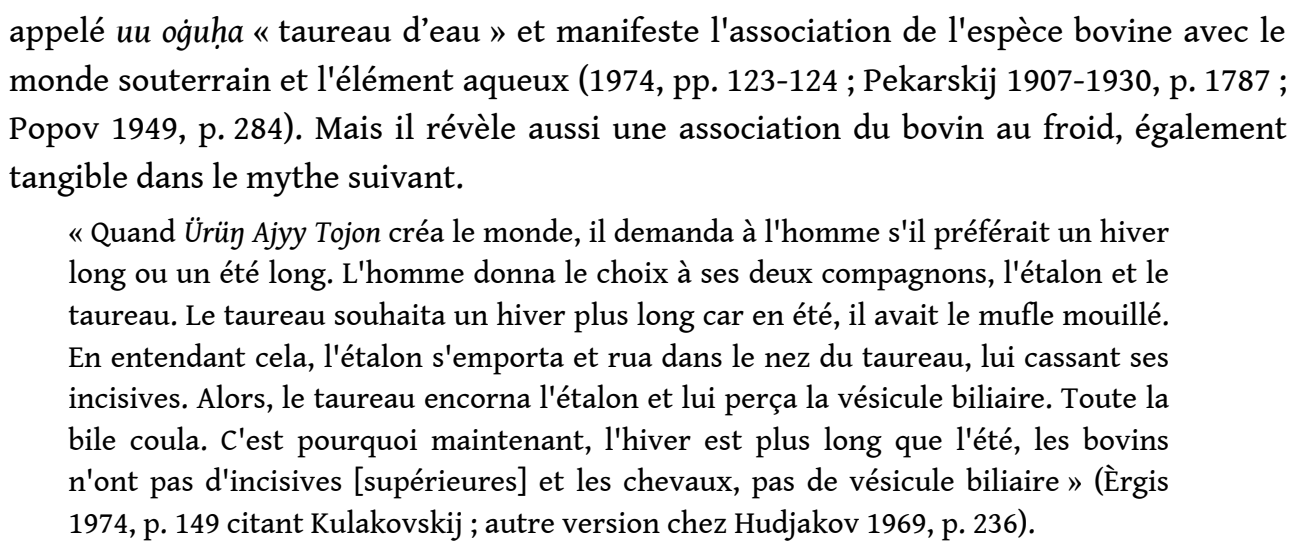
appelé uu og̉uha «taureau d'eau » et manifeste l'association de l'espèce bovine avec le monde souterrain et l'élément aqueux (1974, pp. 123-124 ; Pekarskij 1907-1930, p. 1787 ; Popov 1949, p. 284). Mais il révèle aussi une association du bovin au froid, également tangible dans le mythe suivant.

«Quand Ürüy Ajyy Tojon créa le monde, il demanda à l'homme s'il préférait un hiver long ou un été long. L'homme donna le choix à ses deux compagnons, l'étalon et le taureau. Le taureau souhaita un hiver plus long car en été, il avait le mufle mouillé. En entendant cela, l'étalon s'emporta et rua dans le nez du taureau, lui cassant ses incisives. Alors, le taureau encorna l'étalon et lui perça la vésicule biliaire. Toute la bile coula. C'est pourquoi maintenant, l'hiver est plus long que l'été, les bovins n'ont pas d'incisives [supérieures] et les chevaux, pas de vésicule biliaire " (Èrgis 1974, p. 149 citant Kulakovskij ; autre version chez Hudjakov 1969, p. 236).

r G. U. Èrgis, ce personnage du taureau-hiver est à rapprocher du mammouth,

Le cheval et la vache forment donc un couple antithétique en s'insérant dans un système d'oppositions, où c'est toujours l'équidé qui a la bonne place : du côté droit (car toujours abordé à gauche ${ }^{79}$ ), lumineux, extérieur, collectif, tandis que le bovin doit se contenter d'un lot moins prestigieux, à gauche, avec les femmes, les mauvais esprits, dans l'obscurité, le froid et l'étroitesse de la sphère privée.

\section{Troupeaux paissant dans un alaas ${ }^{80}$}

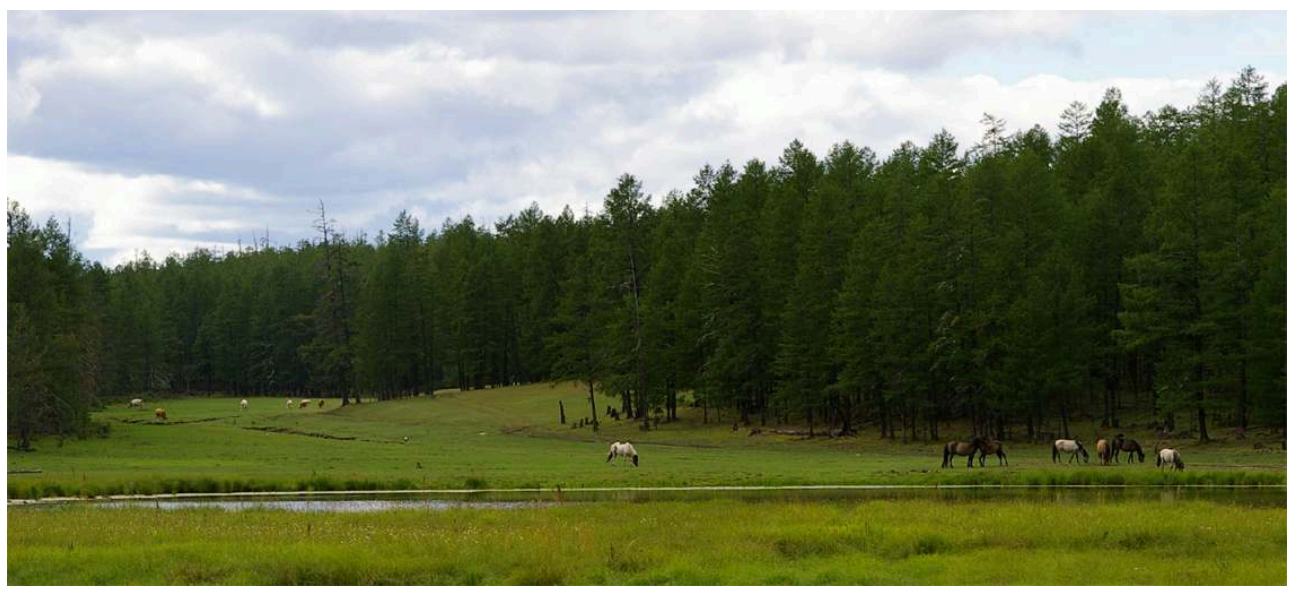

Au premier plan des chevaux ; au second plan des vaches. Ust'-Aldan, août 2008

Photographie de Carole Ferret

Tout en étant dénigrée, la vache représente pourtant le bétail le plus proche, le plus familier, qui vit avec les êtres humains et que tout un chacun sait soigner. "Aujourd'hui les gens savent tout sur les vaches parce qu'elles vivent près d'eux, dans le hoton. Ici, personne ne connaît rien aux chevaux parce que les chevaux vivent loin des gens ", m'a dit M. A. Artamonov. C'est notamment pour cette raison que le cheptel bovin - qui n'avait pas été aussi intégralement collectivisé que l'équin - a d'abord un peu moins souffert de la privatisation, au début des années 1990. 


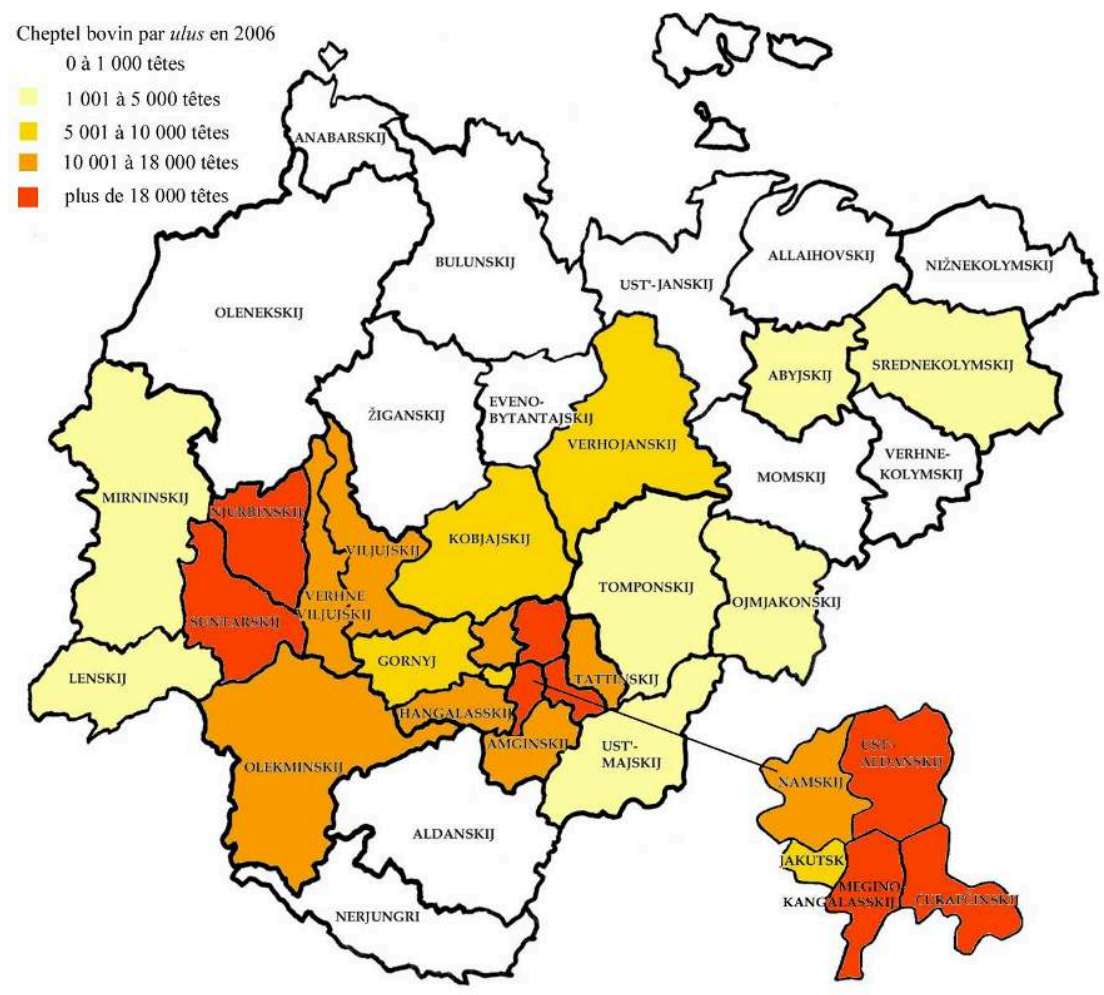

Carte de Carole Ferret

97 Les bovins sont surtout élevés dans les régions centrales et la vallée de la Viljuj, où ils sont omniprésents dans chaque village. S. Crate montre que les Iakoutes de la Viljuj vivent dans un " cows-and-kin system », marqué par la prépondérance de l'élevage bovin et la prépotence des liens de parenté, un système où les vaches marquent d'une empreinte indélébile l'espace et le temps villageois.

"In Viliui Sakha villages, cows are everywhere - they freely roam the streets, exercising their right of way over a milieu of motorcycles with sidecars, pedestrians, occasional cars, and bicycles. Where there is not a cow, there are cow signs - the ever-growing piles of dung that line the snow-covered streets in winter, the khotons with their corrals that consume half of each cow-keeping household's yard, the cow paths that wind through the scraggly spruce, fir, larch, and birch lining the village lanes and the river's banks. Cow rhythms and cow signs change with the seasons [...].

Cows are not only everywhere, but they are everything to survival in Viliui Sakha villages. [...] Viliui Sakha are a cow-centered people. [...] Sakhas' annual calendar of subsistence activities is essentially a cow calendar, dominated by cow-care and cow activities. We can think of Sakha as "The Nuer of the North". Contemporary Sakha villages are built for cows, in the same way that cities are often designed for cars " (2006, pp. 93, 110-111).

Vivant dans une étable autrefois attenant à la maison - avec parfois une porte commune - et maintenant la jouxtant, les bovins font un peu partie de la famille. Dès la naissance, l'homme assiste la venue au monde des petits veaux et leur donne un nom, tandis que les juments mettent bas toutes seules et que la plupart des chevaux ne seront jamais nommés individuellement. Le récit d'E. W. Pfizenmayer témoigne de l'intimité de cette cohabitation : 
"L'écurie des bœufs est accolée à l'iourte et communique avec elle par une porte ; l'Iakoute doit en effet les tenir l'hiver au chaud, tandis que les chevaux restent à l'air, même par les plus grands froids, et cherchent leur nourriture sous la neige [...]. Nous dormîmes pourtant magnifiquement jusqu'au matin et je ne me réveillai que lorsque le museau humide d'un veau m'eut effleuré le visage. Le veau était entré par la porte ouverte entre l'écurie et l'iourte et il exécuta quelques gambades pour notre amusement, mais je le réexpédiai lestement, lorsqu'il se mit à se conduire comme à l'écurie et témoigna, par-dessus le marché, trop d'intérêt pour notre sac de biscottes » (1939, pp. 72-73).

Un veau se repose dans un jardin

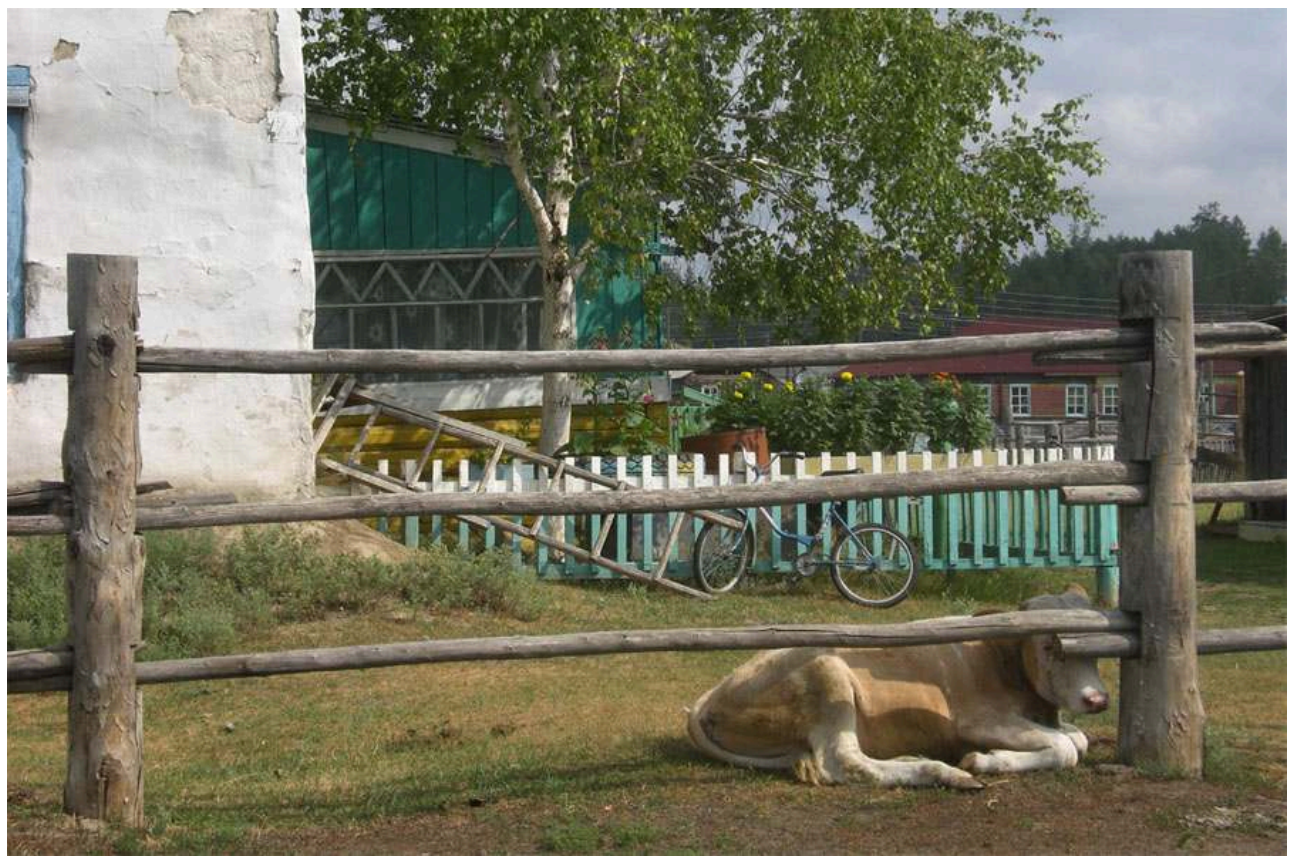

Ust'-Aldan, juillet 2008

Photographie de Carole Ferret

99 L'espèce bovine est à la fois vécue comme familière, domestique dans les différents sens du terme (Ferret 2009, p. 302) et conçue comme plus dissemblable de l'homme que ne l'est l'équidé. Proches des humains, les vaches sont trop asservies à eux et trop dépendantes d'eux pour les représenter. En dépit de son éloignement, c'est l'espèce équine qui porte l'identité nationale et qui se substitue symboliquement à l'homme.

«Par exemple, voir en rêve la perte d'un étalon chef de troupeau présage le décès d'un chef de clan ou d'un Iakoute respecté. S'il s'agit d'une jument, cela présage la mort d'une femme iakoute respectée. Si c'est un bon taureau, cela présage la mort d'un Russe (un homme respecté ou un fonctionnaire). Si c'est une vache, cela présage la mort d'une femme russe. Si c'est un poulain, cela présage la mort d'un enfant iakoute. Si on voit un čoroon (récipient iakoute) se briser en rêve, cela présage la mort d'une jument. Mais si c'est une tasse de bois russe, ce sera une vache qui mourra " (Hudjakov 1969, p. 236).

Les Iakoutes disaient aussi de leurs colonisateurs «qu'ils mangent des champignons comme des vaches" (Hudjakov 1969, p.59; cf. Seroševskij 1896, p. 308). Même si l'interprétation de ces rêves ne serait pas aussi claire de nos jours ${ }^{81}$, le prestige du cheval demeure intact, et c'est un cavalier que la République Sakha s'est choisi pour 
emblème. Libre et indépendant, le cheval, «bétail national iakoute » (Hudjakov 1969, p. 72), offre une image assurément plus flatteuse que la vache.

Mise en meule du foin près d'un hoton dans le village d'Us Küöl

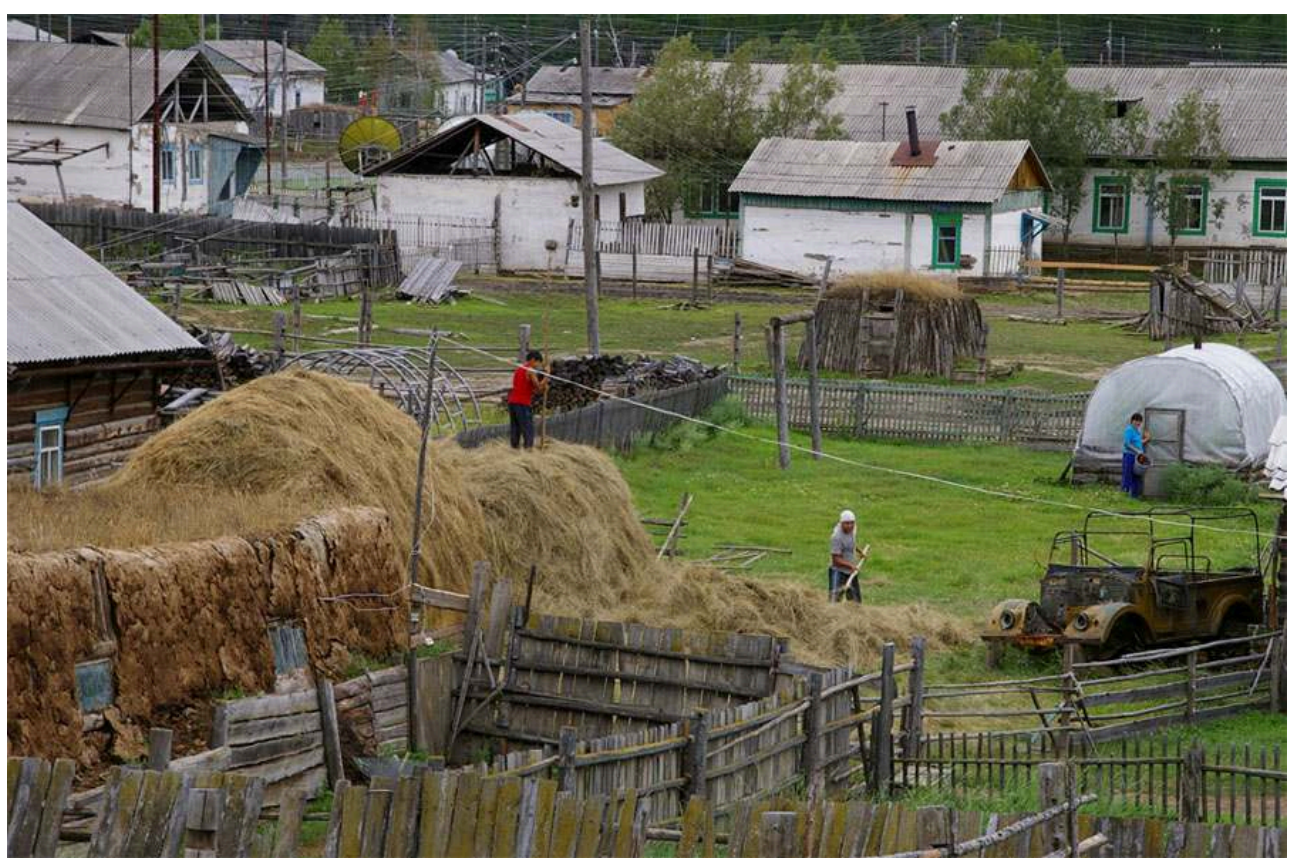

Ust'-Aldan, août 2008

Photographie de Carole Ferret

\section{Un troupeau de chevaux entre dans la taïga}

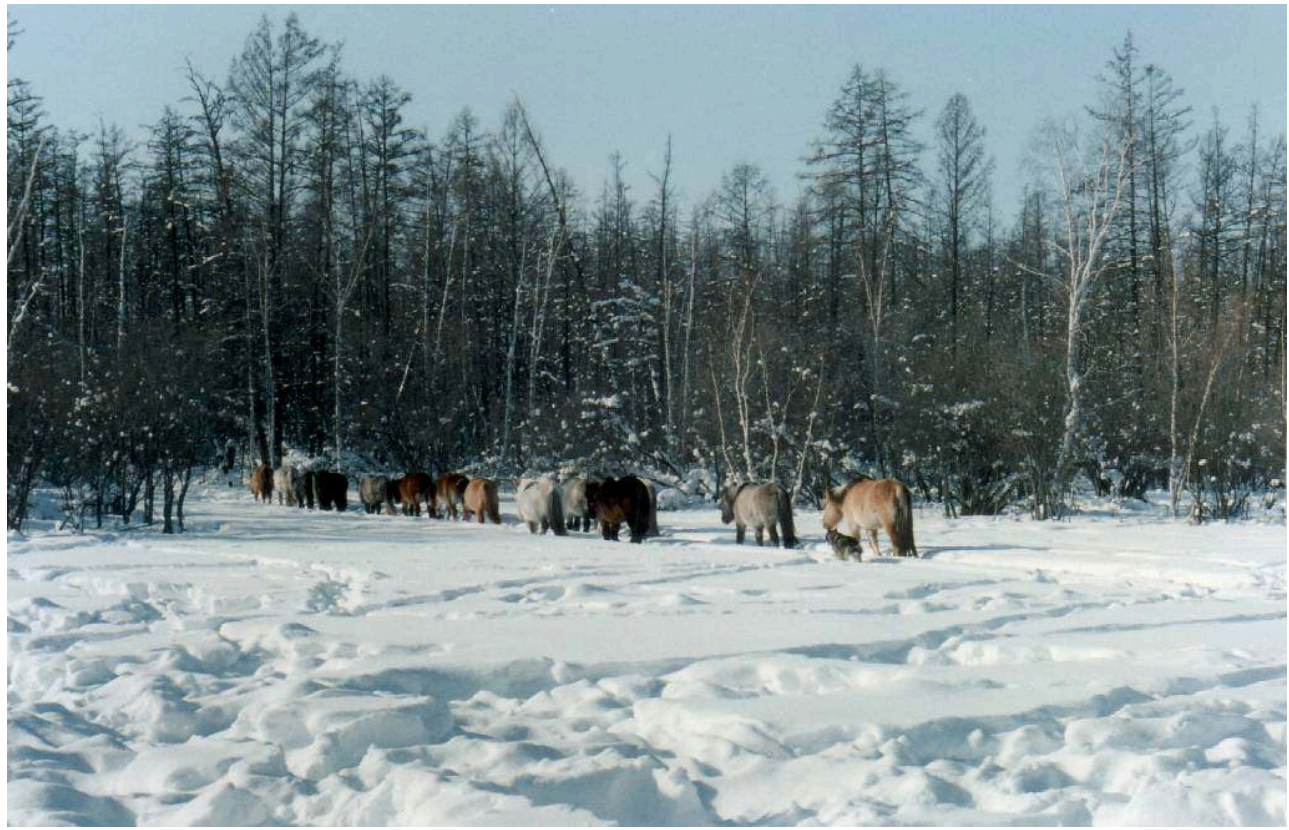

Ust'-Aldan, mars 1994

Photographie de Carole Ferret 
Le pacage libre des chevaux s'oppose à la longue stabulation hivernale des bovins. S'il est vrai que l'entretien de ces derniers nécessite nettement plus de travail, l'absence d'affouragement des chevaux est toutefois une légende ${ }^{82}$, car ces animaux reçoivent un complément alimentaire ponctuel, à l'entrée et à la sortie de l'hiver. Il est vrai que, sur l'année, un cheval mange en moyenne trois fois moins de foin qu'une vache (S. I. Protopopov, Ust'-Aldan), mais il est faux de croire qu'il ne coûte strictement rien. Cette sous-évaluation de l'alimentation équine tend à exagérer la disparité entre les deux élevages.

Elle constitue également un des arguments majeurs visant à souligner la rentabilité de l'élevage équin et appelant à son développement. L'évolution récente, dans les années 2000 , de l'élevage en Iakoutie, prouve que la démonstration a porté ses fruits.

Évolution du cheptel bovin et équin en lakoutie depuis 1921

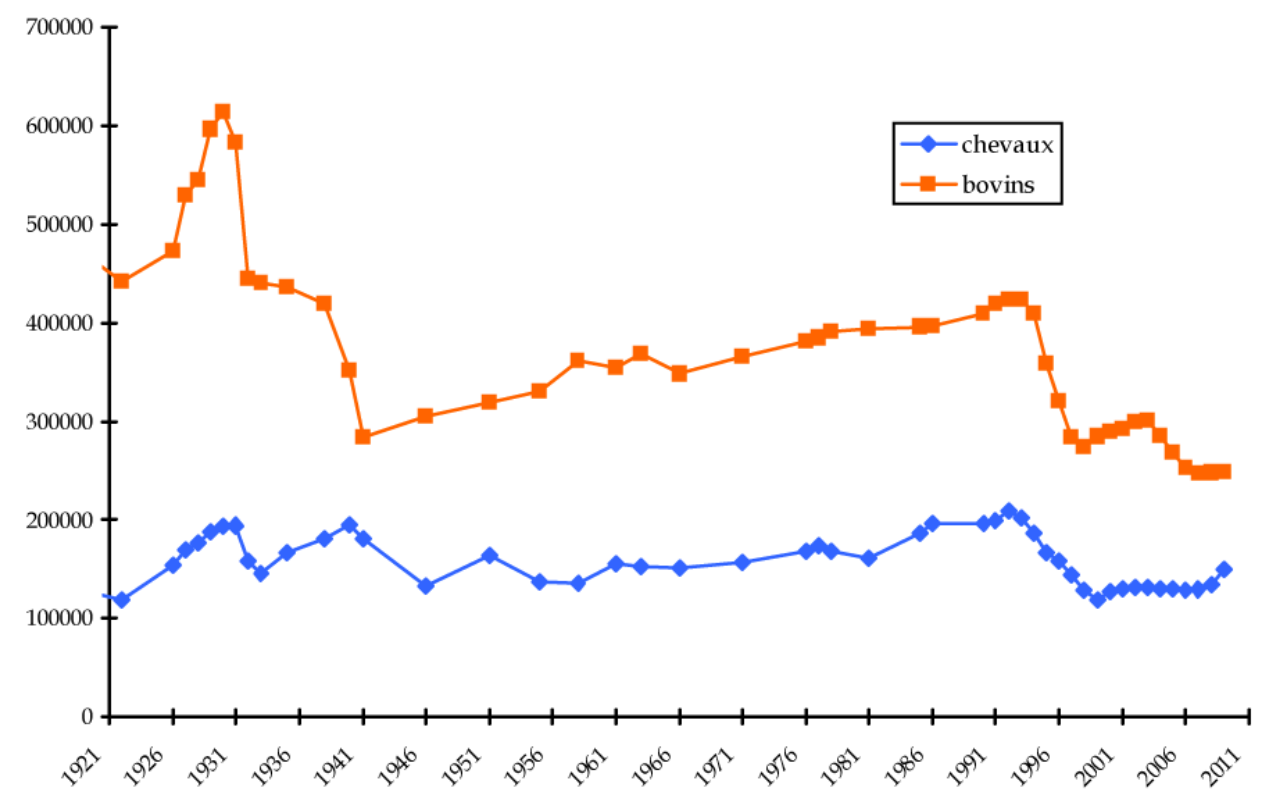

Schéma de Carole Ferret

Dans les années 1990, la dislocation des sovkhozes s'est accompagnée d'une privatisation du bétail. Chaque travailleur a reçu une part (rus. paj) du bétail, calculée suivant des normes variables, mais généralement proportionnelle au nombre d'années travaillées au sovkhoze. Le cheptel équin, qui avait été presque entièrement collectivisé (Ferret 2009, pp. 264-268), a grandement souffert de cette privatisation. Dans les années 1990, « on a mangé tous les chevaux » m'a dit N. D. Alekseev. En effet, beaucoup de ces nouveaux propriétaires, ayant perdu le contact avec l'animal et ne sachant plus le soigner, ont préféré abattre le cheval reçu plutôt que de le voir disparaître dans la taïga. Entre 1992 et 1999, le nombre de chevaux a diminué de 43 \% en Iakoutie, tandis que le cheptel bovin baissait légèrement moins (- $33 \%)$.

Depuis quelques années, le mouvement semble s'être inversé. L'élevage équin, reconnu comme "une filière de l'économie iakoute traditionnelle ", a fait l'objet de plusieurs lois promulguées par l'assemblée d'État Il Tümèn, notamment après un voyage de Vladimir Poutine en République Sakha et l'organisation à Iakoutsk d'un congrès international sur l'élevage des chevaux en troupeaux, en juillet 2006. Cette activité 
connaît à présent un certain redressement - au moins quantitatif -, favorisé par les subventions gouvernementales (Štyrov 2008, p. 3).

En République Sakha, l'orientation de l'élevage dépend dorénavant étroitement des aides accordées par le gouvernement, comme c'est depuis longtemps le cas en Europe. Et on y entend désormais le même type de discours. "Tout le monde court après les subventions, mais personne ne veut travailler» m'a déclaré par exemple M. A. Artamonov à Aryylaah.

Or la vache, elle, n'a pas bénéficié des mêmes largesses que le cheval iakoute ${ }^{83}$, dans ces arbitrages où se mêlent intimement des considérations politiques et économiques. L'élevage bovin n'est pas reconnu comme une activité "traditionnelle», notamment parce que la vache iakoute a quasiment disparu. Les races locales ont été mieux préservées pour les équidés que pour les bovidés. À l'exception de quelques spécimens conservés dans l'ulus Èveno-Bytantaj, la vache iakoute, résistante mais peu productive, a été engloutie dans des croisements avec des Simmental venant de Suisse et des Kholmogory originaires de la région d'Arhangelsk (V. Z. Kirillina, Verhojansk. Savvinov 2000).

Bœuf iakoute attelé à un traîneau

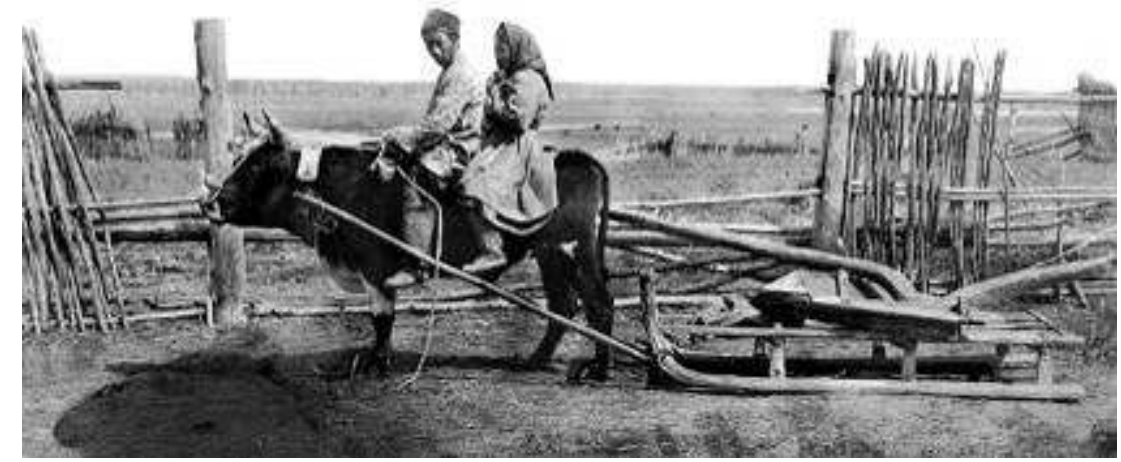

Photographie de la collection Jochelson, début du xx siècle

Aussi les petits propriétaires se tournent de plus en plus vers les chevaux et délaissent leurs vaches, car ceux-là réclament moins de travail et sont plus rentables (S. I. Protopopov, Ust'-Aldan). Beaucoup ont fait leurs comptes et en concluent que « ça ne vaut pas le coup d'élever des vaches» (P. P. Okoëmov). Ceux qui poursuivent cette activité ne bénéficient pas toujours pleinement des produits de leurs bêtes car, faute de liquidités, nombre de villageois sont contraints de vendre tout le lait qu'ils traient sans en garder pour leur autoconsommation. Mais la vente de lait est limitée par des quotas si bien qu'à Us Küöl par exemple, la plupart des éleveurs avaient déjà écoulé dès le mois de juillet 2008, les 700 litres de lait autorisés par vache laitière et par saison et la fabrique de beurre, seul débouché local, ne leur en achetait plus (V. V. Nogovicyn, Ust'Aldan).

Déchirée, comme beaucoup de ses compatriotes, par les contradictions qui incitent à maintenir l'élevage bovin et qui empêchent de le faire, K. G. Gorohova me disait à la fois : 
" la vie est difficile, il y a de moins en moins de vaches. Seuls les gens de quarantecinquante ans en possèdent. Pas les jeunes parce qu'ils ne veulent pas s'en occuper, ça demande trop de travail. À l'avenir il n'y aura plus de vaches du tout ici et d'ailleurs, il n'y aura plus de village non plus. Mais sans les villages, les Sakhas ne sont plus des Sakhas ${ }^{84} "$, et :

« moi aussi, j'aimerais bien ne pas avoir à venir ici chaque été pour aider mon frère et ma mère pour la traite et les foins. C'est dur. J'aimerais mieux qu'ils mangent leurs vaches, et moi, alors je pourrais aller voyager comme je le souhaite au lieu de devoir passer tous les étés au village ». paissaient en troupeaux loin des villages, où n'apparaissaient guère que quelques hongres de selle et les rus. tabunščik (iak. sylgyhyt), gardiens spécialisés, parcouraient de grandes distances pour aller, à intervalles plus ou moins fréquents suivant la saison, vérifier l'intégrité des troupeaux. Avec la privatisation du bétail, la propriété des chevaux s'est disséminée et chacun préfère désormais, en hiver, nourrir ses chevaux près du village, voire les garder dans un enclos, plutôt que de courir après eux d'alaas en alaas dans la taïga ou de les confier à un tabunščik qu'il faudrait rémunérer. Ayant pris l'habitude de paître près des villages, les chevaux ne s'en éloignent plus, même en été. Les terres aux alentours sont gâtées par le surpâturage, tandis que les pâtures éloignées demeurent inexploitées (S. I. Protopopov; N. D. Alekseev. Osipov 2008, pp. 78-79; Vinokurov 2008, pp. 108-109).

Des chevaux traversent la rue principale d'Us Küöl

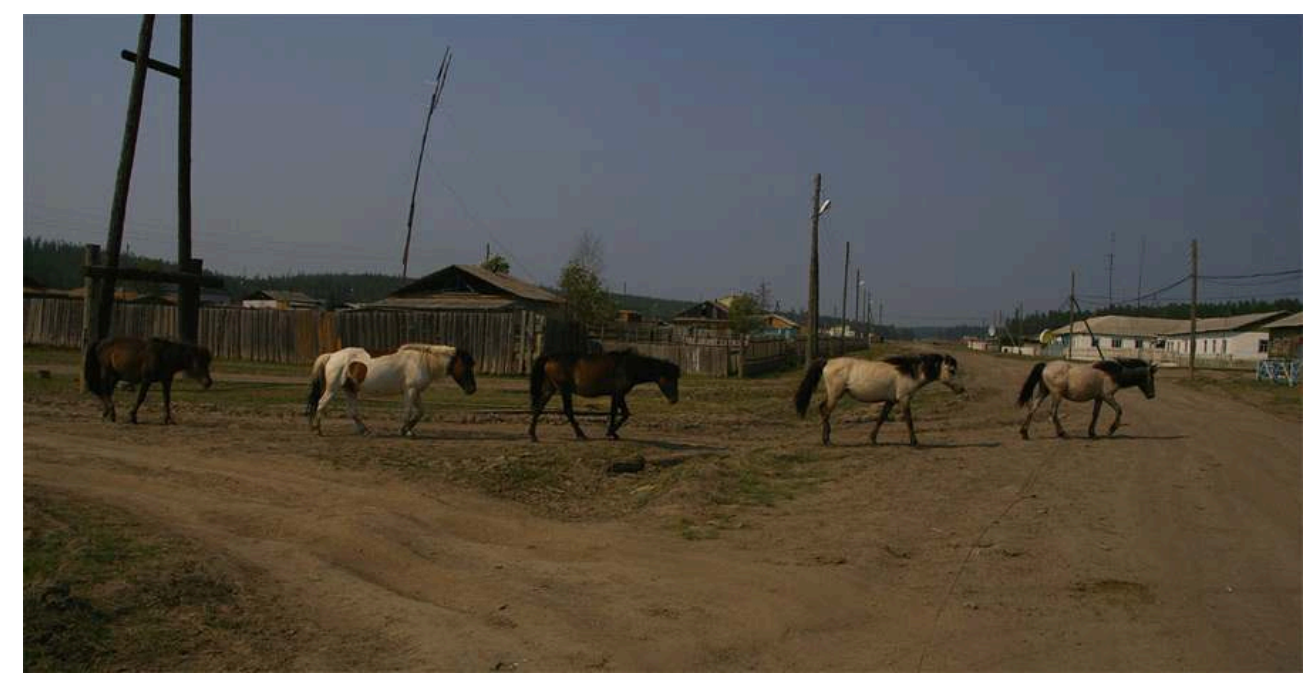

Ust'-Aldan, juiclet 2008

Photographie de Carole Ferret

112 À force d'être nourris comme des vaches, les chevaux risquent fort, de devenir, eux aussi, moins rentables et de péricliter. Sauf, mais c'est peu probable, si les hommes se 
mettent à suivre leurs chevaux et que la privatisation du bétail soit suivie d'une dissémination de l'habitat, de la même manière que la collectivisation s'était accompagnée du regroupement en villages. Aujourd'hui certains Iakoutes ont renoué avec une forme de semi-sédentarité et passent l'été isolés dans des estivages avec leurs bêtes (observations à Kurbusah et Aryylaah, Ust'-Aldan), mais ce mouvement reste sporadique.

Complémentaires, les élevages équin et bovin sont difficilement compatibles au sein d'une même exploitation, comme le remarque M. A. Artamonov, éleveur prospère qui possède quarante chevaux, une vache et un veau.

« Si je n'avais pas de chevaux, j'aurais une dizaine de vaches, mais c'est difficile de faire les deux en même temps: on ne va pas aux mêmes endroits, on n'a pas les mêmes rythmes, on ne porte pas les mêmes vêtements ".

Le cheval et la vache en Iakoutie, c'est aussi une question de générations. "Nos ancêtres élevaient surtout des chevaux. Nos père et nous-mêmes, qui sommes nés sous le régime soviétique, nous avons élevé des vaches et maintenant les jeunes, préfèrent avoir des chevaux parce qu'ils ne veulent pas travailler ", entend-on actuellement. Ces assertions ne sont pas strictement conformes à la réalité, mais traduisent néanmoins une tendance générale quant à l'évolution du rapport entre bovidés et équidés. L'avenir dira si elle se confirme.

\section{Chevaux et vaches dans un village}

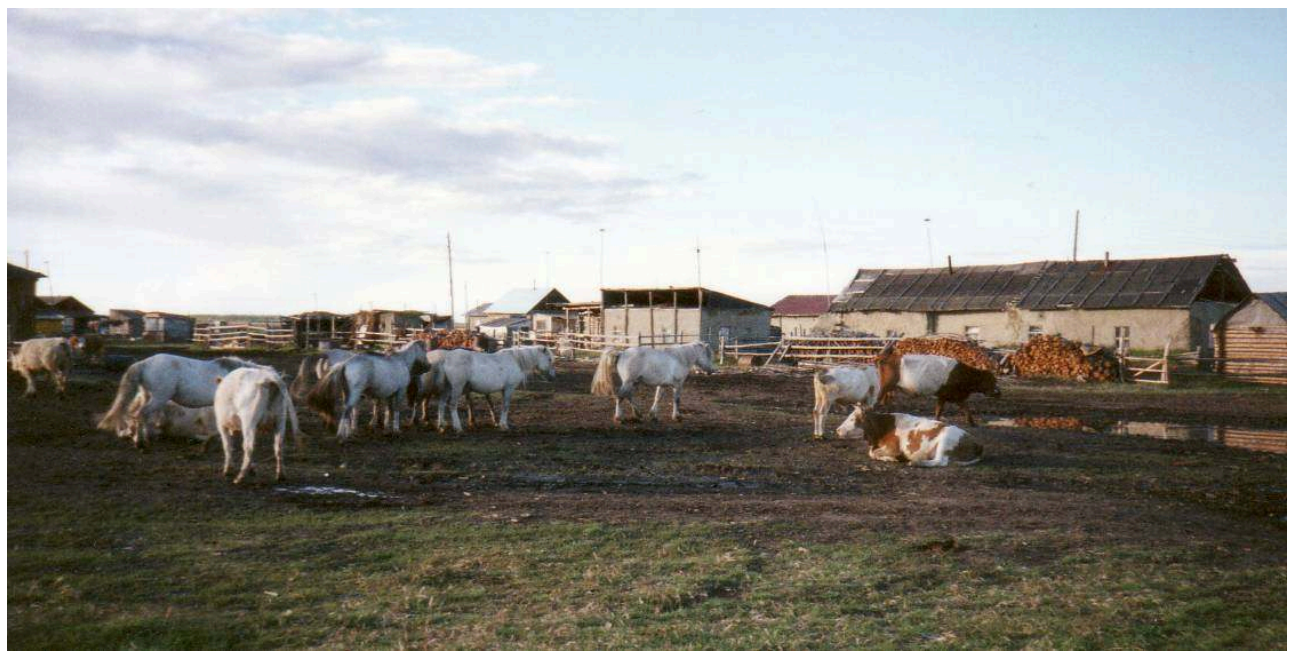

Ulus de Srednekolymsk, juillet 1995

Photographie de Carole Ferret

115 Confronter le cheval à différentes autres espèces animales disparues (mammouth), bien présentes (renne, vache), discrètes (porc) ou carrément distantes (mouton, chameau) dans le monde iakoute fournit l'occasion de brosser un portrait en négatif de l'animal, mettant en évidence sa place inégalée dans la culture iakoute.

En même temps, cette confrontation révèle l'extraordinaire polyvalence de cet animal, capable de se métamorphoser en de multiples avatars pour mieux servir l'homme dans chacune des fonctions remplies par les autres espèces: pour le nourrir, le vêtir, le transporter, l'enrichir autant concrètement que symboliquement, jusqu'à lui fournir un emblème national. En Iakoutie, le cheval sert l'homme dans tous les registres tout en 
préservant son indépendance. Même si le discours commun a tendance à minimiser le coût de l'élevage équin, son utilité, tant économique que sociale, est largement avérée.

117 Les trois principales espèces élevées par les Iakoutes (bovins, rennes et chevaux) ne forment pas à proprement parler un trio, car, rarement mises concomitamment sur le même plan, elles sont plutôt comparées deux à deux. Ce sont, le plus souvent, le cheval et la vache, qui sont confrontés, car ils jouent des rôles antagonistes et complémentaires, alors que le renne, substitut du cheval, a une place un peu à l'écart.

\section{BIBLIOGRAPHIE}

Abramov, A. F.

2008 Èkologičeskie uslovija zon razvedenija jakutskoj lošadi [Les conditions écologiques des zones d'élevage du cheval iakoute], in Ustojčivoe razvitie tabunnogo konevodstva...(Jakutsk, JaNIISH),

pp. 121-123.

Afanas'ev, P. S.

1965 Govor verhojanskih jakutov [Le dialecte des Iakoutes de Verhojansk] (Jakutsk, Jakutskoe knižnoe izdatel'stvo).

Afanas'ev, P. S., M. S. Voronkin \& M. P. Alekseev (ed.)

1976 Dialektologičeskij slovar' jakutskogo jazyka [Dictionnaire dialectologique de la langue iakoute]

(Moskva, Nauka).

Alekseev, N. A.

1975 Tradicionnye religioznye verovanija jakutov v XIX - načale XX vv. [Les croyances religieuses traditionnelles des Iakoutes] (Novosibirsk, Nauka).

Alekseev, N. D.

1984 Adaptacija lošadej k temperaturnym faktoram sredy [L'adaptation des chevaux au facteur de la température du milieu] (Avtoreferat dissertacii na soiskanie učenoj stepeni kandidata biologičeskih nauk, Rjazan', VNIIK).

2008 Osobennosti razvedenija lošadej porod tabunnogo soderžanija [Les particularités de l'élevage des races de chevaux gardées en troupeau], in Ustojčivoe razvitie tabunnogo konevodstva... (Jakutsk, JaNIISH), pp. 71-76.

Alekseev, N. D. \& G. P. Postnikov

1988 Konevodstvo segodnja [L'élevage du cheval aujourd'hui], in Produktivnoe konevodstvo Jakutii (Jakutsk, Jakutskoe knižnoe izdatel'stvo), pp. 3-6.

Alekseev, N. D., N. P. Andreev \& S. D. Andreevna

1976 Èkologo-fiziologičeskie osobennosti jakutskoj lošadi [Les caractéristiques écologiques et physiologiques du cheval iakoute], in Èkologo-fiziologičeskie osobennosti životnyh Jakutii (Novosibirsk, Nauka), pp. 173-184.

Alekseev, N. D., M. P. Neustroev \& R. V. Ivanov

2006 Biologičeskie osnovy povyšenija produktivnosti lošadej [Les bases biologiques de l'augmentation de productivité des chevaux] (Jakutsk, JaNIIISH). 
Alekseev, V.P.

1990 Le cheval mongol (Moscou, manuscrit inédit), 22 p.

Ammosova, T. V.

1988 Kumys darit zdorov'e [Le kumys donne la santé], in Produktivnoe konevodstvo Jakutii (Jakutsk, Jakutskoe knižnoe izdatel'stvo), pp. 25-27.

2008 Itogi naučnyh issledovanij po kumysoproizvodstvu v Jakutii [Conclusions de recherches scientifiques sur la production de kumys en Iakoutie], in Ustojčivoe razvitie tabunnogo konevodstva... (Jakutsk, JaNIISH), pp. 124-126.

Andreev, N. P.

1980 Tabunnoe konevodstvo na Krajnem Severe, in Mastera tabunnogo konevodstva [L'élevage des chevaux en troupeaux dans le grand Nord] (Jakutsk, Ministerstvo sel'skogo hozjastva Jak. ASSR), pp. 3-6.

Antipin, V. P., Z. V. Gogolev, F. I. Golovnyh \& Ju. A. Poljakov

1963 Istorija jakutskoj ASSR t. III. Sovetskaja Jakutija [Histoire de la république autonome de Iakoutie. III. La Iakoutie soviétique] (Moskva, Izdatel'stvo AN SSSR).

Antonov, N. K.

1971 Materialy po istoričeskoj leksike jakutskogo jazyka [Matériaux pour l'étude historique du lexique de la langue iakoute] (Jakutsk, Jakutskoe knižnoe izdatel'stvo).

Atlasov, S. V.

1992 Istorija razvitija skotovodstva $i$ konevodstva v Jakutii (1917-1928 gg.) [Histoire du développement de l'élevage équin et bovin en Iakoutie (1917-1928)] (Jakutsk, Jakutskij naučnij centr SO RAN).

Bahrušin, S. V.

1927 Istoričeskie sud'by Jakutii, in Jakutija. Sbornik statej pod redakciej P. V. Vittenburga [Destins historiques de la Iakoutie] (Leningrad, Izdatel'stvo AN SSSR), pp. 273-322.

Balzer M. M. \& U. A. Vinokurova

1996 Nationalism, Interethnic Relations and Federalism: The Case of the Sakha Republic

(Yakutia), Europe-Asia Studies, 48(1), pp. 101-120.

Barmincev, Ju. N., V. S. Kovešnikov, I. N Nečaev \& al.

1980 Produktivnoe konevodstvo [L'élevage productif du cheval] (Moskva, Kolos).

Bašarin, G. P.

1962 Istorija životnovodstva v Jakutii (vtoroj poloviny XIX - načala XX v.) [L'histoire de l'élevage en Iakoutie (deuxième moitié du XIX $\mathrm{e}^{\mathrm{e}}$ début du XXe siècle)] (Jakutsk, Jakutskoe knižnoe izdatel'stvo).

Bogatyreva, L. E.

2008 Kyl-sièl ojohuk kistèyè (D'okuuskaj, Bičik).

Böhtlingk [Bëtlingk], O.

1989 [1851] O jazyke jakutov [Sur la langue des Iakoutes] (Novosibirsk, Nauka).

Boué, A.

1952 L'originalité du chameau, Revue d'élevage et de médecine vétérinaire des pays tropicaux, 5(3), pp. 109-114.

Burykina, N. N.

1928 Jakutskie obyčai, svjazannye s roždeniem rebenka [Les coutumes iakoutes liées à la naissance des enfants], Sbornik trudov issledovatel'skogo obščestva « Saha kèskilè », 5, pp. 143-147. 
Bychkova Jordan B.\& T. G. Jordan Bychkov

2001 Siberian Village. Land and Life in the Sakha Republic (Minneapolis - London, University of Minnesota Press).

Cochrane, J. D.

1993 [1824] Récit d'un voyage à pied à travers la Russie et la Sibérie tartare, des frontières de Chine à la mer Gelée et au Kamtchatka (Boulogne, Le Griot).

Crate, S. A.

2006 Cows, kin and Globalization. An Ethnography of Sustainability (Lanham, Alta Mira Press).

Dabrasov, V. R.

1982 Organizacionno-èkonomičeskie osnovy tabunnogo konevodstva Jakutii [Les bases organisationnelles et économiques de l'élevage des chevaux en troupeaux en Iakoutie] (Jakutsk, Jakutskoe knižnoe izdatel'stvo).

Danilov, V. A.

1907 Osobennosti psihičeskogo mira jakutov Kolymskogo okruga v zavisimosti ot ih kul'tury [Les caractéristiques du monde psychique des Iakoutes du district de la Kolyma par rapport à leur culture], Živaja starina, III \& IV, pp. 170-180 \& 226-234.

Delaby, L.

1987 Piquets d'attache pour chevaux célestes, Études mongoles et sibériennes, 18, pp. 48-74.

D'jačenko, V. I.

1988 Vospitanie detej $u$ jakutov [L'éducation des enfants chez les Iakoutes], in Tradicionnoe vospitanie detej u narodov Sibiri (Leningrad, Nauka), pp. 186-205.

Dor, R.

1993 Les huchements du berger turc. II : Du huchement-aux-morts à l'appel des chevaux, Études turques et ottomanes, 3, pp. 27-41.

Èrgis, G. U.

1974 Očerki po jakutskomu fol'kloru [Précis de folklore iakoute] (Moskva, Nauka).

Ermolova, N. M.

$1983 \mathrm{~K}$ voprosu o sibirskom « centre » odomašnivanija lošadi, in Izyskanija po mezolitu i neolitu SSSR (Leningrad, Nauka), pp. 188-191.

Ferret, C.

2004 De l'attache des chevaux à la fécondation des femmes en passant par la cuisine. Quelques pistes pour l'exploration des notions altaïques de chaud et de froid, Études rurales, 171-172, pp. 243-270.

2005-2006 Un espace à l'aune du bétail, Études mongoles et sibériennes, centrasiatiques et tibétaines, 36-37, pp. 139-162.

2006 Techniques iakoutes aux confins de la civilisation altaïque du cheval. Contribution à une anthropologie de l'action (Thèse de doctorat nouveau régime en anthropologie sociale et ethnologie, EHESS, Paris), 3 vol.

2009 Une civilisation du cheval. Les usages de l'équidé de la steppe à la taïga (Paris, Belin).

2010 Hippophiles et hippophages, Anthropozoologica, 45, 29 p.

Finbert, E. J.

1938 La vie du chameau, le vaisseau du désert (Paris, Albin Michel).

Gabyšev, M. F.

1957 Jakutskaja lošad'. Tipy jakutskih lošadej, sposoby ih razvedenija i soderžanija [Le cheval iakoute : types, méthodes d'élevage et de nourrissage] (Jakutsk, Jakutskoe knižnoe izdatel'stvo). 
1972 Izbrannye trudy. Jakutskoe konevodstvo. Èkonomičeskie i organizacionnye osnovy konevodstva [Oeuvres choisies. L'élevage iakoute du cheval, ses bases économiques et son organisation] (Jakutsk, Jakutskoe knižnoe izdatel'stvo).

Gabyšev, M. F. \& G. M. Gogolev

1949 Organizacija rabot na konevodčeskoj ferme kolhoza [L'organisation du travail dans les fermes d'élevage équin des kolkhozes] (Jakutsk, JaKGIZ).

Gmelin, J. G.

1767 [1751-1752] Voyage en Sibérie [...] fait aux frais du gouvernement russe [Reise durch Sibirien von dem Jahr 1733 bis 1743] (Paris, Desaint), 2 t.

Gogolev, Z. V.

1970 Jakutija na rubeže XIX-XX vv. [La Iakoutie au tournant des XIX et XX ${ }^{\mathrm{e}}$ siècles] (Novosibirsk, Nauka).

Gogolev, A. I.

1993 Jakuty (problemy ètnogeneza i formirovanija kul'tury) [Les Iakoutes (problèmes d'ethnogenèse et de formation d'une culture)] (Jakutsk, Izdaltel'stvo JaGU).

1999 Istorija Jakutija (obzor istoričeskih sobytij do načala XX v.) [L'histoire de la Iakoutie (aperçu des événements historiques jusqu'au début du Xx siècle)], http://www.ysu.ru/facultet/kfi/books/ HistoryOfYakutia.htm

Gol'man, V.

1877 Zametki o konevodstve v Jakutskoj oblasti [Remarques sur l'élevage du cheval dans la région de Iakoutie], in Pamjatnaja knižka Jakutskoj oblasti za 1871 g., pp. 122-137.

Gotovcev, B. V.

1988 Rezerv mehovogo syr'ja [Une réserve de matière première pour la pelleterie], in Produktivnoe konevodstvo Jakutii (Jakutsk, Jakutskoe knižnoe izdatel'stvo), pp. 18-20.

Grison, B.

2006 Le Dolgan, le Scientifique \& le Mammouth : ethnographie cognitive d'un programme de recherche sibérien, ethnographiques.org, 10, http://www.ethnographiques.org/2006/Grison.html

Grousset, R.

1965 [1938] L'empire des steppes. Attila, Gengis-Khan, Tamerlan (Paris, Payot).

Les guerriers célestes du pays yakoute-saxa. Elleï: son origine, sa descendance. Niourgon le Yakoute, guerrier céleste. Grand Koudansa, le présomptueux 1994 (Paris, Gallimard).

Gur'ev, I. P.

$1983 \mathrm{~K}$ voprosu o proishoždenii jakutskoj lošadi [Sur la question de l'origine du cheval iakoute], in Termologičeskie issledovanija v Jakutii (Jakutsk, JaF SO ANSSSR), pp. 50-57.

Gur'ev, I. P. \& A. K. Ahremenko

1992 Tipy belkov krovi jakutskih lošadej i proishoždenie jakutov [Les types de protéines du sang $\mathrm{du}$ cheval iakoute et l'origine des Iakoutes], in Čelovek i sever : istoričeskij opyt, sovremennoe sostojanie, perspektivy razvitija, t. I (Jakutsk, Jakutskij Institut jazyka, literatury i istorii SO RAN), pp. 78-84.

2008 Proishoždenie jakutskoj lošadi i naroda saha v svete genetičeskoj arheologii i istorii [L'origine du cheval iakoute et du peuple sakha à la lumière de l'archéologie génétique et de l'histoire], in Ustojčivoe razvitie tabunnogo konevodstva...(Jakutsk, JaNIISH), pp. 117-120.

Gurvič, I. S.

1977 Kul'tura severnyh jakutov-olenevodov. K voprosu o pozdnih ètapah formirovanija jakutskogo naroda 
[La culture des Iakoutes septentrionaux éleveurs de rennes. Sur la question des étapes tardives de la formation du peuple iakoute] (Moskva, Nauka).

Hamayon, R. N.

1997 Taïga terre de Chamans [Photographies de M. Garanger] (Paris, Imprimerie Nationale).

Hudjakov, I. A.

1890 Verhojanskij sbornik. Jakutskie skazki, pesni, zagadki i poslovicy, a takže russkie skazki i pesni, zapisannye $v$ Verhojanskom okruge I. A. Hudjakovym [Recueil de Verhojansk. Contes, chansons, devinettes, proverbes iakoutes ainsi que contes et chansons russes enregistrés dans le district de Verhojansk par I. A. Hudjakov] (Irkutsk, Zapiski Vost-Sib. otd. IRGO po ètnografii, I, 3).

Hudjakov, I. A.

1969 Kratkoe opisanie Verhojanskogo okruga [Brève description du district de Verhojansk]

(Leningrad, Nauka).

Ionova, O. V.

1952 Žilye i hozjajstvennye postrojki jakutov [Les maisons d'habitation et leurs dépendances chez les Iakoutes] (Moskva, Institut ètnografii AN SSSR, Sibirskij ètnografičeskij sbornik - novaja serija -, XVII), pp. 239-319.

Ivancova, $\mathrm{N}$.

2006 Začem Jakutii bizony [Des bisons en Iakoutie, pourquoi faire ?], Jakutija, 12.04.2006, http:// www.gazetayakutia.ru/archive/read.asp?id=30826-18

2009 Bizonarij ždet gostej [Les bisons attendent les visiteurs], Jakutija, 30.05.2009.

Ivanov, S. V.

1976 Jakutskie konovjazi [Les piquets d'attache iakoutes des chevaux] in Material'naja kul'tura narodov Sibiri i Severa (Leningrad, Nauka), pp. 213-224.

Ivanov, V. F.

1979 Pis'mennye istočniki po istorii Jakuti XVII veka [Les sources écrites sur l'histoire de la Iakoutie au XVII ${ }^{\mathrm{e}}$ siècle] (Novosibirsk, Nauka).

Ivanov, V. N.

2002 Vhoždenie Jakutii v sostav Rossijskogo gosudarstva : kak èto bylo [L'entrée de la Iakoutie dans l'Etat russe : les faits], Ilin, 2(29), http://ilin-yakutsk.narod.ru/2002-2/ivanov.htm

Ivanov, P. V.

2008 Konceptual'nye položenija razvitija tabunnogo konevodstva v Sibiri i na Dal'nem Vostoke [Positions conceptuelles du développement de l'élevage équin en Sibérie et en Extrême-Orient], in Ustojčivoe razvitie tabunnogo konevodstva...(Jakutsk, JaNIISH), pp. 66-70.

Jakovlev, V. F.

1992-1993 Sèrgè (Konovjaz') [Le sèrgè (piquet d'attache des chevaux)] (Jakutsk, Centr kul'tury i iskusstva im. A. Kulakova Ministerstva kul'tury Respublika Saha), 2 t.

Jochelson, W.

1933 The Yakut (New York, American Museum of natural history, Anthropological papers, XxxIII, 2), pp. 33-225.

Kalašnikov, V. V.

2008 Prošloe, nastojaščee i buduščee konevodstva Rossii [Passé, présent et futur de l'élevage du cheval en Russie], in Ustojčivoe razvitie tabunnogo konevodstva...(Jakutsk, JaNIISH), pp. 20-45. 
Kerblay, B.

1962 L'évolution de l'alimentation rurale en Russie (1896-1960), Annales. Économies, sociétés, civilisations, XVII, 5, pp. 885-913.

Kočnev, D. A.

1895 [1894] O pogrebal'nyh obrjadah jakutov Viljujskogo okruga Jakutskoj oblasti [Sur les rites funéraires des Iakoutes du district de la Viljuj dans la région de Iakoutie], Izvestija obščestva arheologii, istorii i ètnografii pri Imperatorskom Kazanskom Universiteta, XII, 5, pp. 455-465.

Konskij volos i jakutskie izdelija iz nego. Okraska konskogo volosa [Le crin chevalin et ses produits iakoutes. La teinture du crin chevalin] 1914 Jakutskoe hozjajstvo, Jakutsk, pp. 4-5.

Konstantinov, I. V.

1971 Material'naja kul'tura jakutov XVIII v. (po materialam pogrebenij) [La culture matérielle des Iakoutes au XVIII ${ }^{\mathrm{e}}$ siècle (d'après les matériaux des sépultures)] (Jakutsk, Jakustkoe knižnoe izdatel'stvo).

Kovalik, S.

1895 Verhojanskie Jakuty i ih èkonomičeskoe položenie [Les Iakoutes de la région de Verhojansk et leur situation économique], Izvestija vostočno-sibirskogo. otd. IRGO, XXV, 4-5, pp. 1-50.

Kovlekov, S. I.

1993 Sel'skoe hozjajstvo Jakutii (1971-1985 gg.) [L'agriculture de Iakoutie (1917-1985) (Jakutsk, Jakutskij naučnij centr SO RAN).

Kozlov, S. A. \& K. S. Borisov

2008 Konceptual'nye problemy razvitija otrasli tabunnogo konevodstva v respublike Saha (Jakutija) [Les problèmes conceptuels du développement de l'élevage équin dans la République Sakha (de Iakoutie)], in Ustojčivoe razvitie tabunnogo konevodstva...(Jakutsk, JaNIISH), pp. 163-165.

Krivošapkin, V. G. \& V. I. Mordovskaja

2008 Rol' polinenasyšennyh žirnyh kislot (omega)-3 žerebjatiny v profilaktike ateroskleroza sredi korennogo naselenija Severa" [Le rôle des acides gras polyinsaturés (omega 3) de la viande de poulain dans la prévention de l'artériosclérose chez les peuples autochtones du Nord], in Ustojčivoe razvitie tabunnogo konevodstva...(Jakutsk, JaNIISH), pp. 93-97.

Ksenofontov, G. V.

1992 [1937] Uraanghaj-sahalar. Očerki po drevnej istorii jakutov [Les Sakhas-Uraanghaïs. Essai sur l'histoire ancienne des Iakoutes] (Jakutsk, Nacional'noe izdatel'stvo Respubliki Saha - Jakutija).

Kulakovskij, A. E.

1925 Jakutskie poslovicy i pogovorki [Proverbes et dictons iakoutes] (Jakutsk, Sbornik trudov issledovatel'skogo obščestva "Saha kèskilè », 2).

1928 Vidy životnogo i rastitel'nogo carstv, izvestnye jakutam [Les espèces des règnes animal et végétal connues des Iakoutes], Izvestija jakutskogo otdela gosudarstvennogo. rossijskogo geografičeskogo obščestva, III, Jakutsk, pp. 17-40.

Kuz'mina, I. E.

1977 O proishoždenii i istorii teriofauny sibirskoj arktiki [Sur l'origine et l'histoire de la theriofaune de l'arctique sibérien], in Fauna i flora antropogena severo-vostoka Sibiri (Leningrad, Nauka, Trudy zoologičeskogo instituta, 63), pp. 18-55.

Kyys Dèbilijè : Jakutskij geroičeskij èpos [Kyys Debilijè : épopée héroïque iakoute] 1993 (Novosibirsk, Nauka). 
Laruelle, M.

2004 Continuité des élites intellectuelles, continuité des problématiques identitaires. Ethnologie et « ethnogenèse » à l'Académie des Sciences d'Ouzbékistan, Cahiers d'Asie centrale, 13-14, pp. 45-75.

Lazarev, P. A.

1971 Sovremennik mamonta [Contemporain du mammouth], Konevodstvo i konnyj sport, 10, p. 16. 1977 Istorija nahodki trupa selerikanskoj lošadi i ego izučenija [Histoire de la découverte du cadavre du cheval de Selerikan et de son étude], in Fauna i flora antropogena severo-vostoka Sibiri (Leningrad, Nauka, Trudy zoologičeskogo instituta, 63], pp. 56-59.

1980 Antropogenovye lošadi Jakutii [Les chevaux anthropogènes de Iakoutie] (Moskva, Nauka).

Leroi-Gourhan, A.

1936 La civilisation du renne (Paris, Gallimard).

Lipping, V. O.

1937 Jakutskaja lošad' [Le cheval iakoute], Konevodstvo, 6, pp. 29-30.

Lošad' jakutskoj porody [Le cheval de race iakoute] 1992 (Jakutsk, Jakutskoe knižnoe izdatel'stvo).

Maak, R. K.

1887 Viljujskij okrug Jakutskoj oblasti. Čast' III [Le district de la Viljuj dans la région de Iakoutie. III] (Sankt-Peterburg, A. Tranščel').

Maj, E.

2007 Le cheval chez les Iakoutes chasseurs et éleveurs. De la monture à l'emblème culturel (Thèse de doctorat en anthropologie religieuse, EPHE, Paris).

Majdel', G.

1894 Putešestvie po severo-vostočnoj časti Jakutskoj oblasti v 1868-1870. T. I [Voyage dans la partie nord-est de la région de Iakoutie en 1868-1870. I] (Sankt-Peterburg, Zapiski Imperatorskoj AN, 74).

Majnov, I. I.

1927 Naselenie Jakutii [La population de la Iakoutie], in Jakutija. Sbornik statej pod redakciej

p. V. Vittenburga (Leningrad, Izdatel'stvo AN SSSR), pp. 321-420.

Middendorf, A. F.

1869-1877 Putešestvie na sever i vostok Sibiri. Čast' II [Voyage dans le nord et l'est de la Sibérie. II] (Sankt-Peterburg, Tipografija Imperatorskoj AN).

Miller, G. F.

1999-2005 Istorija Sibiri [Histoire de la Sibérie] (Moskva, Vostočnaja literatura), 3 t.

Mizgirev, D.

2006 Jakutskaja lošad' - apteka na kopytah [Le cheval iakoute, une pharmacie à pattes], Naše vremja, 07.07.2006, http://www.nvpress.ru/?id=10070617\&dates=7/7/2006

Molodyh, I. F.

1927 Puti soobščenija Jakutii [Les voies de communication en Iakoutie], in Jakutija. Sbornik statej pod redakciej p. V. Vittenburga (Leningrad, Izdatel'stvo AN SSSR), pp. 575-673.

Naumov, G. V.

1953 Jakutskaja lošad' i ee hozjajstvennoe značenie [Le cheval iakoute et son importance économique] (Jakutsk, Jakutskoe knižnoe izdatel'stvo).

Nedokučaev, N. K.

1927 Sel'skohozjajstvennoe delo Jakutii [L'agriculture en Iakoutie], in Jakutija. Sbornik statej pod redakciej p. V. Vittenburga (Leningrad, Izdatel'stvo AN SSSR), pp. 491-515. 
Nikolaeva, D.

2009 Neobhodima sozdat' uslovija dlja buduščih laureatov Nobelevskoj premii [Il faut créer de bonnes conditions pour les futurs lauréats du prix Nobel], Uhhan sirè, 14.01.2009, http:// www.uhhan.ru/news/2009-03-06-761

Nosov, M. M.

1955 Odežda i ee ukrašenija u jakutov XVII-XVIII vekov [Les habits et les bijoux des Iakoutes aux XVII - XVIII ${ }^{\mathrm{e}}$ siècles], Sbornik naučnyh statej jakutskogo kraevedčeskogo muzeja im. Emel'jana

Jaroslavskogo, 1, pp. 84-137.

Okladnikov, A. P.

1970 [1955] Yakutia before its Incorporation in the Russian State [Istorija Jakutskoj ASSR. t. I. Jakutija do prisoedinenija k russkomu gosudarstvu] (Montréal \& London, Mac Gill-Queen's University Press. Artic Institute of North America).

Okladnikov, A. P. \& V. D. Zaporožskaja

1959 Lenskie pisanicy. Naskal'nye risunki u derevni Šiškino [Écritures primitives de la Lena. Les pétroglyphes près du village de Šiškino] (Moskva-Leningrad, Izdatel'stvo AN SSSR).

Osipov, V. G.

2008 Istorija ispol'zovnija konskih pastbišč Jakutii [Histoire de l'utilisation des pâtures pour les chevaux en Iakoutie], in Ustojčivoe razvitie tabunnogo konevodstva...(Jakutsk, JaNIISH), pp. 77-82.

Parnikova, A. S.

1998-1999 O rasselenii jakutov v XVII-XVIII vv. [Sur l'occupation du territoire par les Iakoutes aux XVII-XVIII ${ }^{\mathrm{e}}$ siècles], Sibirskaja Zaimka, http://www.zaimka.ru/to_sun/yakut.shtml

Pavlinov, D.

1877 Bračnoe pravo u jakutov [Le droit du mariage chez les Iakoutes], in Pamjatnaja knižka Jakutskoj oblasti za 1871 god (Sankt-Peterburg), pp. 94-122.

Pekarskij, Ł̀. K.

1907-1930 Slovar' jakutskogo jazyka [Dictionnaire de la langue iakoute] (Sankt-PeterburgPetrograd-Leningrad, Tipografija imperatorskoj AN-Izdanie Rossijskoj AN-Izdanie AN SSSR, Trudy jakutskoj èkspedicii na sred. I. M. Sibirjakova - 1894-1896), 3 vol.

Pfizenmayer, E. W.

1939 Les mammouths de Sibérie. La découverte de cadavres de mammouths préhistoriques sur les bords de la Berezovka et de la Sanga-Iourakh (Paris, Payot, trad. G. Montandon).

Popov, A.

1886 O verovanijah jakutov Jakutskoj oblasti [Sur les croyances des Iakoutes de la région de Iakoutie], Izvestija Vost.-Sib. otd. IRGO, XVII, 1-2, pp. 119-136.

Popov, A. A.

1949 Materialy po religii jakutov b. Viljuskogo okruga [Matériaux sur la religion des Iakoutes du district de la Viljuj], Sbornik muzeja antropologii i ètnografii, XI, pp. 255-323.

Popov, A. A.

1955 Pletenie i tkačestvo u narodov Sibiri v XIX i pervoj četverti XX stoletija [Tressage et tissage chez les peuples de Sibérie au XIX et dans le premier quart du Xx ${ }^{\mathrm{e}}$ siècle], Sbornik muzeja antropologii i ètnografii, XVI, pp. 41-146.

Popov, ̇̀. K.

2003 Ètimologičeskij slovar' jakutskogo jazyka. I : A - D' / Saha tylyn ètimologičeskaj tyld'yta

[Dictionnaire étymologique de la langue iakoute. I] (Novosibirsk, Nauka). 
Priklonskij, V. L.

1886 O šamanstve u jakutov [Sur le chamanisme chez les Iakoutes], Izvestija Vost-Sib. otdela IRGO, XVII, 1-2, pp. 84-118.

1888 Materialy po ètnografii jakutov Jakutskoj oblasti. II. Ysyah. Predanija [Matériaux ethnographiques sur les Iakoutes de la région de Iakoutie. II. Yhyah. Légendes], Izvestija Vost-Sib. otdela IRGO, XVII \& XVIII, pp. 1-43.

Randrianarimanana, $\mathrm{P}$.

2006 Et si les mammouths revenaient pour sauver la planète ?, Courrier international, 16.01.2006, http://naturendanger.canalblog.com/archives/fonte_des_calottes_glaciaires/index.html

Rintchen, Y.

1977 Pourquoi on offre des chevaux et des moutons aux esprits chamaniques mongols, L'ethnographie, 74-75, pp. 155-156.

Rogalevič, M. I.

1941 Konevodstvo Jakutskoj ASSR [L'élevage du cheval dans la République autonome de Iakoutie] (Moskva-Leningrad, Izd. AN SSSR).

Roux, J.-P.

1959-60 Le chameau en Asie centrale. Son nom - son élevage - sa place dans la mythologie, Central Asiatic Journal, v, pp. 35-76.

Savvin, A. A.

2005 Pišča jakutov do razvitija zemledelija. Opyt istoriko-ètnografičeskoj monografii [La nourriture des Iakoutes avant le développement de l'agriculture. Essai de monographie historicoethnographique] (Jakutsk, Institut gumanitarnyh issledovanij AN RS - Ja).

Savvinov, A.

1988 Konskaja uprjaž' jakutov [Le harnais équestre des Iakoutes], Severnye prostory, 5, pp. 42-43.

Savvinov, D.

2000 Eksekjuljah i problemy prirodopol'zovanija [Eksekjuljah (A. E. Kulakovskij) et les problèmes liés à l'utilisation de la nature], Ilin, 3(22), http://ilin.sakhaopenworld.org/2000-3/98.htm

Ščeglov, I. V.

1993 Hronologičeskij perečen' važnejših dannyh iz istorii Sibiri : 1032-1882 [Chronologie des événements importants de l'histoire de la Sibérie : 1032-1882] (Surgut, Severnyj dom).

Seroševskij, V. L.

1993 [1896] Jakuty. Opyt ètnografičeskogo issledovanija [Les Iakoutes. Essai de recherche ethnographique] (Moskva, Rossijskaja političeskaja ènciklopedija).

Slepcov, P. A.

1990 Jakutskij literaturnyj jazyk. Formirovanie i razvitie obšče-nacional'nyh norm [La langue littéraire iakoute. Formation et développement de normes nationales] (Novosibirsk, Nauka).

Solov'eva-Ojunskaja, S. P.

1992 Jakutskie narodnye zagadki. Specifika žanra [Devinettes populaires iakoutes. Les spécificités d'un genre] (Sankt-Peterburg, Nauka).

Strandberg, M.

2008 The Yakuts - a Legendary Horse People, The Long Riders' Guild, 21.4.2008 http:// www.thelongridersguild.com/yakuts.htm

Štyrov, V. A.

2008 Vstupitel'noe slovo k otkrytiju I meždunarodnogo kongressa po tabunnomu konevodstvu 
Prezidenta Respubliki Saha (Jakutija) V. A. Štyrova [Ouverture du premier congrès d'élevage équin en troupeaux par le Président de la République Sakha (de Iakoutie), V. A. Štyrov], in Ustojčivoe razvitie tabunnogo konevodstva...(Jakutsk, JaNIISH), pp. 3-4.

Šubskaja, E. I. \& F. I. Saltykov

1931 Jakutskij krupnyj rogatyj skot [Le bétail bovin iakoute] (Leningrad, Izdatel'stvo AN SSSR).

Syrovatskij, D. I.

1994 Olenevodstvo : sostojanie i problemy [L'élevage du renne : situation et problèmes], in Puty soveršenstvovanija naučnogo obespečenija APK rajonov krajnego severa v uslovijah perehoda $k$ rynočnym otnošenijam. Doklady vserossijskoj konferencii (Jakutsk, 2-4. IX. 1993) (Novosibirsk, Sibirskoe otdelenie RASHN), pp. 76-81.

Tabuny vyvodjat na vozvyšennye mesta [Les troupeaux de chevaux vont sur les hauteurs], Vestnik jakutskogo-saha informacionnogo agentstva Saha Novosti, 88(1866), 14.5.1999, http://www.sakha.ru/ SAKHA/hotnews/0599/140599.html\#013

Tokarev, S. A.

1945 Obščestvennyj stroj jakutov XVII-XVIII vv. [L'organisation sociale des Iakoutes aux XVII ${ }^{\mathrm{e}}$ et XVIII ${ }^{\mathrm{e}}$ siècles] (Jakutsk, Jakutskoe gosudarstvennoe izdatel'stvo).

Tokarev, S. A. \& I. S. Gurvič

1964 [1956] The Yakuts, in M. G Levin \& L. P. Potapov (dir.) The peoples of Siberia [Narody Sibiri] (Chicago-London, The University of Chicago Press), pp. 243-303.

Troščanskij, V. F.

1911 Nabroski o jakutah Jakutskogo okruga [Esquisse sur les Iakoutes du district de Iakoutsk] (Kazan', Tipo-litografija Imperatorskogo universiteta).

Ustojčivoe razvitie tabunnogo konevodstva. Materialy naučno-praktičeskoj konferencii I meždunarodnogo kongressa no tabunnomu konevodstvu (g. Jakutsk, 7 sentjabrja 2006 g.), Jakutsk, JaNIISH.

Vjatkina, K. V.

1968 Kul't konja u mongol'skih narodov [Le culte du cheval chez les peuples mongols], Sovetskaja Ètnografija, 6, pp. 117-122.

Vinokurov, I. N.

2008 Mjasnaja produktivnost' molodnjaka severnyh èkotipov jakutskoj porody lošadej [La productivité bouchère des écotypes septentrionaux des poulains de race iakoute], in Ustojčivoe razvitie tabunnogo konevodstva...(Jakutsk, JaNIISH), pp. 100-104.

Vladimirov, L. N.

2008 Osnovye aspekty razvitija tabunnogo konevodstva RS(Ja) [Aspects fondamentaux du développement de l'élevage équin en $\mathrm{RS}(\mathrm{Ja})$ ], in Ustojčivoe razvitie tabunnogo konevodstva...(Jakutsk, JaNIISH), pp. 90-92.

Volens, N. V.

1927 Očerk hozjajstvennogo stroja Jakutii [Précis du système économique de la Iakoutie], in Jakutija. Sbornik statej pod redakciej p. V. Vittenburga (Leningrad, Izdatel'stvo AN SSSR), pp. 675-702.

Watkin, H. R.

1905 The Discovery and Transportation to St. Petersburg of the Berezovka Mammoth (Torquay Natural History Society, 20).

Zarickaja, I.

2009 Segodnja v respublike net koncepcii razvitija svinovodstva [Aujourd'hui dans la République, 
il n'y a pas de conception de l'élevage porcin], JaSIA Jakutskoe-saha informacionnoe agenstvo, 16.9.2009, http://www.ysia.ru/full-news.php?id_news=4174

Zimov, S. A.

2005 Pleistocene Park: Return of the Mammoth's Ecosystem, Science, 308 (5723), 6.5.2005, http:// www.sciencemag.org/cgi/content/full/308/5723/796

Zykov, F. M.

1989 Tradicionnye orudija truda jakutov (XIX - načalo XX veka) [Les instruments traditionnels du travail chez les Iakoutes ( $\mathrm{XIX}^{\mathrm{e}}$ - début du XX $\mathrm{X}^{\mathrm{e}}$ siècle)] (Novosibirsk, Nauka).

\section{ANNEXES}

Liste des informateurs cités

Entretiens et observations de terrain menés par l'auteur entre 1994 et 2008 auprès de :

En République Sakha (Iakoutie) :

Dans l'ulus d'Ust'-Aldan

- à Us Küöl :

Semën Ivanovič Protopopov, né en 1956, ancien tabunščik devenu zootechnicien puis maire du village de 1994 à 2008 ;

Anna Il'ična Okoëmova, née en 1948, employée des postes ;

Aleksej Nikolaevič Okoëmov, entraîneur de lutte à la retraite ;

Vasilij Vasilevič Okoëmov, zootechnicien puis directeur d'une maison de retraite ;

Pavel Pavlovič Okoëmov, professeur de langue et d'histoire à la retraite ;

Katerina Grigorevna Gorohova, professeur de français à l'école sakha-belge de Kepteny ;

Vladimir Vladimirovič Nogovicyn, spécialiste en agriculture à la mairie de Kurbusah ; - à Aryylaah :

Mihajl Afanas'evič Artamonov, né en 1956, tabunščik puis éleveur de chevaux privé, fils d'un tabunščik héros de l'URSS ;

- à Bèjdinè :

Nikolaj Efimovič Degtjarev, ancien tabunščik à la retraite ;

Ivan Afanas'evič Ohlopkov, né en 1932, ancien facteur, écrivain autodidacte ;

Petr Innokentevič Doktorov, vice-maire du village ;

Ekaterina Ivanovna Artamonov, infirmière ;

- à Iakoutsk :

Nikolaj Dmitrievič Alekseev, spécialiste de l'élevage équin à l'Institut d'agriculture ;

Ljudmila Vasil'evna Burceva, née en 1963, zootechnicienne, femme iakoute mariée à un éleveur evène de l'ulus de Kobjaj ;

Fëdor Mihajlovič Zykov, ethnologue ;

Dans l'ulus de Verhojansk

- à Verhojansk :

Varvara Zaharovna Kirillina, née en 1931, institutrice à la retraite, conservateur du musée de Verhojansk ;

- à Stolby :

Stepan Vasil'evič Potapov, né en 1926, ancien tabunščik;

Nikolaj Alekseevič Slepcov, né en 1924, ancien tabunščik ; 
Dans l'ulus de Srednekolymsk

- à Suččino :

Nikolaj Innokent'evič Kolesov, né en 1925, tabunščik à la retraite ;

Pelageja Vasil'evna Berezkina, née en 1933 ;

Anisija Il'ična Tyrylgina, née en 1933, trayeuse de vaches à la retraite ;

Au Kazakhstan, région du Sud kazakh :

Qajrat Äuelbekov, né en 1968, ancien instituteur devenu comptable.

\section{NOTES}

1. ... mais qui a été, espère-t-on définitivement, battue en brèche par deux récentes thèses de doctorat consacrées au cheval iakoute (Ferret 2006 ; Maj 2007).

2. Anonyme, Beschreibung der Reise auff Ziberien und weiter ins Land, Orth und Stelle, cité par Ivanov 1979, p. 228.

3. A. Kamienski-Dluzyk, Dyazyusz wierienia moskiewskiego miast i miejsc, Poznan, 1874, pp. 378-388, cité par Ivanov 1979, p. 229.

4. La date usuellement retenue pour la conquête de la Iakoutie est 1632, année de construction d'un fort sous le commandement d'un chef cosaque, P. Beketov, à $70 \mathrm{~km}$ de l'actuelle Iakoutsk (Ščeglov 1993, p. 68).

5. En 1619, des prisonniers evenks parlent aux gens du fort de Mangazej du «grand fleuve Lin » où habite un peuple nombreux, qui a des maisons « comme les Russes » et des chevaux : il s'agit vraisemblablement des Iakoutes, selon S. V. Bahrušin (Ivanov 2002). En 1630, un groupe dirigé par A. Dobrynskij, après avoir emprunté la basse Tunguska, parvient jusqu'à la Lena par la Viljuj et relate y avoir rencontré konnuju jakutckuju ordu « la horde cavalière iakoute » (Gogolev 1999). En 1630, le desjatnik « chef » cosaque Ilej Ermolin, navigant sur la Léna, apprend auprès d'Evenks qu'en aval se trouve Jakol'skaja zemlja « la terre iakole [iakoute] », où vivent des gens qui élèvent chevaux et vaches, fait vérifié peu après par l'ataman «chef cosaque » I. A. Galkin sur plusieurs affluents de la Léna (Ivanov 2002). En septembre 1643, le collecteur de jasak - l'impôt sibérien d'abord acquitté en fourrures - Stepan Gavrilov annonce l'arrivée sur la Viljuj en provenance de la Lena de kangalasskie konnye jakuty " Iakoutes Kangalas cavaliers »(Parnikova 1998-1999).

6. Sur les 145166731 habitants de la Fédération de Russie, 949280 vivent en République Sakha (de Iakoutie) d'après le recensement de la population de 2002. Par ailleurs, la Russie compte 1343900 chevaux dont 160200 en République Sakha au $1^{\text {er }}$ juillet 2006, d'après le dernier recensement agricole (cf. www.gks.ru).

7. Iakoute, Yakoute ou Jakut est le nom que les Russes ont attribué à l'ethnie ; Sakha (Saha), celui que ses membres se donnent. En raison de son usage courant, de sa commodité et pour éviter une confusion avec le peuple scythique des Saces $(S a k a)$, je préfère utiliser le premier ethnonyme.

8. Middendorf 1869-1877, p. 538 ; Gol'man 1877, p. 122 ; Maak 1887, p. 148 ; Okladnikov 1970 [1955], p. 238.

9. C'est une caractéristique que j'ai observée sur le terrain, mais également visible sur les pétroglyphes des Kourykanes, ancêtres des Iakoutes (cf. Okladnikov 1959), bien que le modèle de ces chevaux-ci soit nettement plus élancé.

10. I. D. Čerskij, «Opisanie kollekcii posletretičnyh mlekopitajuščih životnyh, sobrannyh Novosibirskoj èkspediciej 1885-1886 g. » in Zapiski Imperatorskoj Akademii Nauk, LXV, priloženie 1, Saint-Pétersbourg, 1891, pp. 353, 516 cité par Seroševskij 1896, pp.156-7; M.V.Pavlova, "Opisanie iskopaemyh mlekopitajuščih, sobrannyh russkoj poljarnoj èkspediciej 1800-1903 gg." in Zapiski Imperatorskoj Akademii Nauk, serija VIII, t. XXI, n.1, Sankt-Peterburg, 1906, cité par Lazarev 1980. 
11. O. Antonius, Die Pferde der austerbenden Tiergruppe. Biologia generalis, VIII, Lieferung, 1936, cité par Rogalevič 1941, p. 46.

12. Entretien recueilli en 1892, Zapadno-Kangalasskij ulus, cité par Seroševskij 1896, p. 157.

13. G. F. Miller rapporte le fait suivant, lorsqu'en 1638 , le détachement de Posnik Ivanov arriva sur l'Indigirka et y affronta des Ioukaguirs: «Pendant le combat, les Ioukaguirs dirigeaient manifestement leurs armes vers les chevaux, animaux qui leur étaient parfaitement inconnus et qu'ils craignaient apparemment davantage que les soldats » (1999-2005, III, p. 84).

14. Hudjakov 1969, p. 77 ; Seroševskij 1896, p. 225. Entretien avec F. M. Zykov.

15. Cf. site de la FAO ftp://ftp.fao.org/docrep/fao/010/a1250e/annexes/ List\%20of\%20breeds\%20documented\%20in\%20the\%20Global\%20Databank\%20for\%20Animal\%20Genetic\%20Resources/ List_breeds.pdf

16. Paléontologue et chercheur à l'Institut de l'écologie du Nord, Petr Lazarev est également le directeur du Musée du mammouth à Iakoutsk.

17. Ce parc vise à démontrer par l'exemple l'idée générale que c'est la faune qui fait la flore et donc qu'en réintroduisant des mammifères présents au pléistocène, on pourrait reconstituer l'écosystème de cette époque.

18. Aussi ce débat a-t-il certainement contribué à la décision de la création officielle de la race du cheval iakoute, le 2 septembre 1987, défini comme « un cheval de race locale, issu de la sélection populaire, destiné à la production de viande, de kumys, de cuir et de fourrure, et utilisé dans les travaux agricoles sous le bât, la selle et le trait » (Alekseev 1988, p. 3).

19. Majnov 1927, p. 328. Pour plus de détails, cf. Parnikova 1998-1999 et les cartes de la répartition territoriale des peuples en Iakoutie, d'après les recensements de 1676 et 1897, in Jochelson 1933, p. 65.

20. À propos du débat actuel sur l'âge optimal à l'abattage et de la distinction entre viande de cheval et viande de poulain, $c f$. Ferret 2010.

21. Le poids moyen de la carcasse à six mois est de $105 \mathrm{~kg}$ (Vinokurov 2008, p. 100).

22. La famille Okoëmov, par exemple, a mangé trois poulains et deux vaches adultes lors de l'hiver 2007-2008.

23. Alekseev, Andreev \& Andreevna 1976, p. 173 ; Lošad'... 1992, p. 5 ; Dabrasov 1982, p. 21.

24. http://www.sitc.ru/culture/foods/html/foods.shtml

25. Pour plus de détails sur la cuisine iakoute du cheval et sur l'hippophagie en général, $c f$. Ferret 2010 et Ferret 2009, pp. 83-92.

26. Cf. Pavlinov 1877, p. 103 ; Danilov 1907, p. 233 ; Troščanskij 1911, p. 85 ; Rogalevič 1941, p. 16 ; Tokarev \& Gurvič 1964 [1956], p. 269 ; Gabyšev 1972, p. 343.

27. Andreev 1980a, pp. 3-4 ; Dabrasov 1982, p. 21.

28. Barmincev \& al. 1980, p. 11 ; Kalašnikov 2008, p. 28 ; Vladimirov 2008, p. 91.

29. Plusieurs récits montrent des voyageurs occidentaux mangeant du cheval chez les Iakoutes, tandis que leurs accompagnateurs russes s'y refusent (Cochrane 1824, pp.167, 169, 172; Pfizenmayer 1939, p. 95).

30. Cet engraissement est impressionnant : en l'espace d'un été, les chevaux adultes gagnent $80 \mathrm{~kg}$ (soit $21 \%$ de leur poids vif) et les poulains de deux à trois ans prennent de 125 à $130 \mathrm{~kg}$ (soit $51 \%$ de leur poids vif), gain que les privations hivernales leur font partiellement perdre (Abramov 2008, p. 147 ; cf. Maak 1887, p. 149 ; Alekseev, Andreev \& Andreevna 1976, pp. 173-184).

31. L'espérance de vie, qui a beaucoup décru depuis la chute de l'URSS, est assez faible en Russie, en comparaison avec les autres pays développés et marquée par un fort différentiel hommes/ femmes (un seuil minimal a été atteint en 1994, avec 57,4 ans pour les hommes). Pour le détail de ces chiffres, voir les statistiques officielles de l'État, disponibles sur http://www.gks.ru

32. Cette fête n'a jamais cessée d'être célébrée sous le régime soviétique, sauf peut-être durant «la grande guerre patriotique» (1941-1945), mais elle a connu un renouveau inédit dans les années 1990, portée par une vague de nationalisme et de folklorisation. 
33. Cette limitation dans le temps est usuelle, dans la mesure où les contraintes de la traite pluriquotidienne des juments s'accordent mal au labeur estival de la fenaison. Elle est également présentée comme une volonté de ne pas nuire au développement des poulains (I. A. Ohlopkov, Ust'-Aldan. Ferret 2006, p. 663 et s.).

34. Dans la première moitié du XIX ${ }^{e}$ siècle, la consommation moyenne de kumys a été évaluée à $560 \mathrm{~kg}$ par famille et par an sur le plateau de l'interfluve entre la Léna et l'Aldan (Savvin 2005, p. 16). Dans les années 1950 , les sovkhozes iakoutes produisaient plus de 500 tonnes de kumys durant l'été ; dans les années 1980, moins de $100 \mathrm{t}$; en 1999, moins de $50 \mathrm{t}$; mais plus récemment, $134 \mathrm{t}$ en 2008 (Ammosova 1988, p. 25 ; Tabuny... 1999; Ammosova 2008, p.125; données du Ministère de l'Agriculture de la République Sakha (Iakoutie) consultées sur http:// www.agro.sakha.ru

35. Outre les usages cités, le sérum sanguin et le suc gastrique chevalins sont également utilisés en pharmacopée (Vladimirov 2008, p. 91).

36. Majdel' 1894, p. 24 ; Seroševskij 1896, 163 ; Troščanskij 1911, p. 85 ; Gabyšev 1972, pp. 342, 344. Les citations complètes se trouvent dans Ferret 2009, p. 101.

37. Cf. http://faostat.fao.org; http://www.franceagrimer.fr

38. Les premiers porcs élevés par des Iakoutes étaient nourris principalement avec du lait écrémé, du tar (lait écrémé, bouilli puis fermenté et gelé, conservé sous forme solide) et du poisson (Bašarin 1962, p. 75).

39. L'ours, appelé iak. èhè "grand-père ", est censé comprendre le iakoute. Aussi la chasse à l'ours nécessite l'emploi d'un lexique propre, un double langage employé pour tromper la proie. Il convient néanmoins de relever que, pour les Iakoutes, le plantigrade n'a pas l'apanage de la compréhension du langage humain. En effet, même si ce fait est beaucoup moins connu, il semble que, lorsqu'ils se livraient à la cueillette, ils aient également transformé les dénominations des plantes qu'ils cueillaient, par crainte de les offenser (Savvin 2005, p. 55).

40. Selon Tokarev \& Gurvič 1964 [1956], p. 257, les Iakoutes ignoraient le filage de la laine et la fabrication du feutre avant la colonisation.

41. Obzor Jakutskoj oblasti, 1910, p. 130, cité par Bašarin 1962, p. 76.

42. En 2006, la République compte 100 moutons et 2168 chèvres, d'après les résultats du recensement agricole disponibles sur http://www.gks.ru

43. Les unty «bottes de fourrure " les plus appréciées sont faites en renne, ensuite en cheval, enfin en vache.

44. À l'intérieur du balaġan, maison de bois en forme de pyramide tronquée qui était l'habitat traditionnel des Iakoutes, des lits-bancs (iak. oron) étaient disposés le long des murs Selon Pekarskij, le mot oron désigne à la fois le lit-banc et le tapis qui le recouvre (1907-1930, p.1870). Ionova (1952, p. 247) note que les places d'honneur était couvertes de peaux de loups ou d'ours, de préférence au cheval.

45. Entretiens avec V. V. Okoëmov, S. I. Protopopov, V. Z. Kirillina, N. I. Kolesov, A. I. Tyrylgina (Ust'-Aldanskij, Verhojanskij, Srednekolymskij ulus). Hudjakov 1969, p. 190 ; Priklonskij 1888, p. 37 ; Kočnev 1894, p. 455 ; Kovalik 1895, p. 23 ; Seroševskij 1896, pp. 318-323, 327 ; Pekarskij 1907-1930, pp. 432, 1320, 2082, 2375, 2423-4, 2630, 2682, 2277-8, 3207 ; Nosov 1955, p. 120, 122 ; Jochelson 1933, pp. 149-150, 156, 165-166 ; Konstantinov 1971, p. 69, 72 ; Gabyšev 1972, p. 353 ; Dabrasov 1982, p. 12 ; Gotovcev 1988, p. 20 ; Atlasov 1992, p. 68 ; Ferret 2009, pp. 123-127.

46. Maak 1887, tab. VI $n^{\circ} 12$; Priklonskij 1888, p. 32 ; Seroševskij 1896, pp. 359, 446 ; Kočnev 1899, p. 57 ; Popov 1955, pp. 60-61; Okladnikov 1970 [1955], p. 243.

47. Observation au musée de Verhojansk. Priklonskij 1888, p. 33 ; Kovalik 1895, p. 29 ; Seroševskij 1896, p. 326 ; Gabyšev \& Gogolev 1949, p. 18 ; Naumov 1953, p. 10 ; Nosov 1955, p. 123.

48. Ainsi qu'un auteur le relevait dès le début du xxe siècle (Konskij volos... 1914, pp. 4-5).

49. Observations à Verhojansk et Suččino, dans l'ulus de Srednekolymsk. Gmelin 1767 [1751], I, p. 317 ; Kovalik 1895, p. 22 ; Seroševskij 1896, p. 360 ; Bahrušin 1927, p. 288 ; Jochelson 1933, 
p. 139 ; Pfizenmayer 1939, pp. 72, 73 ; Gabyšev 1949, p. 18 ; Ionova 1952, p. 245 ; Naumov 1953, p. 10 ; Bašarin 1962, p. 100 ; Tokarev \& Gurvič 1964 [1956], pp. 250, 257 ; Gabyšev 1972, p. 354 ; Dabrasov 1982, p. 12 ; Savvinov 1988, p. 42 ; Atlasov 1992, p. 69.

50. N. E. Degtjarev, Ust'-Aldan. Pekarskij 1907-1930, p. 684 ; Konskij volos... 1914, p. 5 ; Guerriers... 1994, p. 137 ; Popov 2003, p. 163, attribue une origine mongole à ce mot.

51. Pekarskij 1907-1930, pp. 688, 2039 ; Jochelson 1933, p. 199.

52. V. Z. Kirillina, Verhojansk. Hudjakov 1969, pp. 208-209 ; 231 ; Popov 1886, p. 127 ; Troščanskij 1911, pp. 26-27 ; Burykina 1928, p. 148 ; Popov 1949, p. 283, 300 ; Antonov 1971, p. 123 ; Ivanov 1976, p. 220 ; D'jačenko 1988, pp. 186, 193, 194 ; Zykov 1989, p. 75 ; Jakovlev 1993, II, pp. $8,15$.

53. Hudjakov 1969, p. 204 ; Jakovlev 1992, I, p. 19 ; Hamayon 1997, p. 188.

54. Seroševskij 1896, p. 614 ; Troščanskij 1911, pp. 22, 27 ; Burykina 1928, p. 147 ; Ionova 1952, pp. 303-304.

55. Hudjakov 1969, pp.139, 287 ; Pekarskij 1907-1930, pp.3765-3766, parle de sièl yjaa et sièl yjaabyt. Pfizenmayer 1939, p. 67.

56. Démonstration par P. V. Berezkina, à Suččino. Entretiens avec V. V. Okoëmov, S. V. Potapov, N. A. Slepcov (Ust'-Aldanskij, Verhojanskij ulus). Seroševskij 1896, p. 360 ; Konskij volos... 1914, p. 5 ; Gabyšev 1949, p. 18 ; Naumov 1953, p. 10 ; Popov 1955, pp. 75-77; Tokarev \& Gurvič 1964 [1956], p. 257 ; Gabyšev 1972, p. 354 ; Savvinov 1988, p. 42 ; Ferret 2009, p. 141.

57. Pekarskij 1907-1930, p. 1956 ; Hudjakov 1969, p. 180.

58. Seroševskij 1896, p. 613 ; Pekarskij 1907-1930, p. 778 ; Jochelson 1933, p. 118 ; Alekseev 1975, p. 158 ; Delaby 1987, p. 49.

59. Middendorf 1869-1877, p. 78 ; Maak 1887, annexe XIII, légende tab. VI $\mathrm{n}^{\circ} 6$; Seroševskij 1896, pp. 360, 446-447 ; Pekarskij 1907-1930, p. 2188 ; Konstantinov 1971, p. 100 ; Guerriers... 1994, pp. 91-92.

60. Voir, par exemple, les articles présents dans une brochure consacrée à l'utilisation du crin (Bogatyreva 2008) : tableaux, figurines, bijoux, coiffes et habits en crin.

61. En 2005 la laine grossière valait 20 tenge le kilo, mais en 2008, plus que 3 tenge (soit moins de 2 centimes d'euro).

62. Observation au marché aux bestiaux de Karabulak. Entretien avec Q. Äuelbekov, Sud kazakh.

63. Voir Ferret 2009, chapitre 4.

64. Remarquons avec A. Boué et contrairement à l'opinion courante, que le dromadaire «se présente comme l'animal le moins mal adapté au désert, ce qui ne veut pas dire pour autant qu'il le soit parfaitement » ni qu'il pourrait y survivre sans l'homme (1952, p. 110).

65. À propos des ovins, cf. Middendorf 1869-1877, p. 764, cité par Seroševskij 1896, p. 250. Des ossements ovins ont été trouvés chez les Kourykanes, qui ne représentaient pourtant pas ces animaux dans leurs pétroglyphes (Okladnikov \& Zaporožskaja 1959, pp. 114-115).

66. Le dictionnaire de Pekarskij note que kyyl ne qualifie pas seulement les bêtes sauvages, mais aussi tout ce qui sort de l'ordinaire, tout ce qui frappe la vue ou l'ouïe (1907-1930, pp. 1375-1377). P. A. Slepcov souligne que le champ sémantique de ce terme est très large, en particulier chez les Iakoutes de la haute Kolyma qui l'appliquent à n'importe quel objet $(1990$, p. 120) et en font le synonyme de « chose " (Afanas'ev, Voronkin \& Alekseev 1976, p. 141).

67. Sur la question de la consommation de viande de chameau chez les peuples turcs et mongols, cf. Roux 1959-1960, pp. 67-73. Selon son hypothèse, cette viande aurait été taboue dans la partie méridionale et occidentale de l'Asie intérieure avant l'islamisation. Quoi qu'il en soit, le chameau était, dans toute la zone, moins présent que les autres espèces domestiques, d'où la rareté de sa viande.

68. Tüön : mèche d'amadou en forme de cône qu'on plaçait et brûlait sur un organe malade en vue de le soigner, utilisée en particulier pour les soins dentaires (Pekarskij 1907-1930, p. 2902).

69. Ainsi qu'un autre animal, dont la figure, esquissée dans l'autre sens, se superpose au premier chameau et qui pourrait être un renne (Okladnikov 1959, p. 50). 
70. Je ne parle pas ici de l'idée fausse, évoquée au début de l'article, selon laquelle le renne serait le seul bétail élevé dans le nord de la Sibérie.

71. Plus de 15000 têtes en 2006 dans chacun des ulus Anabarskij, Bulunskij, Nižnekolymskij, Èveno-bytantajskij, Tomponskij, Momskij et Kobjajskij.

72. Sur la complémentarité saisonnière du cheval et du renne en tant qu'animaux de selle dans l'ulus Èveno-bytantaj, voir Maj 2007, §1.5.2.1.1.2.

73. Entretien à Iakoutsk en 2008. Voir aussi Syrovatskij 1994, pp. 78-79.

74. Sur le débat quant à l'importance relative des bovidés et des équidés dans l'économie iakoute ancienne, $c f$. Ferret 2009, pp. 40-42.

75. Hudjakov 1890, pp. 100-102 ; Kočnev 1890, p. 48 ; Seroševskij 1896, pp. 255-256 ; Popov 1949, p. 260 ; Guerriers... 1994, p. 62.

76. Kyys Dèbilijè 1993, pp.118-119 et note p. 301. Afanas'ev 1965, p. 128, oppose de même hara tüülèè «ceux qui ont une robe noire " (les bovins) à ürüy tüülè̀h «ceux qui ont une robe blanche » (les chevaux).

77. Plusieurs faits incitent à nuancer cette bipolarisation en termes de couleurs, qu'il n'est pas dans mon propos d'examiner ici.

78. Le sacrifice actif se traduit par la mise à mort de l'animal, le sacrifice passif par sa consécration aux esprits et la cessation de son exploitation (Ferret 2009, p. 281, 287 et passim).

79. Sur la question du rapport entre latéralisation et espèces animales, notamment équine, voir Ferret 2005-2006.

80. Alaas: Formation géomorphologique typique de la Iakoutie, composée d'une clairière en cuvette et d'un lac.

81. Pour A. A. Popov par exemple, rêver qu'on abat une vache présage de la mort d'un homme, sans plus de précision quant à son sexe, son âge, son origine ni son statut (1949, p. 296).

82. Cette idée préconçue engendre parfois de fâcheuses conséquences: des chevaux iakoutes exportés en Bouriatie du Nord ont péri en quelques années, car les éleveurs locaux ont naïvement cru que, fidèle à sa réputation, le cheval iakoute n'avait nul besoin d'être affouragé en aucune circonstance (M. A. Artamonov).

83. En 2008, la subvention accordée par tête de bétail dépend principalement, pour les bovins, du type d'entreprise où l'animal est enregistré. S'il s'agit d'une «coopérative ", entreprise collective, la subvention est de 3200 roubles par an et par vache; dans les entreprises "paysannes » (qui doivent compter au moins 40 bovins, dont 15 vaches laitières), elle est de 1300 roubles et il n'y en a pas dans les entreprises individuelles. Le système est différent pour les chevaux: la subvention ne varie pas suivant le type d'entreprise et existe même pour les particuliers. Depuis 2000, elle s'élève à 1000 roubles par jument et par an (et 3000 roubles si le propriétaire de la dite jument a eu la chance de la voir enregistrée comme plemennoj « de race »).

84. En 1989, $74 \%$ des Iakoutes vivaient à la campagne et seuls $13 \%$ de population urbaine de la République était de nationalité iakoute (Balzer \& Vinokurova 1996, p. 104).

\section{RÉSUMÉS}

Confrontant pratiques et représentations, l'article tente de démêler le vrai du faux parmi les discours tenus sur le cheval iakoute, un animal extraordinaire, jugé plus méritant que bien d'autres espèces (mammouth, porc, mouton, chameau, renne et vache) dans les domaines les plus 
variés, et qui fait l'objet d'un élevage original, dans les confins septentrionaux du monde turcique.

Comparing practises with representations, this paper attempts to distinguish fact from fiction among the discourses about the Yakut horse, an extraordinary animal, considered as more deserving of respect than other species (mammoths, pigs, sheep, camels, reindeer and cows) for many uses and which is bred in a very special way the northernmost part of the Turkic area.

INDEX

Mots-clés : cheval, élevage, représentations, mammouth, porc, renne, chameau, bovin

Keywords : horse, animal husbandry, representations, mammoth, pig, reindeer, camel, cow Thèmes : animal, changement, économie, idéologies, nationalisme, représentations, transport Index géographique : Iakoutie, Sakha, Sibérie orientale nomsmotscles Iakoute, Sakha

\section{AUTEUR}

\section{CAROLE FERRET}

Carole Ferret, docteur en ethnologie et anthropologie sociale, chercheur à l'Institut français d'études sur l'Asie centrale (Tachkent) et chercheur affilié au Laboratoire d'anthropologie sociale (Paris), auteur, entre autres, de Une civilisation du cheval. Les usages de l'équidé de la steppe à la taïga (Paris, Belin, 2009).

caroleferret@wanadoo.fr 